\title{
FERNANDO FUJIMURA
}

Eng, ${ }^{\circ}$ de Minas, Escola Politécnica da USP - 1969

\section{CARACTERISTICAS DE RESISTÊNCIA AO CISALHAMENTO DE ROCHAS FRATURADAS}

Dissertação apresentada à Escola Politécnica da Universidade de São Paulo para obtenção do Titulo de Mestre em Engenharia

Orientador:

PROF. DR. WILdOR THEODORO HENNIES

Prof. Adj. do Depto. de Engenharia de Minas da EPUSP 
Aos meus pais,

aos ineus irmãos,

A APARECIDA

e

REBECA 
o autor deseja expressar a gratidão ao Prof. Dr. Wildor Theodoro Hennies pelo incentivo e orientação neste trabalho.

Ao Instituto de Pesquisas Tecnológicas de São Paulo, especialmen te à Divisão de Minas e Geologia Aplicada onde foi possível rea lizar a maior parte do trabalho e pesquisa bibliogräfica.

A Themag Engenharia Ltda e ao Departamento de Minas da USP pelas facilidades concedidas.

Aos amigos do IPT pelo apoio.

Ao amigo Shigueru Miyamoto pela ilustração das peças gräficas.

A Bernadete Massinelli de Toledo pela dedicação na datilografila do texto. 


\section{RESUMO}

A presente dissertação enfoca as caracteristicas de resistência ao cisalhamento e os mecanismos básicos que governam o fenômeno de atrito em rochas fraturadas.

Especial atenção ē dedicada à identificação de fatores geomètri cos e geotécnicos importantes e a sua relação com o comportamen to e esforços resistentes de rochas fraturadas.

A caracterização de fraturas por meio de parâmetros geomecânicos adequados permitirá incluí-los nos modelos de cálculo e si mular mais realisticamente o comportamento geomecánico do maciço rochoso fraturado. 


\section{SUMMARY}

This thesis focuses on the shear strenght and mechanisms that change the shear characteristics of jointed rocks.

Special attention was devoted to the identification of geometric and geotechnical factors and its relationship with the behavior and strenght of jointed rocks.

The characterization of the fractures by apropriated geomechanical parameters will permite to include them in the models and to simulate more realistically the behavior of fractured rock mass. 
2.2 Influência das Descontinuidades Geolögicas 04

2.3 Importancia e os Tipos de Descontinuidades Geológicas 08

\section{JUNTAS ROCHOSAS}

3.1 origem 10

3.2 0corrência 13

3.3 Investigação $\quad 14$

3.3.1 Frequência e espaçamento 15

3.3.2 Comprimento 16

$\begin{array}{lll}3.3 .3 & \text { Rugosidades e irregularidades } & 17\end{array}$

3.4 Anälises 21

4 RESISTENCIA AO CISALHAMENTO DE ROCHAS FRATURADAS 25

4.1 Teoria de Deslizamento em Rochas Fraturadas 25

4.2 Métodos de Ensaios 35

4.2.1 Cisalhamento por rotação 36

4.2.2 Cisalhamento sob carregamento triaxial 36

4.2.3 Cisalhamento direto-laboratörio e campo 38

4.3 Técnicas de Ensaio 43

4.4 Fatores que Influem nas Características de Cisalhamento 47

4.4.1 Fatores geométricos 48

4.4.2 Fatores geotécnico-geomecànicos 57 
$\mathrm{Pg}$.

4.4.3 Fatores tensoriais

4.5 Paràmetros Geomecànicos

4.5.1 Parâmetros de resistência

70

4.5.2 Parámetros de comportamento

71

5 CONCLUSÖES

76

6 REFERENCIAS B I BL IOGRAF ICAS 
NOTAÇÕES 
A maioria dos símbolos é definida no próprio texto quando menciona dos, porém os mais usuais são os seguintes:

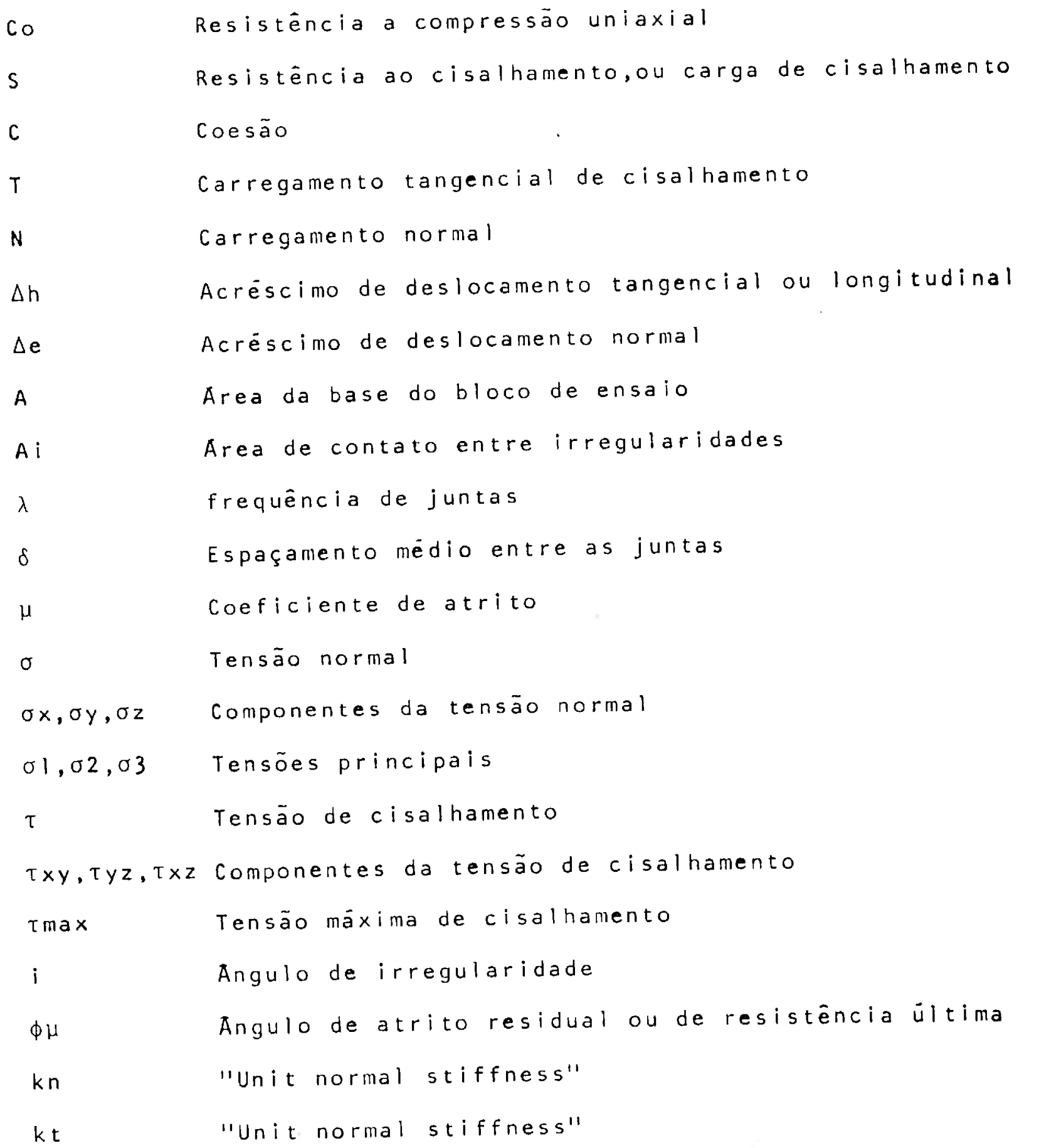



Figura 1 - Papel da Descontinuidade na Resistência ao Cisalhamen to.

Figura 2 - Seção Esquemática do Deslizamento do Talude Natural na Barragem de Vaiont.

Figura 3 - Caracteristica de Resistência ao Cisalhamento.

Figura 4 - Envoltória de MOHR e seus Planos de Ruptura.

Figura 5 - Desenvolvimento de Juntas de Tração e Compressão (Apud RAMSAY, 1967).

Figura $\dot{6}$ - Representação Esquemática de juntas Sistemática e não Sistemática.

Figura 7 - Frequéncia de Fraturas no Plano de Observação (HUDSON e PRIEST - 1979).

Figura 8 - Medidas de Amplitude Comprimento das Irregularidades

Figura 9 - Ilustração Esquemática das Cinco Categorias de Irregularidades (Apud PITEAU - 1970).

Figura 10 - Irregularidades de Primeira Ordem (ondulações) e Irregularidades de segunda Ordem (rugosidades) (Apud PATTON e DEERE - 1970).

Figura 11 - Medidas de Rugosidade de Superficie Rochosa com Diferentes Comprimento de Base.

Figura 12 - Distribuição e Relação entre Sistema de Juntas (Apud BARTON - 1975).

Figura 13 - Contato entre Superficies Irregulares. 
Figura 14 - Planos de Deslizamento no Contato entre Partículas Gra nulares.

Figura 15 - Envoltória de Cisalhamento com Diferentes Inclinaça e Nümeros de Dentes.

Figura 16 - Envoltória Teórica Típica para Superfícies Irregulares.

Figura 17 - Mecanismo de Ruptura do "Dente" em função da Força de Cisalhamento e Deslocamento Horizontal.

Figura 18 - Figura Esquemática dos Componentes da Força de Cisalha mento.

Figura 19 - Cisalhamento por Torção de Cilindros.

Figura 20 - Célula Triaxial Concebida por HOEK e FRANKLIN.

Figura 21 - Método do Deslizador.

Figura 22 - Cisalhamento Simples em Amostras Cilindricas (Apud PROTODYAKNOV - 1969).

Figura 23 - Cisalhamento Simples em Amostras Cübicas (Apud PROTODYKONOV - 1969).

Figura 24 - Esquema de Montagem de Ensaios de Cisalhamento Utiliza do pelo IPT, Caixas de $20 \times 20 \mathrm{~cm}$.

Figura 25 - Dispositivo para Ensaios de Cisalhamento em Laboratório Desenvolvido por I.G. GONCHAROV para Amostras de Grandes Dimensões. (Apud EVDOKIMOV e SAPEgIN - 1967).

Figura 26 - Montagem Esquemática de Ensaios de Cisalhamento Direto "In Situ" em Blocos de $70 \times 70 \mathrm{~cm}$. 
Figura 27 - Ensaios de Cisalhamento Direto com Onica Direção de Carregamento.

Figura 28 - Prensa com Unica Direção de Carregamento Idealizada por PROTODYAKONOV.

Figura 29 - Ensaios de Cisalhamento Direto com Duas Direçöes de Car regamento.

Figura 30 - Ensaios de Cisalhamento Direto com Carga Normal Excēntrica.

Figura 31 - Resultados de Ensaios em Fraturas Artificiais (Apud SCHNEIDER - 1972).

Figura 32 - Relação entre Superficies de Contato e Dilatáncia Durante Cisalhamento (Apud FECKER e RENGERS - 1971).

Figura 33 - Relação entre arctgt/o e a Dilatância.

Figura 34 - Relação entre o/Co e Ângulo de Dilatáncia (i).

Figura 35 - Resistência ao Cisalhamento e Dilatância.

Figura 36 - Mudanças no Comportamento em Função do Comprimento da Fratura (Apud BANDIS - 1979).

Figura 37 - Efeito condicionado pelo Tamanho do Bloco (BARTON e CHOUBEY - 1977).

Figura 38 - Curva de Resistência ao Cisalhamento sob Tensões Normais Diferentes.

Figura 39 - Distribuição de Tensões no Plano de Ruptura (Apud LORENTE DE NO - 1968). 
Figura 40 - Distribuição de Tensões na Base do Bloco.

Figura 41 - Estudo Comparativo da Distribuição e Concentração de Tensões na Base do Bloco.

Figura 42 - Elementos de Juntas kt e kn Definidos por GOODMAN.

Figura 43 - Diagrama de llustração da Influência do Fechamento da Junta e Resistência da Parede Rochosa.

Figura 44 - "Unit Shear Stiffness" da Junta em Função da Dimensão do Bloco e da Tensão Normal de $3,5-7,0$ - 35,0.- $70,0 \mathrm{kgf} / \mathrm{cm}^{2}$ (Apud BARTON - 1972).

\section{LISTA DE TABELAS}

Tabela 1 - Classificação de Espaçamento de Juntas - After I.S.R.M - 1975

Tabela 11 - Classificação de Tamanho de Bloco - After I.S.R.M - 1975

Tabela 111 - Curvas Características de Comportamento. 
I INTRODUÇÃO 
Quando em 1928 a Barragem de St. Francis, no Sulda California, ruiu, vitimando pessoas e causando prejuízos de milhōes de dólares, a en genharia despertou para um fato extremamente importante: as medidas de segurança de um projeto envolvem muito mais do que um dimen sionamento estrutural criterioso das construções.

Antes desse lastimável evento nem tọdos compreendiam a necessidade de um estudo cuidadoso dos condicionantes geológicos locais,preceden do o projeto das estruturas.

A partir de entāo a caracterizaçāo geotëcnica do meio ambiente tor nou-se obrigatória na elucidação de propriedades e comportamentos perante às ações provenientes das obras de engenharia.

Em relação ao maciço rochoso, o comportamento geomecânico de rochas fraturadas tem merecido atenção de värios investigadores e a sua importancia destaca-se em inümeros trabalhos existentes na b $\underline{i}$ bliografia especializada.

Com a noção de atrito $\phi$ e coesão C, introduzida pela Teoria de Navier-Coulomb, as anälises de estabilidade passaram a ser realizadas utilizando esses parámetros como valores caracteristicos do ma terial ou para definir envoltörias de cisalhamento.

Todavia, a rápida evolução de modelos matemäticos determinada pelo uso rotineiro de computadores introduziu, na técnica de análises estruturais, importante avanços requerendo parâmetros geomecánicos adequados para traduzir as complexas interaçöes entre as estruturas e maciços rochosos.

Nesse contexto as caracteristicas de cisalhamento de rochas fraturadas exercem uma influencia significativa no comportamento geomecànico e nas condições de estabilidade do maciço rochoso.

Assim, o conhecimento de fatores e mecanismos que alteram essas ca racteristicas pode representar um passo fundamental na escolha de 
soluçōes seguras, simples e econômicas, adequadas com os condicionantes geológicos locais. 
2 GENERAL I DADES 
2. I Histörico

0 primeiro conhecimento sobre as leis que governam as caracte risticas de atrito em superficies contínuas e homogèneas data por volta do século 16 e foi apresentado por Leonardo da Vin ci. Conforme mais tarde observado por Mac CuRdY (1938), essas leis versavam sobre a proporcionalidade direta entre o atrito e a força normal e da independência da ärea de contacto.

Contudo, essas leis cairam no esquecimento ate 1699 quando G. Amonton, engenheiro francês, apresentou-as à Academia Real Francesa de Ciências. Entretanto elas sömente tornaram-se co nhecidas no meio científico através de trabalhos realizados por COULOMB $(1875)$.

Mais tarde TERZAGH (1925) investigou a origem do fenômeno de atrito e propós como causa as ligações moleculares formadas na ärea real de contacto e a resistência ao corte dessas liga ções.

Em rocha, a grande parte de nossos conhecimentos iniciais deriva de trabalhos de BOWDEN (1954) e do seu colaborador TABOR $(1950,1964)$ que pesquizou atrito em superficies metálicas.

Valores de atrito em superficies lisas de rocha foram relata dos por JAEGER (1959), BYERLEE (1967a), JAEGER e ROSENGREN (1969), COULSON (1972) e outros. Atritos em minerais isolados foram medidos por HORN e DEERE (1962).

Em superficies rochosas naturais ou artificialmente produzidas tal fenómeno foi exaustivamente investigado por inúmeros pesquizadores como: MAURER (1966), LADANYI e ARCHAMBAULT (1969), SCHNEIDER (1974), GOODMAN (1974) e outros. A experiência adquirida e resultados dessas investigações constituem hoje fun damentos para compreensão do mecanismo de resisténcia ao cisa Ihamento de rochas fraturadas. 
2.2 Influência das Descontinuidades Geológicas

Dentre os värios fatores é inegävel ainfluência das descontinui dades geológicas nas caracteristicas de deformabilidade e re sistência mecánica de maciços rochosos.

A redução da resistência é tanțo mais acentuada quanto mais a atitude das descontinuidades for paralela à direção de car regamentos, sejam eles naturais ou impostos. Em tais circunstân cias a resistência passa a ser controlada quase exclusivamente pela caracteristica geométrica e geotécnica dessas descontinuidades. As condições de estabilidade se alteram de acordo com o material de preenchimento, que afeta diretamente as cur vas de mobilização de resistência ao longo dessas descontinui dades, Figura 1 .

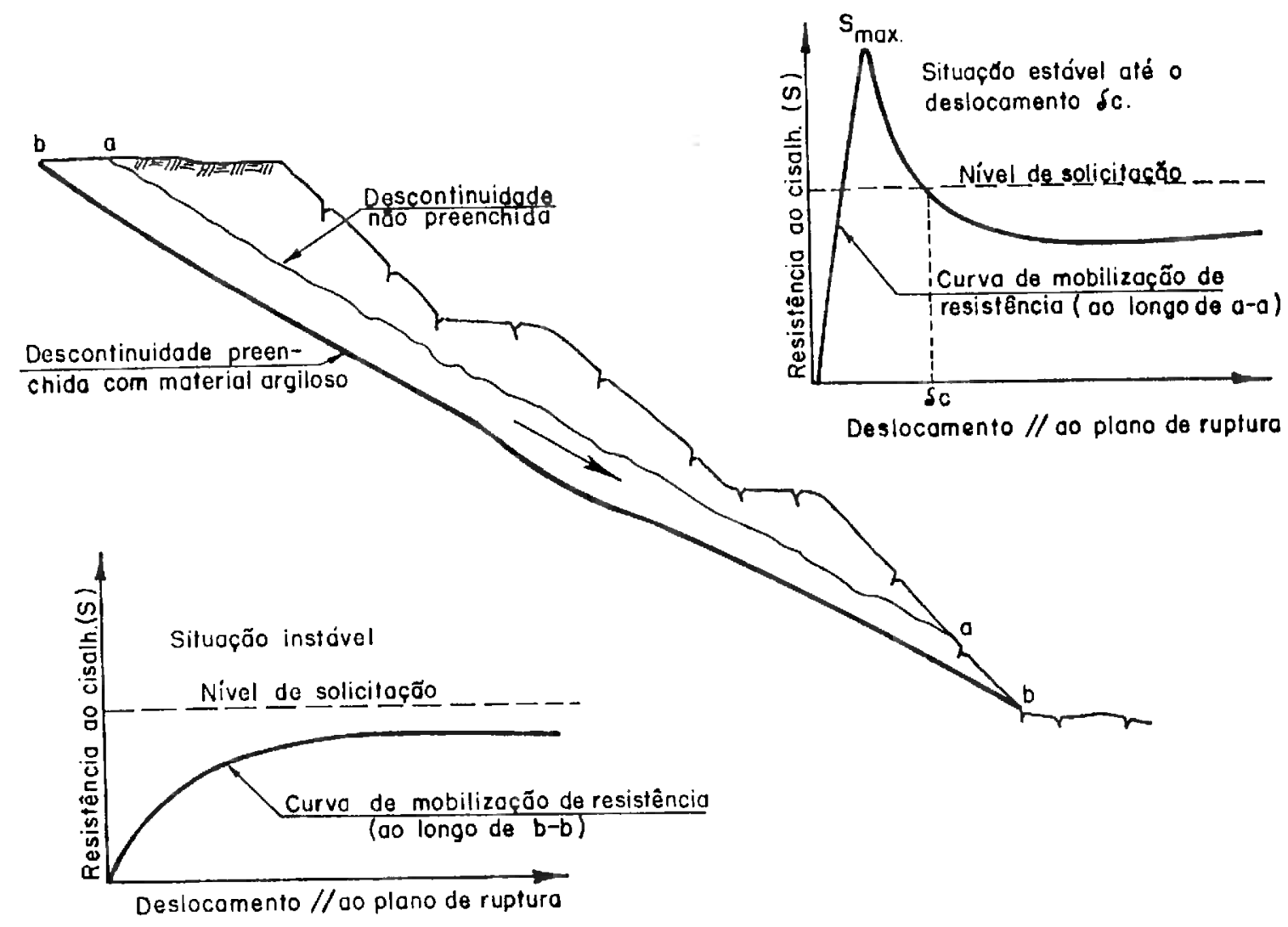

Figura 1 - Papel da Descontinuidade na Resistência ao Cisalhamento 
Presença de descontinuidades nas rochas de fundação e mudanças nas condições naturais de equilibrio provocaram rupturas na Barragem de Malpasset na França e Barragem de Yellowtail em Montana - USA.

Contudo, o mais grave acidente registrado na Histöria com ví timas aconteceu na $\mid \mathrm{ta} l i$ a com a Barragem de Vaiont.

Em outubro de 1963, um catastrófico deslizamento ocorreu ao longo de descontinuidade litológica, segundo planos de estratificação das camadas sedimentares no talude natural do lado esquerdo do reservatōrio, Figura 2. Segundo LANE (1966) cerca de $2,4 \mathrm{~km}$ de extensão e $220 \mathrm{milhões}$ de $\mathrm{m}^{3}$ de volume de mate rial deslizou em direção ao reservatório em alguns segundos. Em consequência, uma gigantesca onda de $150 \mathrm{~m}$ de altura galgou a crista da Barragem e seguiu vale abaixo destruindo a Vi la Longarone causando a morte de 2.050 pessoas.

Tais eventos motivaram nestes ültimos anos intensa campanha de investigações visando determinar as variäveis que regem as caracteristicas de resistência ao cisalhamento dessas descont nuidades.

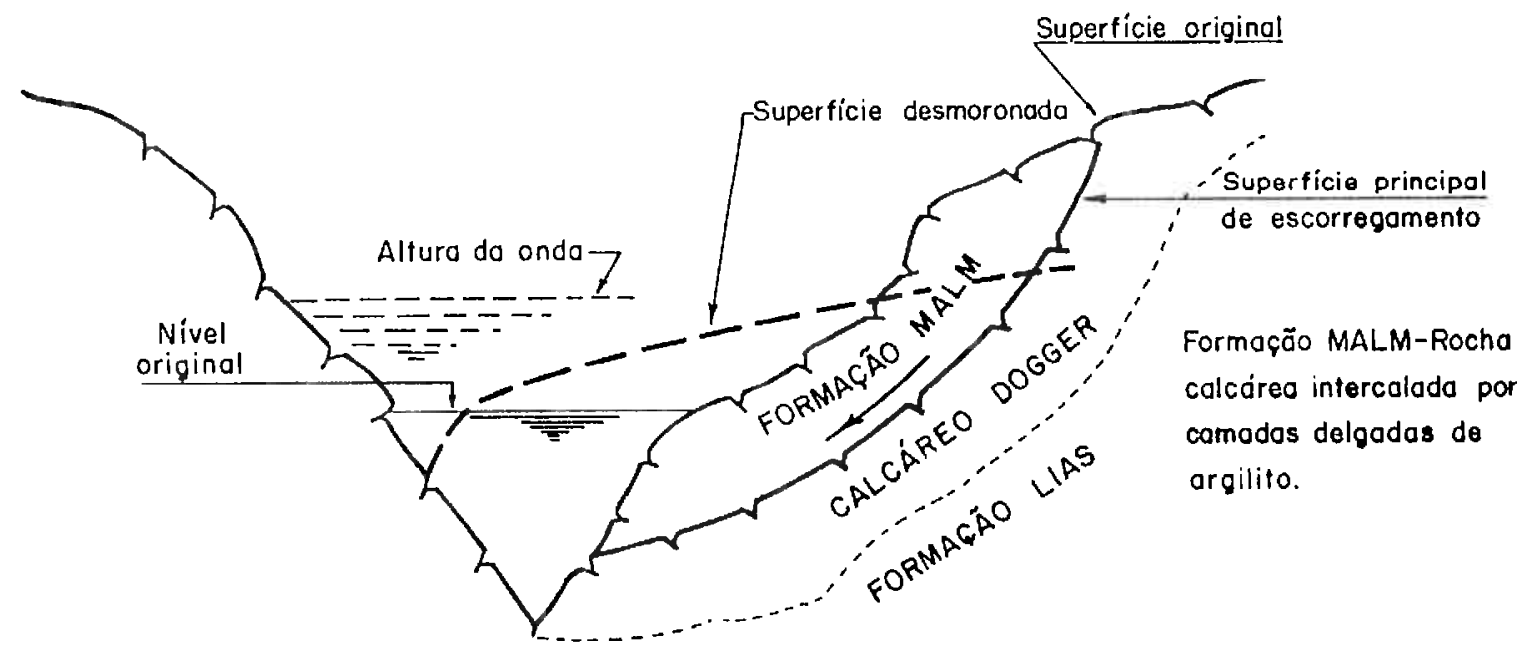

Figura 2 - Seção Esquemätica do Deslizamento do Talude Natural na Barragem de Vaiont. 
MÜLLER (1963a) sugere uma redução de até 1/300 na resistēncia intrinseca da rocha devido a presença de planos de fraqueza. Em parte, essas reduçōes se devem à incapacidade dessas descontinuidades de resistirem ao esforço de tração.

Os estudos realizados por ZARUBA e MENCL (1969) confirmam a importancia dos planos de acamamentos com forte mergulho como causa de grandes deslizamentos rochosos.

No ámbito mundial, BARTON (1977) observa que os planos parale los ao acamamento rochoso são as feições estruturais mais fré quentes em deslizamentos ocorridos.

Guardadas as devidas proporções, as curvas de mobilização de resisténcia ao cisalhamento de tais descontinuidades são qua litativamente comparáveis aquelas obtidas em ensaios usualmen te realizados em laboratório e campo, Figura 3 a.

No caso 1, acha-se representada a curva característica de rup tura, ao longo de uma superficie irregular, contato rocha-rocha, sob esforço normal N. A carga tangencial de cisalhamento (s), atinge um valor máximo com pequenos deslocamentos, instante em que ocorre uma queda brusca seguido de redução progressiva até atingir o patamar. A resistência no caso,após $u \underline{1}$ trapassar o valor mäximo, diminui gradualmente com o deslocamento até atingir assintoticamente ovalor mínimo que corresponde à resistência ültima (ultimate strenght), também conhecido como resistência residual em analogia a solos.

No caso 11 , em superficie plana ou preenchida de argila, a resistência cresce continuamente com o deslocamento até atingir o patamar da resistência ültima.

A figura 3b, ilustra as envoltórias de resistēncia intrínseca, para cada um dos casos, sob o mesmo carregamento normal. A dis tância vertical entre as envoltórias indica a redução de re- 
sistēncia determinada pelas características superficiais da ro cha fraturada.

- tipo de ruptura descrito no caso 1 envolve em geral movimen to coletivo de maciço rochoso que, após deslocamentos lentos de pequena extensão, inicia bruscamente o movimento räpido incontrolável de duração relativamente curta, envolvendo volume de escorregamento em geral bem definido.

No caso 11 , os movimentos são contínuos, progressivos egeral mente lentos e podem apresentar ou não volume definido ao ion go da superficie de movimentação. Via de regra ocorrem grandes deformações ou deslocamentos antes do movimento se tornar incontrolàvel.

Assim o conhecimento das curvas de mobilizaçāo de resistência ao cisalhamento, obtidas através de ensaios, pode orientar a solução técnico-económica, quando não a própria concepção da obra.

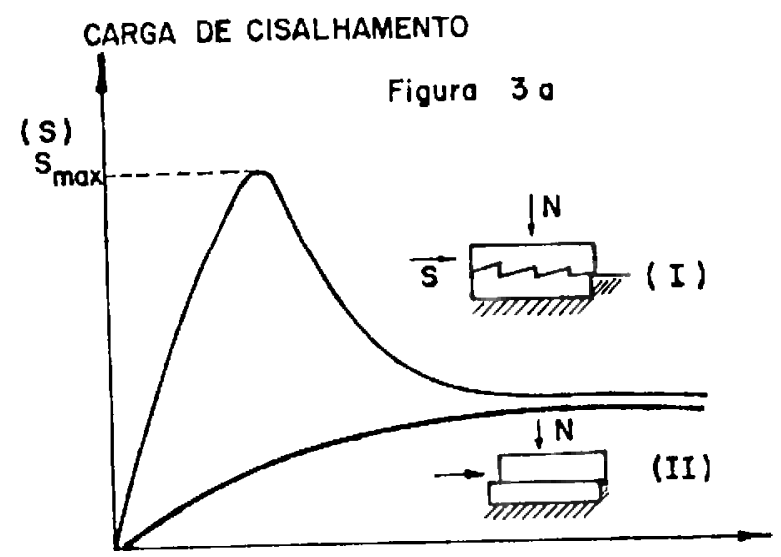

DESLOCAMENTO HORIZONTAL $(\Delta h)$

\section{TENSĀO DE CISALHAMENTO}

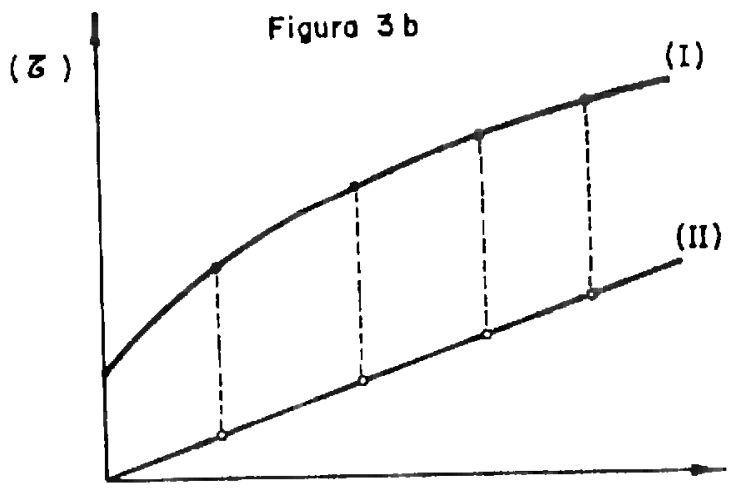

TENSĀO NORMAL $(\sigma)$

Figura 3 - Característica de Resisténcia ao Cisalhamento 
2.3 Importáncia es Tipos de Descontinuidades Geológicas

os maciços rochosos invariavel mente contèm numerosas superfícies reais ou descontinuidades potenciais, tais como: juntas, acamamentos, contatos litolögicos, clivagens, xistosidades, es foliações, zonas cisalhadas, falhas e etc..

- comportamento geomecánico refilete a presença dessas descontinuidades acrescidas da influência de: água, campo de tensões, resistências mecánicas, deformabilidade e permeabilidade.

Em bases geolögicas, podem ser estabelecidas as diferenças en te as descontinuidades acima referidas conforme apresentadas por LEET E JUDSON (1971).

Dentre elas observa-se que as juntas rochosas são de longe a estrutura geológica mais comum da crosta terrestre. Elas são definidas por PRICE (1966) como fendas ou fraturas na rocha ao longo das quais não tenham ocorridos deslocamentos signif cativos.

Normalmente, elas ocorrem em sistema ou conjuntos mais ou me nos paralelos e regularmente espaçados. As vezes, se apresentam em sistemas multiplos cortando em värias direções, compar timentando totalmente o maciço rochoso.

Por esta razão, a importância da junta reside em converter as rochas, mesmo as homogêneas e compactas, em material fisicamente descontínuo e separado em partes pelas superfícies fra turadas tornando-as suceptiveis a deslizamentos.

Assim, a caracterizaçāo da junta para fins de engenharia deve-se iniciar pela quantificação das feições morfológicas e geométricas importantes dessas superficies. 
Sua presença tem sido frequente e inevitável nas obras civis e mineiras. Sua influēncia é particularmente sentida nas ro chas de fundação dos Aproveitamentos Hidroelétricos Brasile ros, exigindo anälises cuidadosas e métodos construtivos ade quados.

Pela significativa presença das juntas nas rochas fraturadas e nas superficies potenciais de escorregamento, descrevem-se a seguir aspectos relacionados com a gênese, investigaçäo e anälises. 
3 JUNTAS ROCHOSAS 
3.1 Origem

Segundo WILLIS e WILLIS (1934) são feiçōes secundärias de açöes tectônicas e como tais se relacionam com as feições es truturais dominantes na região, a saber: eixo de dobramento. falhas de empurrão, bordas de bacia, soerguimentos de montanha, etc..

Do ponto de vista genético a maioria das juntas é plano de ruptura resultante de um campo de tensões e, portanto, a direção e o mergulho guardam uma relação definida com as ten sões principais $\left(\sigma_{1}, \sigma_{2}\right.$ e $\left.\sigma_{3}\right)$ que atuaram na época.

De acordo com o critério de MOHR (1900) a fratura ocorre sob estado de tensões correspondente ao ponto de tangência da en voltória no circulo de MOHR. A inclinação do plano de ruptura em relação a tensäo principal maior $\left(\sigma_{1}\right)$ é representada pelo ãngulo $\theta$. A normal ao plano de ruptura faz um àngulo $\beta$ com a direção de o,. Figura 4.

Durante estägios iniciais de dobramento, a distribuição de tensões muda vagarosamente prevalecendo as tensões de tração nas regiōes superficiais formando inicialmente juntas de tra ção no topo do anticlinal, enquanto na parte mais profunda da borda as tensões de compressäo deveräo atingir valores elevados para provocar as rupturas, Figura 5.

As juntas podem ser resultados de peso de camadas sobrejacentes, forças de compressão, acoplamento regional, movimentos na crosta e contraçōes por resfriamento e ressecamentos etc. Segundo PRICE (1959), a junta se desenvolverá até uma certa profundidade e cessará assim que a região dominada por materiais de comportamento plástico é atingida,quandose con sidera apenas a força de gravidade. 

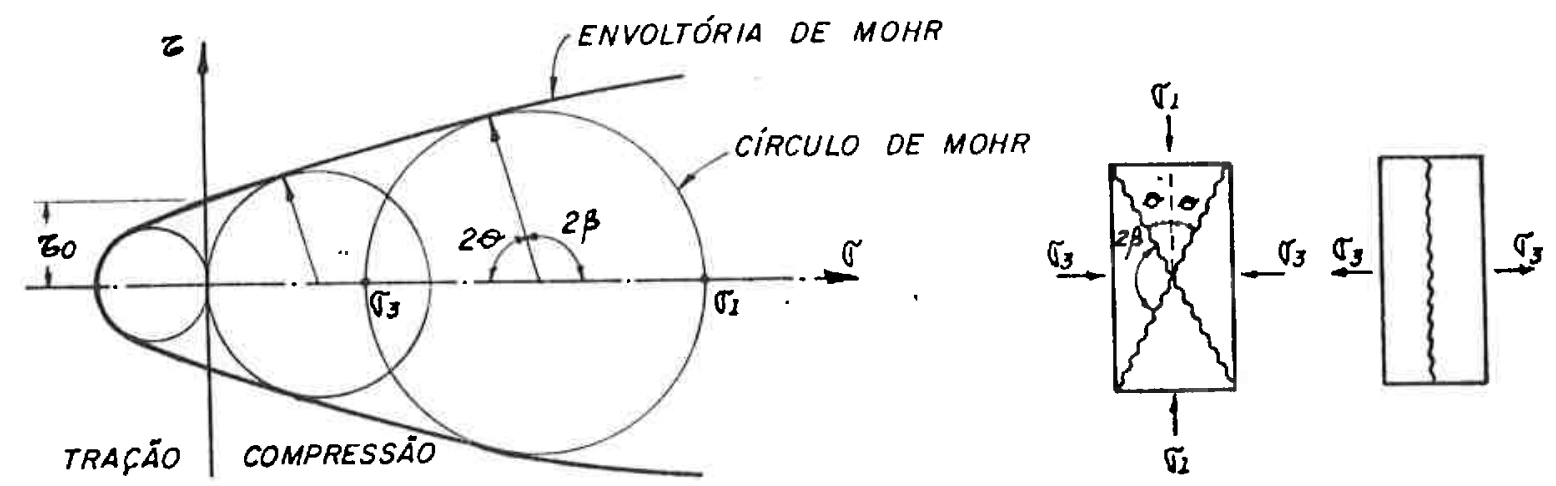

$2 \theta+2 \beta=180^{\circ}$

Figura 4 - Envoltōria de MOHR e seus Planos de Ruptura

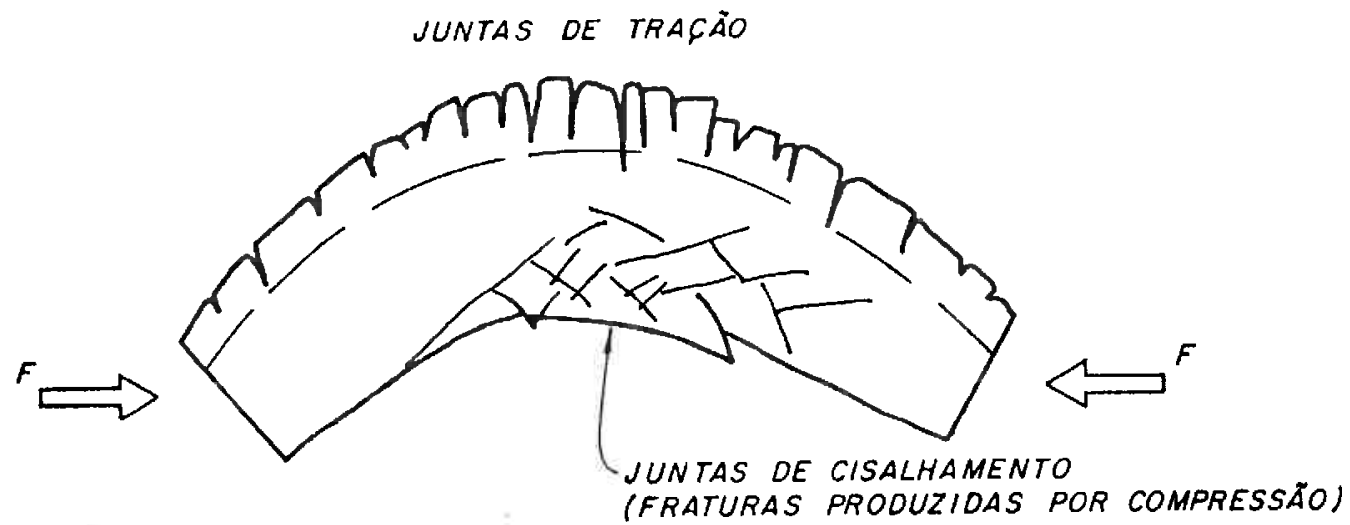

Figura 5 - Desenvolvimento de Juntas de Traçäo e Compressão (Apud RAMSAY, 1967) 
Conforme observado por DE SITTER (1956), as juntas e as faIhas podem ter origem comum pois em escavações subterrâneas ou a céu aberto as juntas se tornam mais frequentes com a aproximação das falhas.

Segundo TWIDALE (1973), qualquer mecanismo de formaçäo de juntas pode ser explicado por. Uma das duas Teorias:Exogenét ca ou Endogenética. Contudo, essas Teorias defendem ponto de vista diametralmente oposto há mais de 130 anos quanto a forma da superficie terrestre. Sob ponto de vista Endogenetica, a mais antiga das duas, as juntas se desenvolveram no embasamento cristalino e a forma da superficie terrestre re sulta dessa estrutura interna.

A Teoria Exogenética, com a hipótese de alivio de tensōes e da descompressão rochosa defendida por GILBERT (1904), foi inquestionavelmente aceita por muitos geólogos a ponto de ser adotado como termo genëtico "juntas de descompressão". A sua principal característica é aceitar a geometria da junta como uma resposta à forma da superficie terrestre.

No quadro abaixo resumem-se os principais fatores responsáveis pela formaçāo de juntas, em cada uma das Teorias.

\begin{tabular}{|l|l|}
\hline \multicolumn{1}{|c|}{ EXOGENETICA } & \multicolumn{1}{|c|}{ ENDOGENETICA } \\
\hline $\begin{array}{l}\text { InSolação- BARTON (1916) } \\
\text { GRIGGS (1936) }\end{array}$ & $\begin{array}{l}\text { Injeção Plutónica } \\
\text { WHITNEY (1865) }\end{array}$ \\
\hline $\begin{array}{l}\text { Alteração Química } \\
\text { BLACKWELDE (1933) }\end{array}$ & $\begin{array}{l}\text { EXPansão Metassomática } \\
\text { BRAJNIKoV (1953) }\end{array}$ \\
\hline $\begin{array}{l}\text { Clivio de Tensões } \\
\text { CHAPMAN (1956) }\end{array}$ & $\begin{array}{l}\text { Soerguimento Vertical } \\
\text { KRANCK (1957) } \\
\text { Compressão Lateral } \\
\text { TWIDALE (1964, 1971) }\end{array}$ \\
\hline
\end{tabular}




\subsection{Ocorrência}

Em função do modo de ocorrència, as juntas podem ser classificadas em sistemätica e não sistemätica.

As juntas sistemáticas são aquelas em que as juntas individuais são paralelas ou sub-paralelas entre si.

As juntas não sistemäticas não possuem padrões definidos e frequentemente terminam cortadas pelas juntas sistemáticas, F gura 6 .

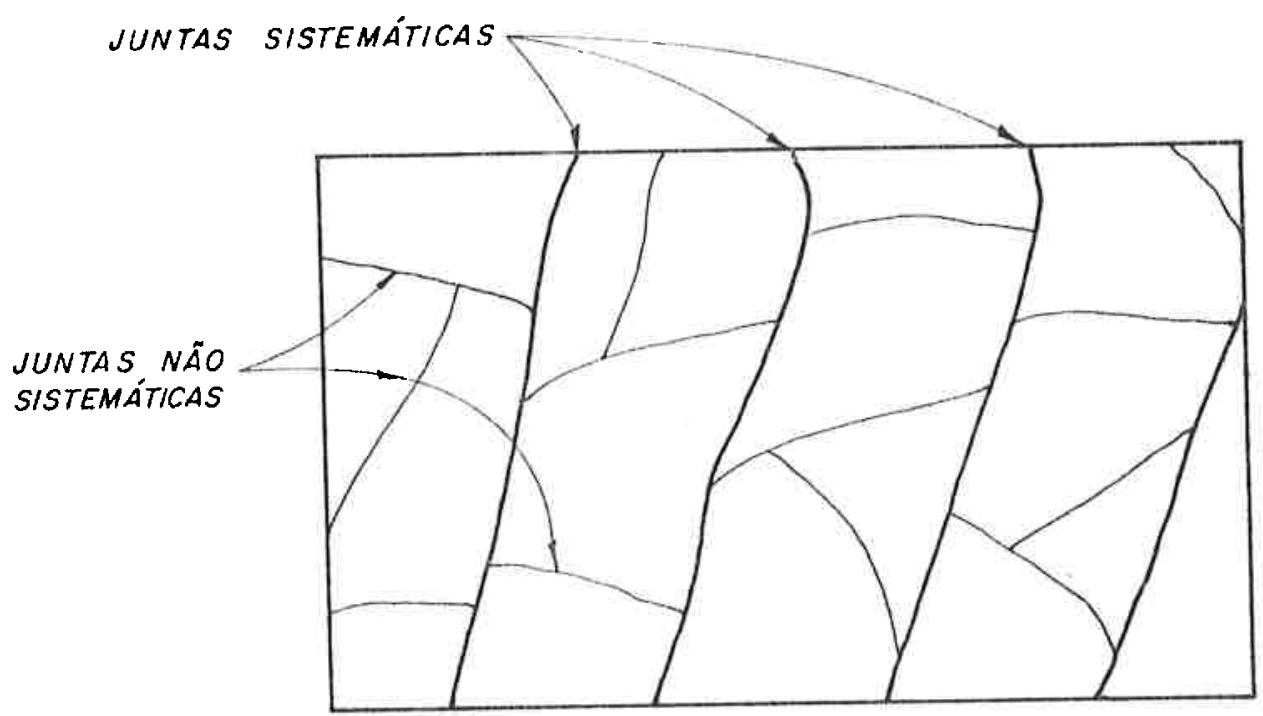

Figura 6 - Representação Esquemätica de Juntas Sistemática e Não Sis temát ica

As juntas ocorrem em todas as escalas. 0 sistema mais importante do ponto de vista da continuidade é denominado de principal, e elas se estendem de dezenas a centenas de metros.

0 conjunto de fraturas que intercepta as juntas principais é conhecido como juntas transversais e são usualmente de menor. 
importancia e se apresentam mais curvadas e irregularmente es paçadas, HODGSON (1961). Todavia, sob aspecto de comportamento geomecañico, os dois sistemas podem ser igualmente importantes.

o espaçamento entre as juntas pode variar de metros a escala microscōpica. Contudo, as juntas finamente espaçadas são frequentemente consideradas como feição da pröpria rocha.

As juntas podem se apresentar preenchidas de material argilo so, expansivo ou não, ou então com vários minerais tais como, calcita, quartzo, dolomita selando, às vezes, totalmente a fenda. Em casos de juntas abertas elas podem conter água sob pressão, constituindo-se no caminho preferencial de percolação.

Juntas devido à contração por resfriamento ou ressecamento são fraturas de alivio e cortam o maciço rochoso em forma colunar, bastante típico em superfícies de derrames basalticos e diques de diabäsio. Contudo, estas feições também podem ocorrer em granitos e em algumas rochas metamórficas.

\subsection{Investigação}

A análise de comportamento geomecánico do maciço rochoso deve incluir o conhecimento das caracteristicas geométricas da es trutura rochosa.

Nesse sentido, um dos aspectos mais importantes é a coleta sis temática e anälisc dos dados visando melhorar o conhecimento básico da geometria estrutural do maciço rochoso.

os principais fatores a serem considerados são os seguintes:

- frequência e espaçamento; 
- comprimento

- rugosidades e irregularidades.

\subsubsection{Frequência e espaçamento}

o nümero de juntas presente num maciço rochoso é usualmente expresso em frequência de juntas $(\lambda)$ que é definida como o nú mero médio de juntas por unidade de comprimento, contado ao longo de um furo de sondagens ou na extensão de uma linha es-

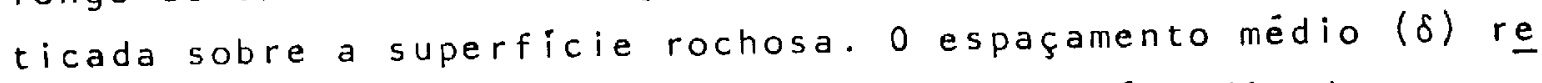
presenta a distância média entre fraturas e é indicado por:

$$
\delta=\frac{1}{\lambda}
$$

Em um sistema simples, plano e paralelo de juntas, Figura 7a, a frequência $\lambda \dot{e}$ a medida ao longo de uma linha perpendicular à direção das juntas, mëtodo que pode ser utilizado facilimente no campo.

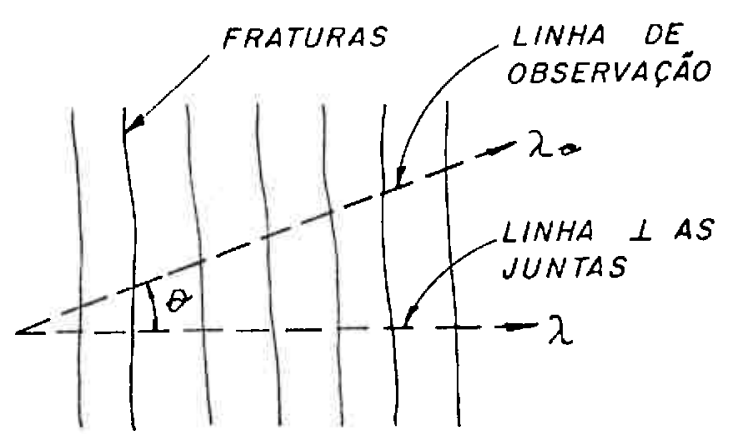

FIGURA $7 a$

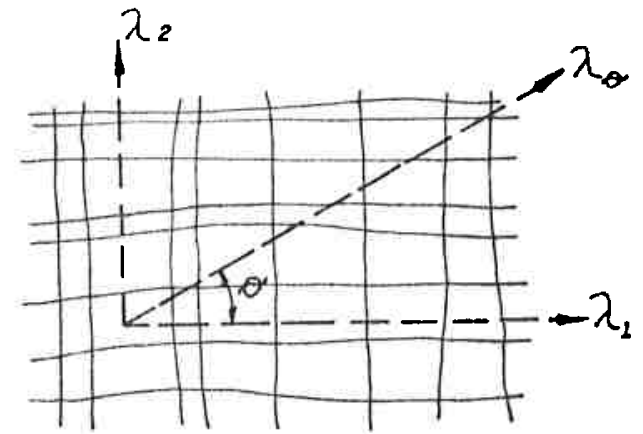

FIGURA $7 b$

Figura 7 - Frequência de Fraturas no Plano de observação (HUDSON, PRIEST - 1979)

Se a frequência de junta for determinada segundo uma linha in clinada de $\theta$ em relação a linha perpendicular, o valor será $\lambda \theta$, expressa por:

$$
\lambda \theta=\lambda \cos \theta
$$


Em caso de dois sistemas de juntas com traços ortogonais na superficie rochosa, com frequênclas de fraturas $\lambda_{1}$ e $\lambda_{2}$, Figura $7 b$, o valor $\lambda \theta$ ao longo de uma linha arbritäria fazendo um àngulo $\theta$ com a direção $\lambda_{1}$ é dada por:

$$
\lambda \theta=\lambda_{1} \cos \theta+\lambda_{2} \operatorname{sen} \theta
$$

Da expressão acima conclue-se que o valor mäximo pode ser obtido por:

$$
\frac{\partial \lambda \theta}{\partial \theta}=0
$$

Nestas condições o $\lambda \theta$ máx. ocorre quando o àngulo $\theta$ é dado por:

$$
\operatorname{tg} \theta=\lambda_{2} / \lambda_{1} \quad \therefore \lambda \theta \max .=\sqrt{\lambda_{1}^{2}+\lambda_{2}^{2}}
$$

o princípio de adição das contribuições de cada sistema de junta, permite determinar a sua frequéncia num caso tridimen sional para qualquer nümero de sistemas presente no maciço rochoso.

$$
\lambda \theta=\sum_{i=1}^{n} \lambda_{i} \cos \theta_{i}
$$

onde:

$\lambda_{i}$ é a frequéncia média no $i$ - ésimo sistema sobre uma linha perpendicular a ele e $\theta_{i}$ é $\circ$ ângulo agudo entre a direção da linha de observação e a normal ao i - ésimo sistema.

Dada a orientação da linha de observação ou do furo de sonda gens e a normal de cada sistema de juntas, o valor de $\theta$ i pode ser rapidamente determinado pela projeção estereogräfica, conforme sugerido por HUDSON e PRIEST (1979).

\section{3 .2 Comprimento}


o comprimento de juntas é medido diretamente numa superficie exposta, quer em afloramentos, taludes ou em paredes de túneis, escolhendo convenientemente a ärea de observação.

o comprimento médio de juntas $\left(L_{t}\right)$, segundo LAMA (1978) pode ser indicado por:

$L_{t}=\frac{\text { àrea total de observação }}{\text { comprimento total de juntas } x \text { número de juntas }}$

Como as juntas visiveis são traços de planos de fraturas na superficie exposta, o comprimento de juntas serä função da posição dessa superfície, da forma e dimensão do plano de fra tura.

3.3.3 Rugosidades e irregularidades

A influencia de irregularidades nas características de cisa Ihamento em superfícies denteadas foi minunciosamente investigada por PATTON (1966).

As principais conclusões acham-se relatadas no item 4.1 , e o significado prático dessa influencia foi demonstrado primeiramente em ensaios em modelos e posteriormente no campo a traves de exames de fotografias dos planos de acamamentos de taludes instāveis.

A inclusão dessas irregularidades nas análises de estabilida de determinou a necessidade de caracterizá-las quantitativamente através de paràmetros geométricos e classificá-las em fun ção da dimensão, continuidade e natureza das irregularidades.

Uma das primeiras sugestões foi apresentada por PlTEAU(1970) que sugere medir amplitude e comprimento com uma escala de I m de comprimento colocada sobre as irregularidades maiores, Figura 8 . 


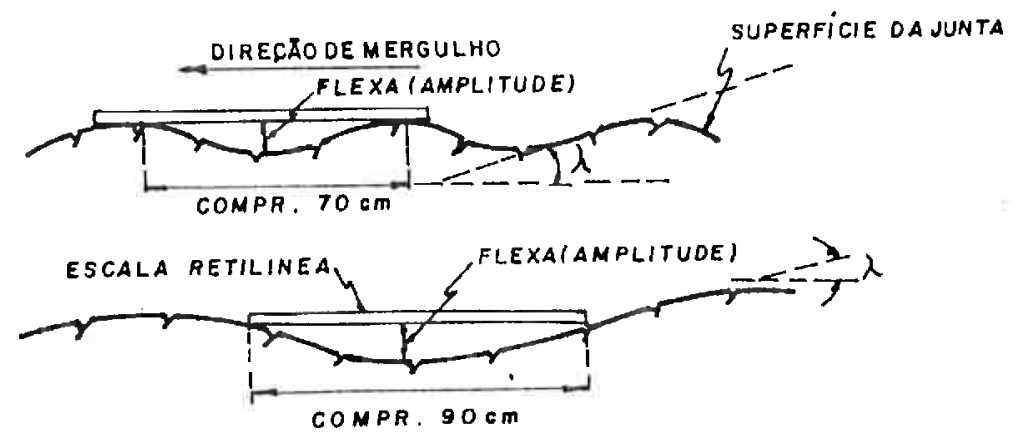

Figura 8 - Medidas de Amplitude e Comprimento das Irregularidades (Apud PITEAU - 1970)

Para irregularidades menores ele propóe cinco categorias de acordo com o modelo apresentado na Figura 9.

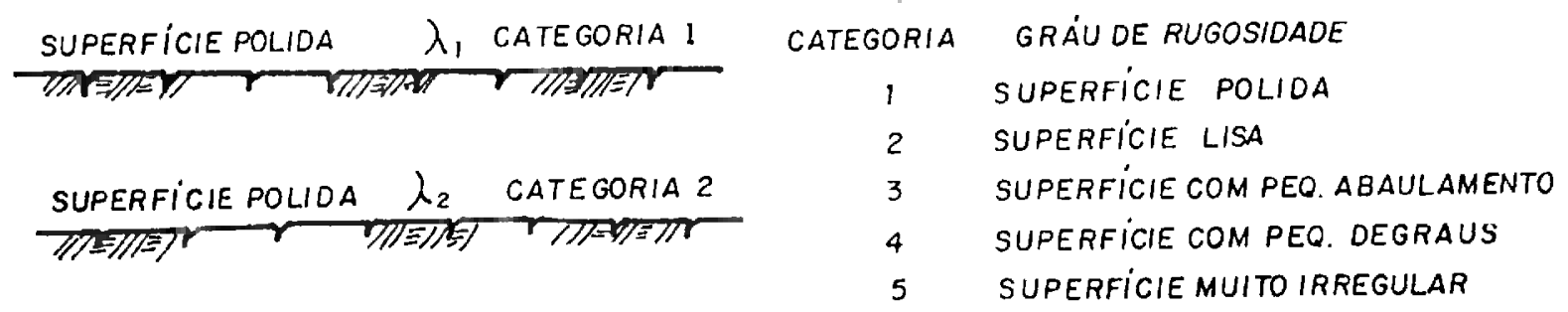
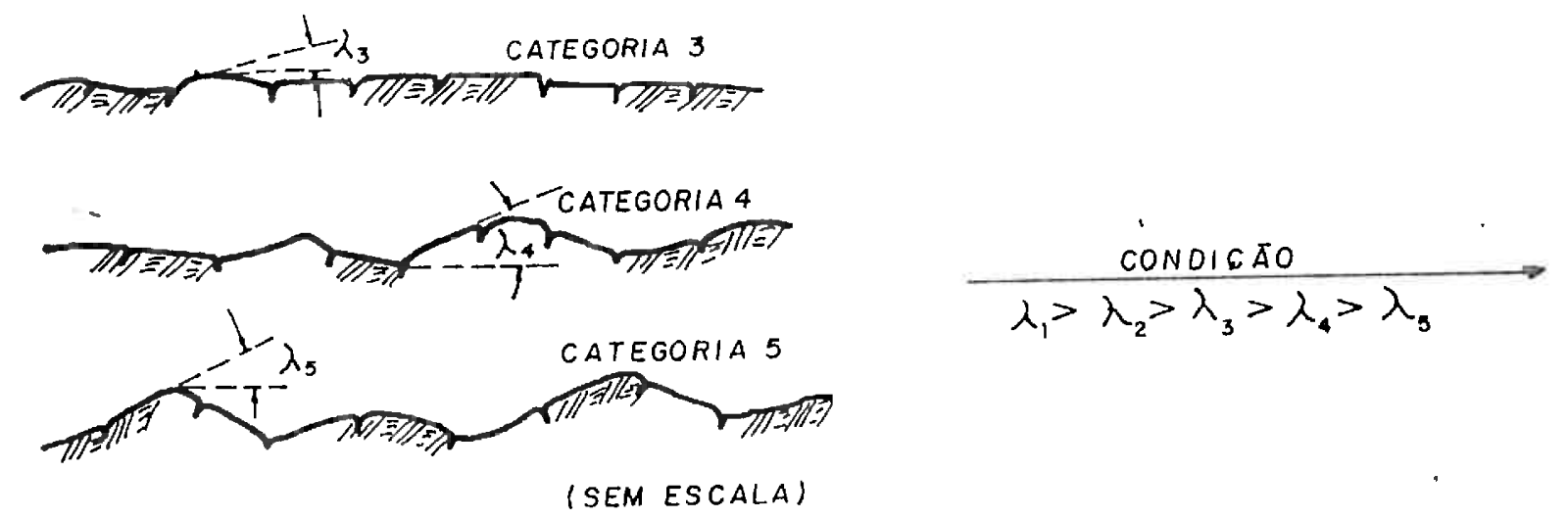

Figura 9 - Ilustração Esquemática das Cinco Categorias de Irregula ridades (Apud PITEAU - 1970) 
Com base na observação de campo PATTON e DEERE (1970), analizaram as irregularidades ao longo de planos de descontinuidades e propuseram classificar em irregularidades de la ordem (ondulações) e irregularidades de 2 a ordem (rugosidades) em função da sua dimensão e continuidade, Figura 10.

o) IRREGUL ARIDADES DE SEGUNDA ORDEM

(RUGOSIDADES)

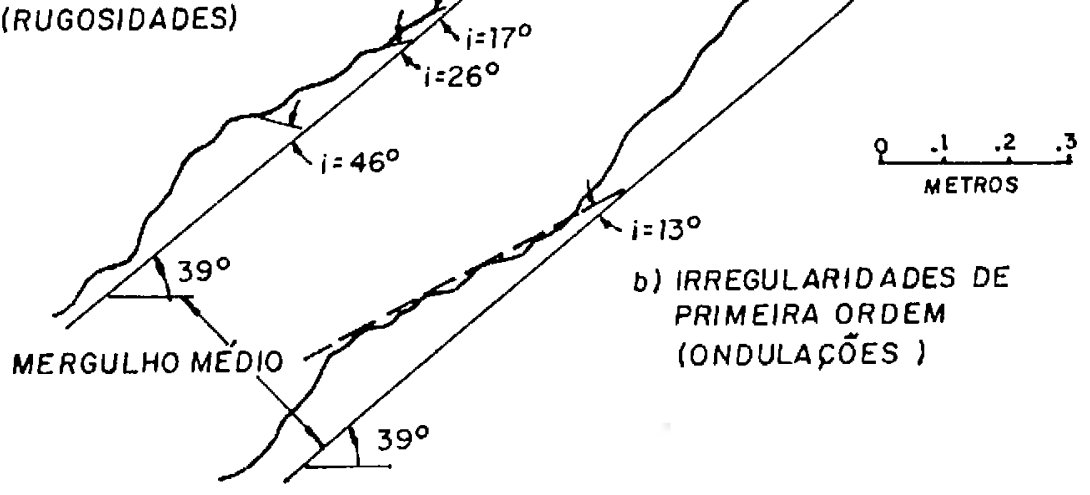

Figura 10 - Irregularidades de Primeira Ordem (ondulações) e Irre gularidades de segunda ordem (rugosidades) (Apud PATTON e DEERE - 1970)

FUJIMURA et alli (1976) examinaram as superficies rugosas de dezenas de amostras de juntas de basalto coletadas para ensaios de cisalhamento e, apoiada na observação direta no cam po, sugeriram as seguintes denominações em função da dimensão das irregularidades.

Dimensäo das irregularidades

Denominação

(cm)

$$
1,0 \text { a } 2,0 \times 10^{1} \quad \text { rugosidades }
$$


Dimensão das irregularidades (cm)

$$
\begin{aligned}
2,0 & \times 10^{1} \text { a } 2,0 \times 10^{3} \\
& >2,0 \times 10^{3}
\end{aligned}
$$

Denominação

ondul ações mergulhos

Visando obter a natureza de distribuição dos ângulos de irregularidades, FECKER e RENGER (1971) desenvolveram um perfilografo e um instrumento expedito que utiliza bússula geológica acoplado numa base de comprimento variável para medidas de ru gos idades.

Conforme observados por HOEK e BRAY (1974), os resultados ob tidos ilustrados na figura 11 revelam que as bases curtas for necem valores de ângulos de rugosidades elevados e dispersos, que diminuem proporcionalmente com o aumento do comprimento da base.

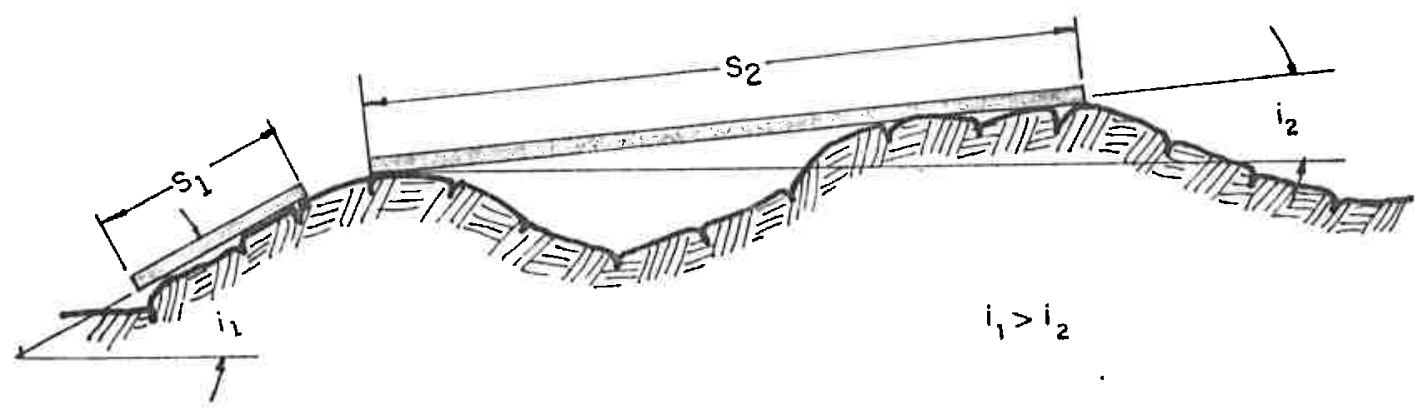

BASES CURTAS FORNECEM VALORES ELEVADOS DE ANGULOS DE IRREGULARIDADES, COM BASES LONGAS OS ANGULOS RESULTAM MENORES (HOEKE BRAY 1974)

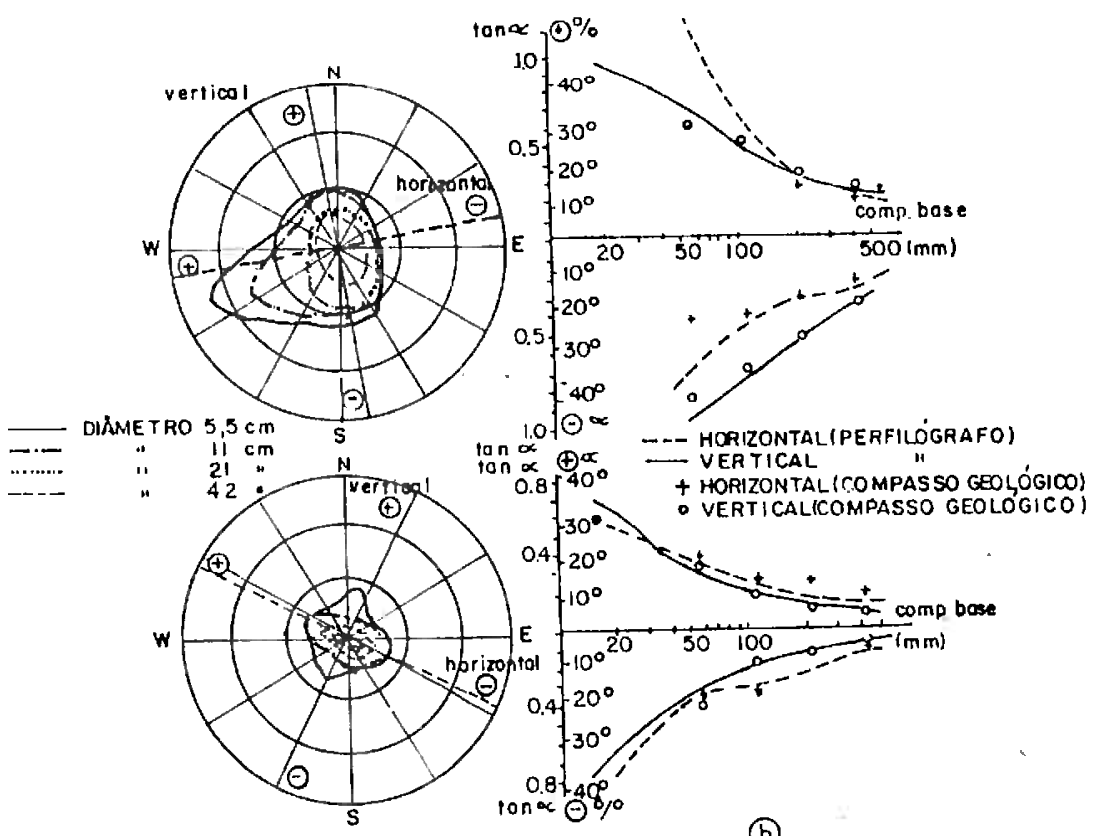

(a) (b)
Finura 11 - Medidas de Sunos idades de SuperfI $\therefore$ ie Pochose com Dife rentes Comprimento de Base 


\subsection{Anälises}

os resultados obtidos devem ser cuidadosamente analisados pois a caracterização das irregularidades e a sua relação com o comportamento geomecânico são chaves para a prática ra cional de projetos em Mecánica das Rochas.

A necessidade de representar com rigor os levantamentos rea lizados e a identificação de sistemas dominantes de fraturas presentes no maciço rochoso conduzem normalmente à métodos estatisticos de anälises e processos gräficos de representação.

Dentre os värios métodos existentes, a projeção estereogräfica utilizando diagrama de WULF (igual àngulo) ou diagrama de. SHIMIDT-LAMBERT (igual àrea), representa a maneira mais con veniente para anälises estruturais de feiçóes geológicas.

A técnica de utilização tem sido extensivamente divulgada pe la literatura especializada, notadamente nos trabalhos de FRIEDMAN (1964), GOODAMN (1963) e TERZAGHI (1962).

As juntas não são sempre contínuas e sua continuidade depen de da natureza do maciço rochoso e dos esforços que deu or $\underline{i}$ gem a juntas.

A ärea da rocha que permanece intacta ao longo das fraturas é denominada de "ponte" e a relação "ärea efetiva da juntal ärea total" é denominada de continuidade da junta por TERZA: GHI (1962).

MULLER (1963) estudou a continuidade levando em consideraçäo a frequéncia, espaçamento e comprimento médio de juntas e de finiu os fatores de continuidades planas e volumétricas que representam respectivamente a somatöria das äreas descontí nuas por unidade de àrea e de volume. 
Tais fatores podem fornecer excelentes indicaçöes quanto a planos de fraqueza estrutural, porosidade, permeabilidade do maciço rochoso em diferentes direçōes.

Usualmente, os comprimentos de juntas são medidos e plotados em diagramas de frequências. Conforme observado por BARTON (1975), eles exibem uma relação linear em escala bi-logaritmica, Figura 12, quando as juntas medidas pertencem ao mesmo sistema de fraturamento ou apresentam a mesma distribuição. Em outros casos a relação se apresentará sob diferentes inclinações.

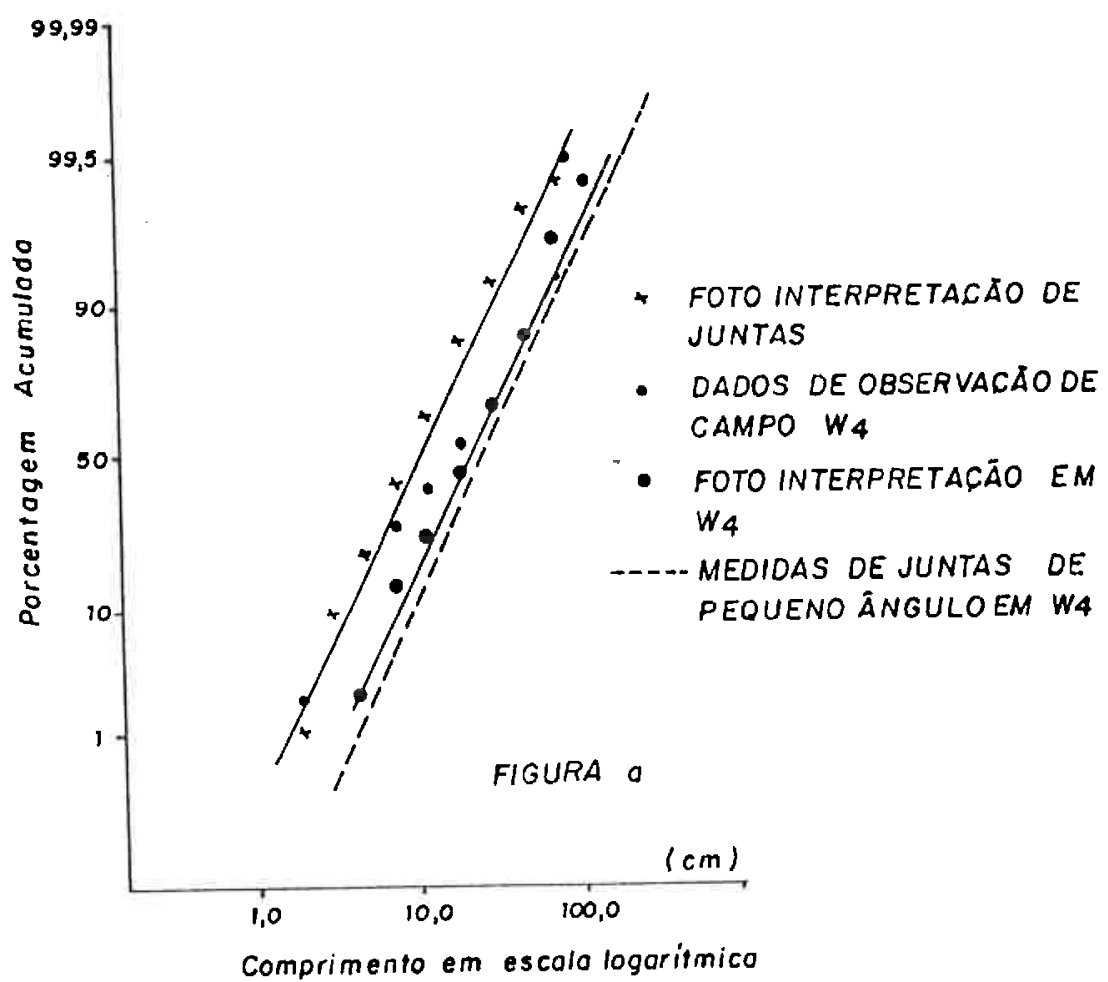

Figura 12 - Distribuição e Relação entre Sistema de Juntas (Apud BARTON - 1975)

HUDSON e PRIEST (1979), estudaram a variação da frequência de fraturas em função da orientação do furo de sondagem ou da linha de observação. 
- valor de espaçamento entre as fraturas contíguas foi anali sado visando obter a distribuição de comprimentos dos blocos no maciço rochoso e sua relação com "Rock Quality Designation" $(R Q D)$. Esta idéia foi estendida para äreas e volumes do blo co, considerando os valores de espaçamento segundo dois e très eixos ortogonais.

os autores concluiram que os espaçamentos obedecem aproximadamente uma distribuição exponencial de expoente negativo, a tingindo o valor máximo numa direçāo e mínimo na outra.

Dentre outras dificuldades, esse fato demonstra a complexida de em estabelecer uma correlação entre RQD e a qualidade me cânica do maciço rochoso.

Quanto ao volume, os estudos indicaram que a distribuiçäo dos blocos é equivalente àquela obtida em curvas granulométricas para solos do tipo mal graduado.

Com relaçāo ao espaçamento de juntas, são propostas inúmeras classificações, porém não hä diferença significativa entre elas. As tabelas 1 e 11 , apresentam respectivamente as classificações de espaçamento de junta e tamanho de bloco sugeri das pela International Society for Rock Mechanics - (ISRM-1975)

TABELA I

Classificação de Espaçamento da Junta

Segundo I.S.R.M. - 1975

\begin{tabular}{|l|r|}
\hline \multicolumn{1}{|c|}{ CLASSIFICAÇÃO } & ESPAÇAMENTO DE JUNTAS \\
\hline Extremamente fecha- & $<3 \mathrm{~cm}$ \\
do & $3 \mathrm{a} 10 \mathrm{~cm}$ \\
Muito fechado & $10 \mathrm{a} 30 \mathrm{~cm}$ \\
Fechado & $30 \mathrm{a} 100 \mathrm{~cm}$ \\
Mëdio & $1 \mathrm{a} 3 \mathrm{~m}$ \\
Extenso & $3 \mathrm{a} 10 \mathrm{~m}$ \\
Muito extenso & \\
Extremamente exten & $>10 \mathrm{~m}$ \\
so & \\
\hline
\end{tabular}


TABELA I |

Classificação de Tamanho de Bloco

Segundo 1.S.R.M. -1975

\begin{tabular}{|l|r|}
\hline \multicolumn{1}{|c|}{ CLASSIFICAÇÃO } & No DE \\
\hline Maciço & 1 \\
Bloco grande & a 3 \\
Bloco médio & 3 \\
Bloco pequeno & $3 a 10$ \\
Bloco muito pequeno & 10 a 30 \\
& $>30$ \\
\hline
\end{tabular}


4 RESISTENCIA AO CISALHAMENTO DE ROCHAS FRATURADAS 
Mais do que qualquer outro, as rochas foram consideradas como ma terial estruturalmente adequado, em suas multiplas aplicaçós, desde o tempo mais longínquo. A experiência adquirida no decor rer dos anos tornou seu uso tão familiar a ponto de prescindir por muito tempo de investigações objetivando melhorar o conhecimento sobre o maciço rochoso.

Contudo, acidentes com barragens, obras de dimensão e concepção arrojadas e a necessidade de construi-las em condiçóes geológicas nem sempre favoráveis induziram o reconhecimento da importann cia dessas investigações.

Do ponto de vista da engenharia, o aspecto mais importante $\bar{e}$ a presença de feiçóes estruturais que pode reduzir sensivelmente a resistência mecànica do maciço rochoso.

A conceituação básica sobre o comportamento do maciço rochoso, a presentada por KLAUS (1962), sintetiza muito bem o domínio da Me cânica das Rochas, bem como a sua importância na concepção de pro jetos em estruturas rochosas, a saber:

1. Para maioria de problemas, o comportamento geomecânico de um maciço rochoso depende mais do sistema de descontinuidades geo lógicas do que da resisténcia mecánica da substância rochosa.

2. A natureza de vinculos entre os blocos de rocha determina o caráter anisotrōpico da resistência ao cisalhamento, que é con siderada como resistência última do maciço.

3. As variaçóes na deformabilidade resultam predominantemente de deslocamentos internos diferenciados entre os blocos de rocha.

4.l Teoria de Deslizamento em Rochas Fraturadas

Ao provocar um deslizamento de uma parte sobre a outra, $\vec{e}$ posta 
em jogo uma importante resistência contra o movimento denominada de atrito.

Em termos globais, segundo LAMA (1972), o fenômeno de atrito pode ser agrupado sob quatro pontos de vista:

1. O primeiro se baseia somente nas considerações geométricas e explica o atrito em termos de micro-rugosidades presentes na superficie (KRAGELSKII-1965);

2. Com o desenvolvimento do conceito da natureza molecular de só lidos, o segundo ponto de vista explica o atrito como resulta do da atração molecular entre dois sōlidos;

3. o terceiro atribui o desenvolvimento do atrito à interpenetra ção de rugosidades de um sölido no outro. Assim que o movimen to se inicia a resistência é desenvolvida deformando o material em torno das rugosidades;

4. 0 quarto é representado por uma teoria composta entre o primeiro e o terceiro pontos de vista.

- fenōmeno de atrito em rochas fraturadas pode ser explicado teo ricamente por qualquer dos pontos de vista acima e, portanto, va lemas leis fundamentais de atrito apresentadas por Amonton em 1699 para superficies secas não lubrificadas e resumidas por BOW DEN E TABOR (1967):

a. A resistência ao atrito (S) entre dois corpos é função direta da força normal (N) agindo sobre a ärea de contato. A constan te de igualdade $\mu$ é conhecida como coeficiente de atrito.

b. A resistencia ao atrito e o coeficiente de atrito são indepen dentes da superficie de contato para uma determinada força normal constante. 
Por mais lisas que elas aparentam ser, as superfícies

rochosas

säo irregulares e o contato é invariavelmente limitado às irregularidades presentes na superficie, Figura 13.
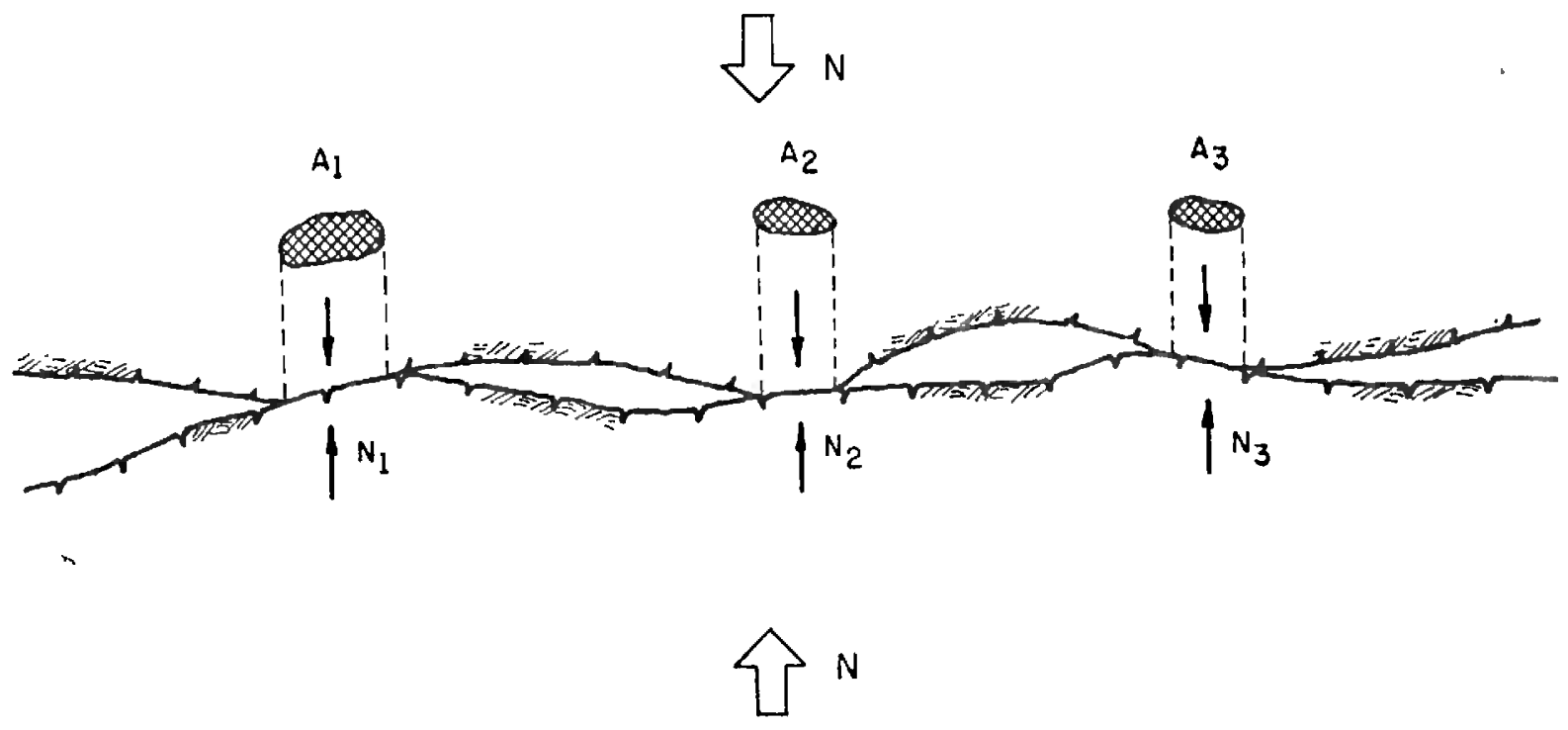

Figura 13 - Contato entre Superfícies Irregulares

Como a àrea de contato entre as superfícies ( $\left.\Sigma A_{i}\right)$ è bastantere duzida, as irregularidades poderão estar sujeitas à tensóes normais relativamente altas e sofrer deformações e rupturas até que a tensāo normal ( $\frac{N_{i}}{A_{i}}$ ) nas irregularidades seja igualada à cedén cia (*) $\sigma_{c}$ da rocha. A força normal (N) estará relacionada a $\sigma_{c}$ através da área de contacto entre irregularidades pela expressão:

$$
N=\sum_{i=1}^{n} N_{i}=\sigma_{c} \sum_{1=1}^{n} A_{i}
$$

A força tangencial ( $T$ ) necessária para produzir deslizamento e a correspondente tensão de cisalhamento (TA) na àrea de contacto po de ser representada por:

$$
T=\sum_{i=1}^{n} S_{i}={ }^{T} \quad \begin{aligned}
& \sum_{A} \\
& =1
\end{aligned} A_{i}
$$

(*) Cedencia: Tensão requerida para causar deformação plástica ou escoamento plástico 
A igualdade entre a força tangencial (T) e a resistência ao atri to (S) se estabelece somente na eminéncia ao deslizamento e vale :

$$
S=\mu N \text { ou } \tau_{A}=\mu \sigma_{C}
$$

Todavia, os resultados obtidos experimentalmente nem sempre se ajustam às predições teóricas acima, indicando que em superfícies rochosas intervém outros fenómenos que alteram os valores de resistència ao cisalhamento.

TAYLOR (1948) analisando ensaios de cisalhamento em materiais gra nulares (areias), foi o primeiro a perceber a influéncia da dila tância (*) nas caracteristicas de cisalhamento. Combase na teo ria de conservação de energia propós introduzir correção no valor obtido.

Mais tarde, NEWLAND e ALLELY (1975) concluiram que o cisalhamento não é uma propriedade intrínseca do material mas que depende do àngulo de deslizamento entre as particulas, Figura 14 .

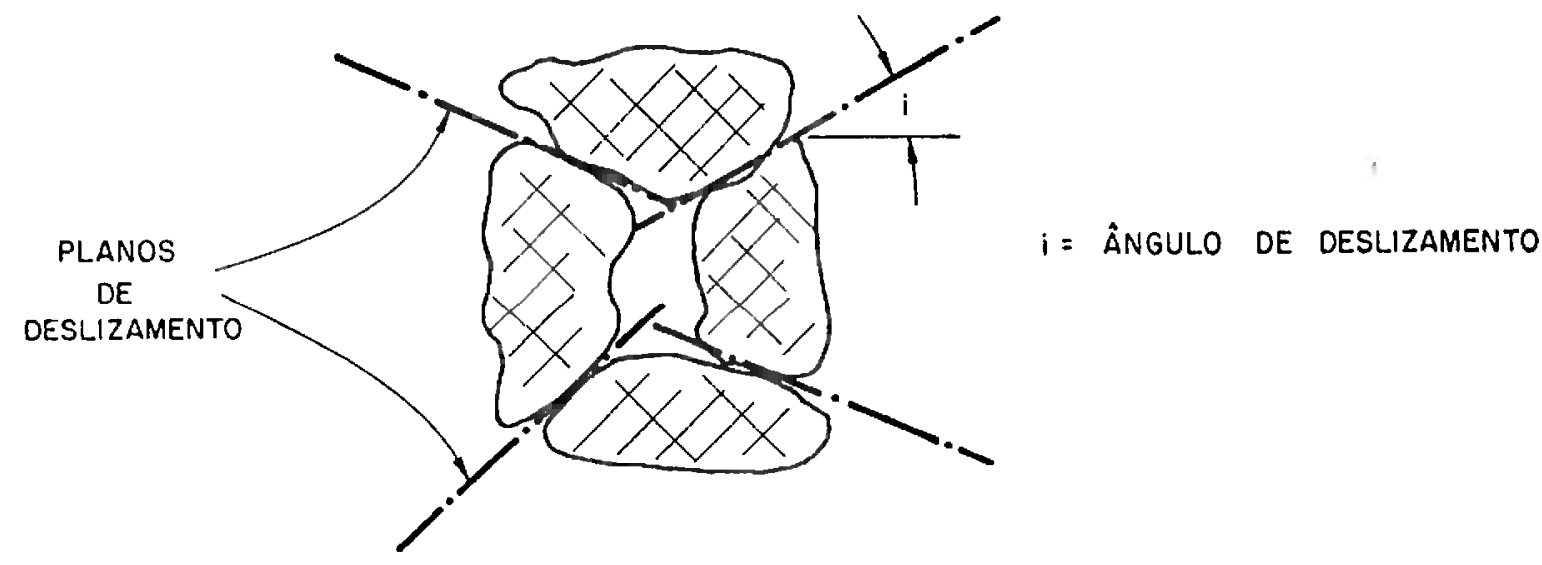

Figura 14 - Planos de Deslizamento no Contacto entre Partículas Gra nulares

(*) Dilatância: Aumento de volume durante o cisalhamento do material. Efeito de dilatância em rocha ver item 4.4 .1 
RIPLEY e LEE (1961) e WITHERS (1964) foram os primeiros a perce ber que as rugosidades das superfícies rochosas poderiam desempenhar importante papel nas caracteristicas de resistència ao cisalhamento.

PATTON (1966) estudou a influência da rugosidade e o fenômeno de "embricamento" na envoltöria de cisalhamento em modelos físicos confecionados em mistura de gesso e caolim simulando "dentes"de

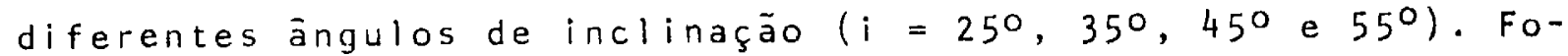
ram moldados dois conjuntos de corpos de prova, um com iquatro dentes e outro com dois, todos com aproximadamente $5 \mathrm{~mm}$ de altu ra. Seus resultados indicaram que a envoltöria de cisalhamento para corpo de prova com $i=25^{\circ}$, sob carregamento normal baixo, pode ser representada pela reta A.Figura 15 .
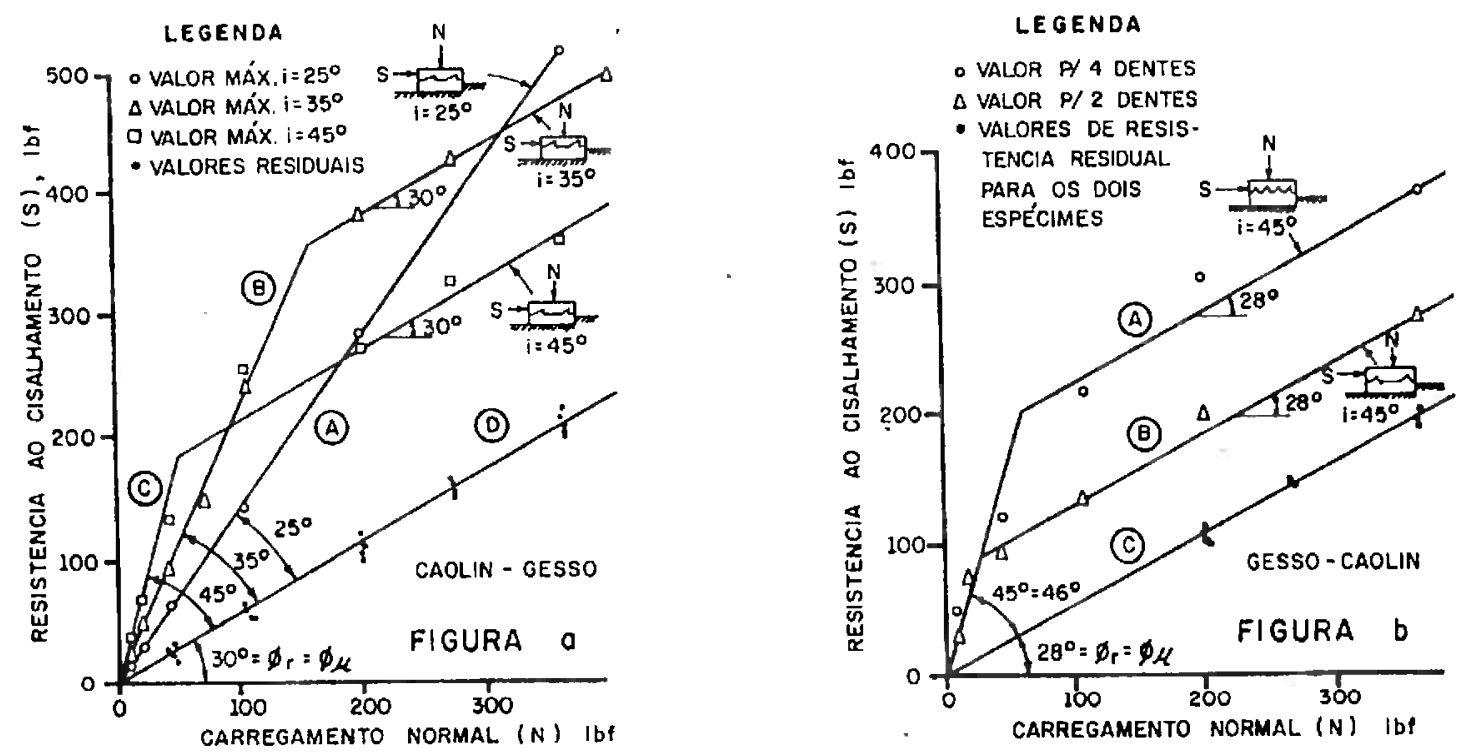

Figura 15 - Envoltória de Cisalhamento com Diferentes Inclinação e Nümeros de Dentes

$0 s$ corpos de prova com $i=35^{\circ}$ e $45^{\circ}$, são representados respect vamente por duas retas $B$ e $C$ quebradas em dois trechos. A incli nação menos acentuada do trecho final das linhas B e C é semeIhante à envoltöria $D$ que representa as condiçōes de resistência residual, enquanto o trecho inicial $\vec{e} \phi_{u}+i$. 
A figura 15b mostra a influéncia do aumento de nümero de dentes. A inclinação acentuada da envoltória é também aproximadamente $\phi_{u}+i$. O efeito mais significativo é a mudança do ponto de quebra abrupta da reta, movendo-o para uma região de tensões normal e de cisalhamento maiores. O seu valor é praticamente o dobro daquele obtido por dois dentes em relação a envoltöria de resistência ültima.

Combase nesses ensaios PATTON (1966) concluiu que as envoltórias de cisalhamento em superficies irregulares são curvas e mudanças na inclinação refletem a mudança no modo de ruptura.

EINSTEIN et allii (1970), analisaram o mecanismo de ruptura em supeficies rochosas e explicaram o fenómeno do "embricamento" entre as rugosidades, Figura 16.

Pequenas tensões normais facilita o deslizamento de uma rugosidade sobre a outra, favorecendo a manifestação da dilatáncia. A mobilização de resistência pode ser representada pela equação:

$$
S=N \operatorname{tag}\left(\phi_{u}+i\right)
$$

onde:

$S=$ Resistência ao atrito

$N=$ Força normal

$\phi_{u}=$ Angulo de atrito residual (resistência ültima)

$i=$ Inclinação da rugosidade em relação ao horizontal, medido no sentido de movimento.

o deslizamento prossegue até a tensão atingir o nivel em que as rugosidades começam a ser cisalhadas. Neste ponto a envoltória quebrabruscamente, indicando mudança no modo de ruptura, segun do PATTON (1966). Este estágio pode ser representado pela equaçāo:

$$
S=c+N \operatorname{tg} \phi_{u}
$$



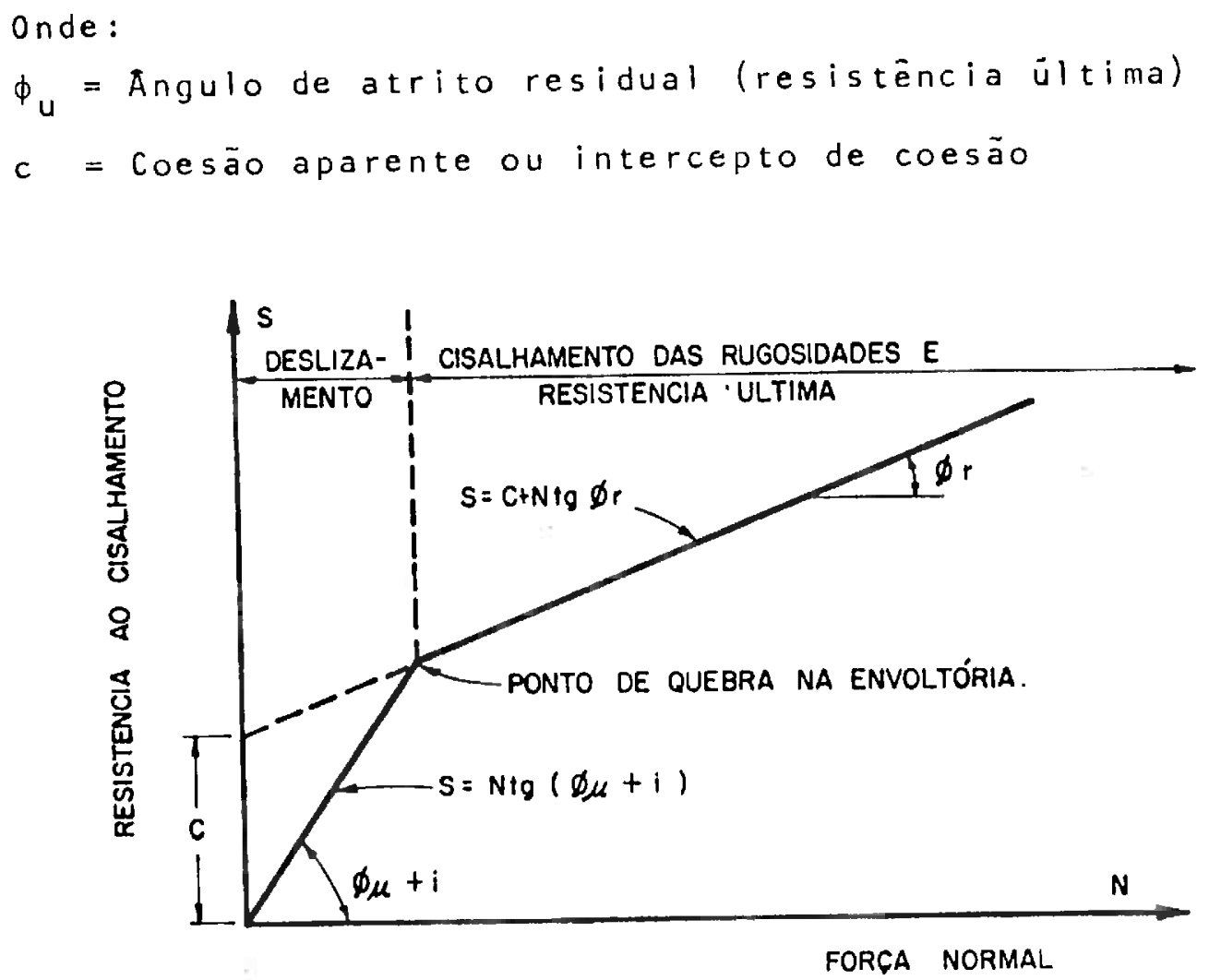

Figura 16 - Envoltöria Teörica Típica para Superficies Irregulares Uma representação esquemätica do mecanismo de ruptura em único "dente" é apresentado na Figura 17.

ROWE et allii (1964), apös estudos cuidadosos, sugeriram diví dir a resisténcia ao cisalhamento (S) em três componentes:

$$
s=s_{1}+s_{2}+s_{3}
$$

onde:

$S_{1}=$ Componente devido ao trabalho externo de dilatancia contra a força normal N.

$S_{2}=$ Componente interno adicional de atrito devido à dilatáncia.

$s_{3}=$ Componente devido exclusivamente ao atrito interno. 

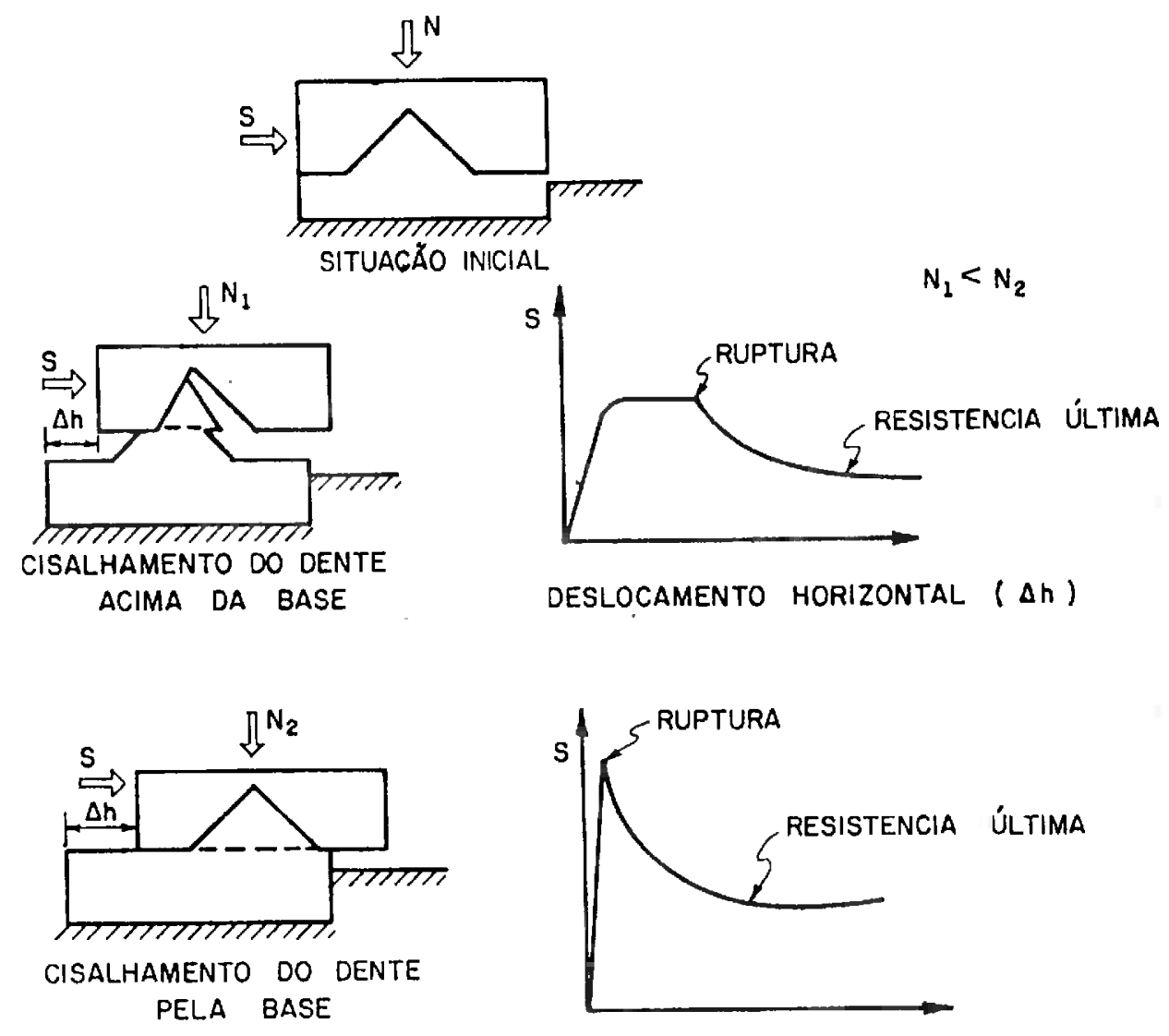

DESLOCAMENTO HORIZONTAL $(\Delta h)$

Figura 17 - Mecanismo de Ruptura do "Dente" em Funçäo da Força de Cisalhamento e Deslocamento Horizontal

Considerando a Figura 18 abaixo:

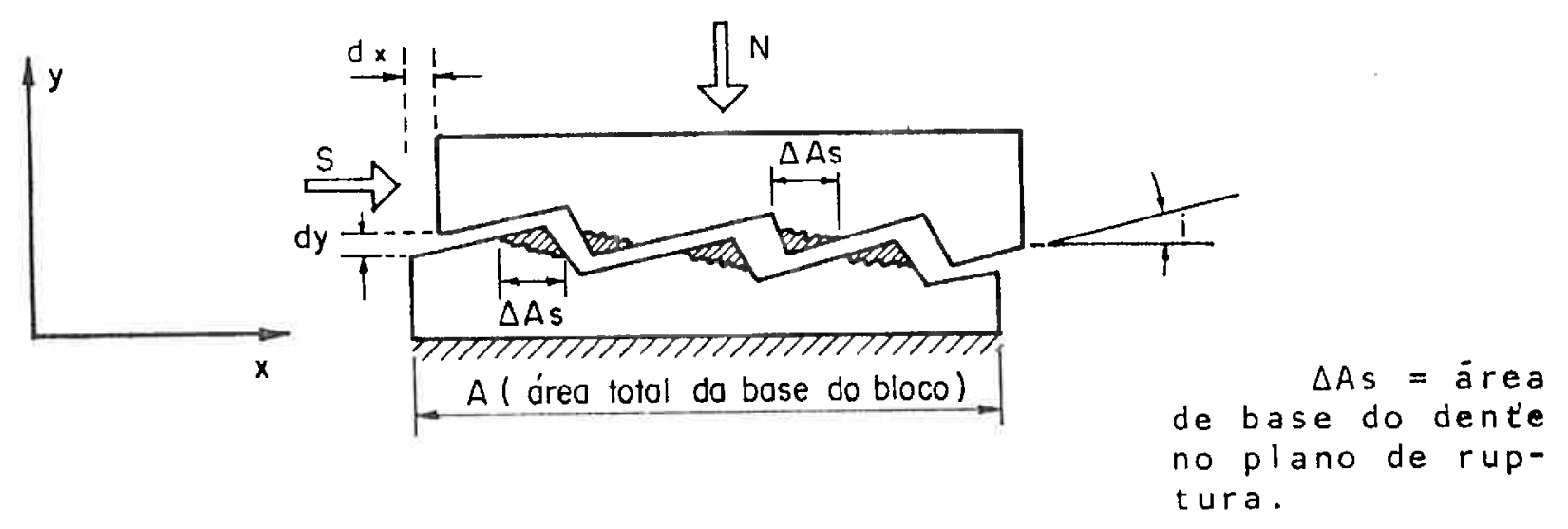

Figura 18 - Figura Esquemática dos Componentes da Força de Cisalha mento 


$$
\begin{aligned}
& S_{1} d x=N d y \\
& S_{1}=N \frac{d y}{d x} \\
& S_{1}=N \operatorname{tgi}
\end{aligned}
$$

onde: $\frac{d y}{d x}=\operatorname{tg} i(t a x a$ de dilatāncia)

Se $S_{2}$ cosi é a resistência ao cisalhamento ao longo do plano de deslizamento e $S$ seni $\bar{e}$ a parcela da força de cisalhamento normal ao plano devido à dilatância, tem-se:

$$
\begin{aligned}
& S_{2} \cos i=S \operatorname{sen} i \operatorname{tg} \phi_{\mu} \\
& S_{2}=S \operatorname{tg} i \operatorname{tg} \phi_{\mu}
\end{aligned}
$$

o componente da força de cisalhamento devido unicamente ao a trito interno serä:

$$
\begin{aligned}
& \mathrm{S}_{3}=N \operatorname{tg} \phi_{\mu} \\
& \phi_{\mu}=\text { àngulo de resisténcia ùltima }
\end{aligned}
$$$$
\text { Portanto, da somatöria das expressöes } \mathrm{S}_{1}, \mathrm{~S}_{2} \mathrm{e} \mathrm{S}_{3} \text { temos: }
$$$$
\mathrm{S}=N \operatorname{tg} i+\operatorname{sgg} i \operatorname{tg} \phi_{\mu}+N \operatorname{tag} \phi_{\mu}
$$$$
\frac{S}{N}=\operatorname{tag} i+\frac{S}{N} \operatorname{tg} i \operatorname{tg} \phi_{\mu}+\operatorname{tg} \phi_{\mu}
$$$$
\frac{s}{N}\left(1-\operatorname{tg} i \quad \operatorname{tg} \phi_{\mu}\right)=\operatorname{tg} \phi_{\mu}+\operatorname{tg} i \quad \frac{s}{N}=\frac{\operatorname{tg} \phi_{\mu}+\operatorname{tg} i}{1-\operatorname{tag} i \operatorname{tg} \phi_{\mu}}=\operatorname{tag}\left(\phi_{\mu}+i\right)
$$ 
$S=N \operatorname{tag}\left(\phi_{\mu}+i\right)$

LADANYI e ARCHAMBAULT (1969) consideraram posteriormente um quarto componente $\left(S_{4}\right)$ assumindo que os "dentes" sejam cisaihados pela base. Assim, o quarto componente pode ser expres so por:

$S_{4}=A_{5} C+N \operatorname{tg} \phi_{0}$

onde:

$A_{s}=$ somatöria das äreas da base do "dente" no plano de rup tura

C e $\phi_{0}=$ parāmetros relacionados à resistência da substância rochosa.

Normal mente os movimentos ao longo de uma superfície irregular ocorrem envolvendo simultaneamente deslizamento e cisaIhamento, com predominância de um sobre o outro em função do tipo de irregularidade e o valor da carga normal aplicado.

Se a somatória das àreas da base das rugosidades cisalhadas é $A_{S}$, dada por $\sum \Delta A_{S}$, o deslizamento ocorrerá sobre a àrea $A-A_{s}$ e o cisalhamento correspondente serä:

$$
s=\left(s_{1}+s_{2}+s_{3}\right)\left(1-a_{s}\right)+s_{4} a_{s}
$$

onde:

$$
a_{S}=\frac{A_{S}}{A} \text { (relação àrea de cisalhamento) }
$$

Substituindo os valores de $S_{1}, S_{2}, S_{3}$ e $S_{4}$ na equação acima e dividindo por A, obtēm-se a expressão geral da tensão de cisalhamento numa superficie irregular. 
$\tau=\frac{S}{A}=\frac{\sigma\left(1-a_{s}\right)\left(\operatorname{tg} i+\operatorname{tg} \phi_{\mu}\right)+a_{s}\left(\sigma \operatorname{tg} \phi_{0}+c\right)}{1-\left(1-a_{s}\right) \operatorname{tag} i \operatorname{tg} \phi_{\mu}}$

Três casos particulares são apresentados a seguir:

a. Para carregamentos normais baixos, admitindo "dentes" regulares, $\operatorname{com} a_{s}=0$

$$
\tau=\sigma \operatorname{tag}\left(\phi_{\mu}+i\right)
$$

b. Para carregamentos normais altos, admitindo cisalhamento de todos os "dentes" pela base, $\operatorname{com} a_{s} \cong 1$ e $i=\dot{0}$

$$
\tau=\sigma \operatorname{tag} \phi_{0}+c
$$

As expressões acima são idênticas aquelas obtidas por PATTON(1966) em ensaios executados em modelos.

c. Para superficie plana descontínua com $i=0$ tem-se:

$$
\tau=\sigma\left(1-a_{s}\right) \operatorname{tg} \phi_{\mu}+a_{s}\left(\sigma \operatorname{tg} \phi_{0}+c\right)
$$

4.2 Métodos de Ensaios

Basicamente, em função do tipo de ensaios, podem ser agrupados da seguinte forma:

- cisalhamento por rotação;

- cisalhamento sob carregamento triaxial;

- cisalhamento direto - laboratório e campo. 
4.2.1 Cisalhamento por Rotaçāo

o método consiste em fixar a amostra contendo fraturas naturais ou artificialmente produzidas em dois cilindros, Figura 19.

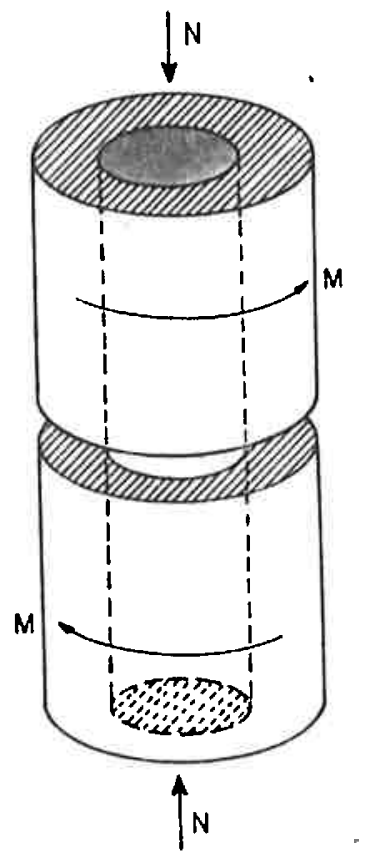

Figura 19 - Cisalhamento por Torção de Cilindros

o torque $M$ á aplicado de forma a girä-los ao longo do seu eixo sob carregamento axial $N$, fazendo os dois cilindros deslizarem um sobre o outro na superficie de contacto.

Esse tipo de equipamento foi construido por N.G.W. Cook no Laboratörio de Pesquisas Minerais de Johannesburg, Africa do Sul. O sistema rotatörio permite estudar o efeito de deslizamentos repetitivos numa mesma superficie. Esse método foi $\underline{u}$ tilizado por investigadores como KUTTER (1974) e CHRISTENSEN et alli $\mathrm{i}(1974)$.

4.2.2 Cisalhamento sob Carregamento Triaxial 
A partir do trabalho pioneiro de JAEGER (1959) a càmara triaxial tem sido muito utilizada para ensaiar as juntas. A primeira câmara foi idealizada por VON KARMAN (1911) e desde en tão sofreu várias modificações e melhorias. Contudo, o princí pio básico permanece inalterado onde o corpo de prova cilíndrico é envolvido por uma membrana plästica ou de borracha pa ra evitar penetração de fluido, confinante nos poros da rocha. A figura 20 apresenta a célula triaxial de HOEK e FRANKLIN (1968).

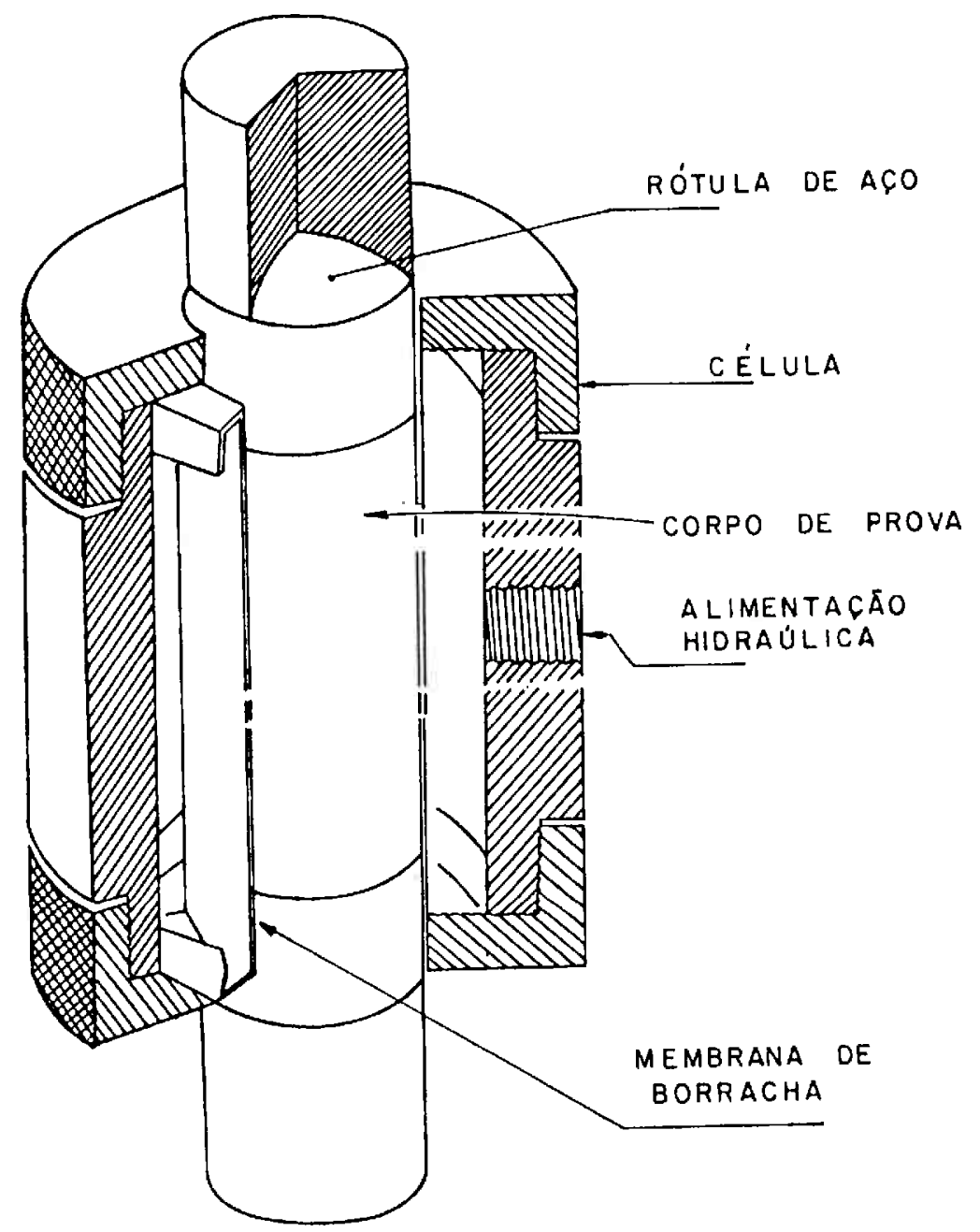

Figura 20 - Célula Triaxial Concebida por HOEK e FRANKLIN. 
4.2.3 Cisalhamento Direto - Laboratörio e Campo

a. Método to deslizador

E talvez o método mais antigo de investigaçāo de atrito co nhecido para minerais e rochas. Este método foi utilizado por HORN e DEERE (1962) e B̧YERLEE (1967b).

Um pequeno móvel sob carregamento normal baixo, Figura 21 , desliza sobre uma superficie maior. Neste sistema, ocorre renovação de àrea em contacto para superficie maior,enquan to para a menor é sempre a mesma. E bastante útil para es tudo de atrito residual mas não representa a condição real na natureza.

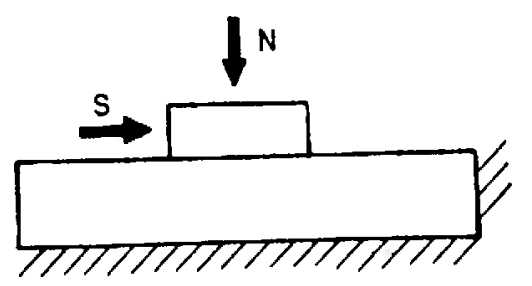

Figura 21 - Método do Deslizador

b. Cisalhamento em amostras cilindricas

- corpo de prova é colocado entre uma peça fixa e outra mó vel, com reentrancia em meia cana, cada qual envolvendo a metade do corpo cilindrico. A superficie de fratura deverá coincidir como plano de cisalhamento situado entre as duas peças, Figura 22 .

c. Cisalhamento em amostras cübicas

o carregamento é dado por dois macacos hidräulicos um deles para carregamento vertical e outro parahorizontal,for çando o deslizamento ao longo da fratura, Figura 23. 


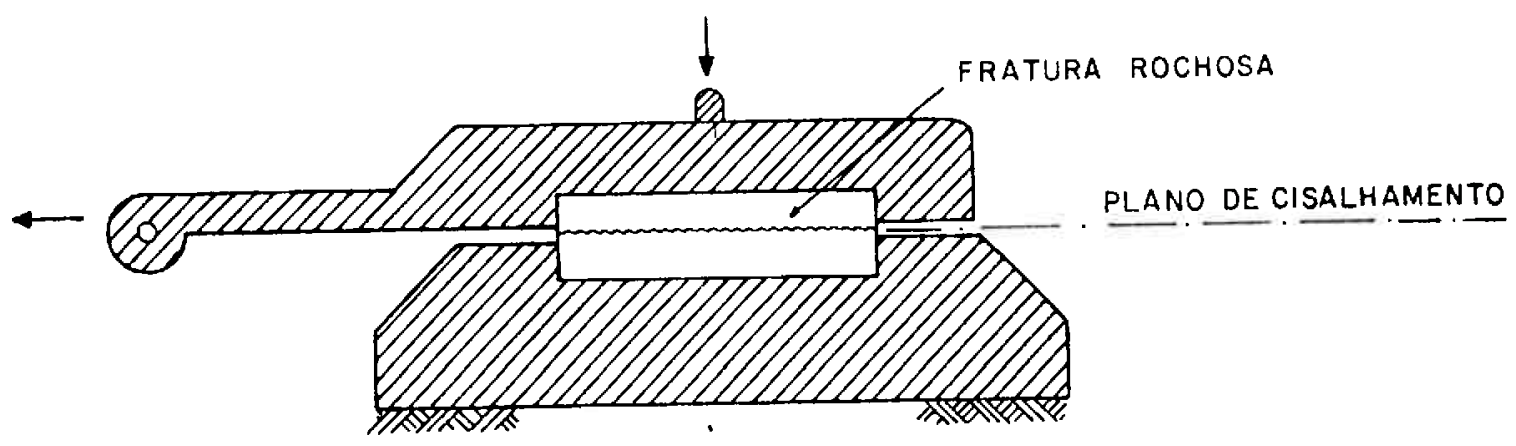

Figura 22 - Cisalhamento Simples em Amostras Cilindricas (Apud PROTODYAKONOV, 1969)

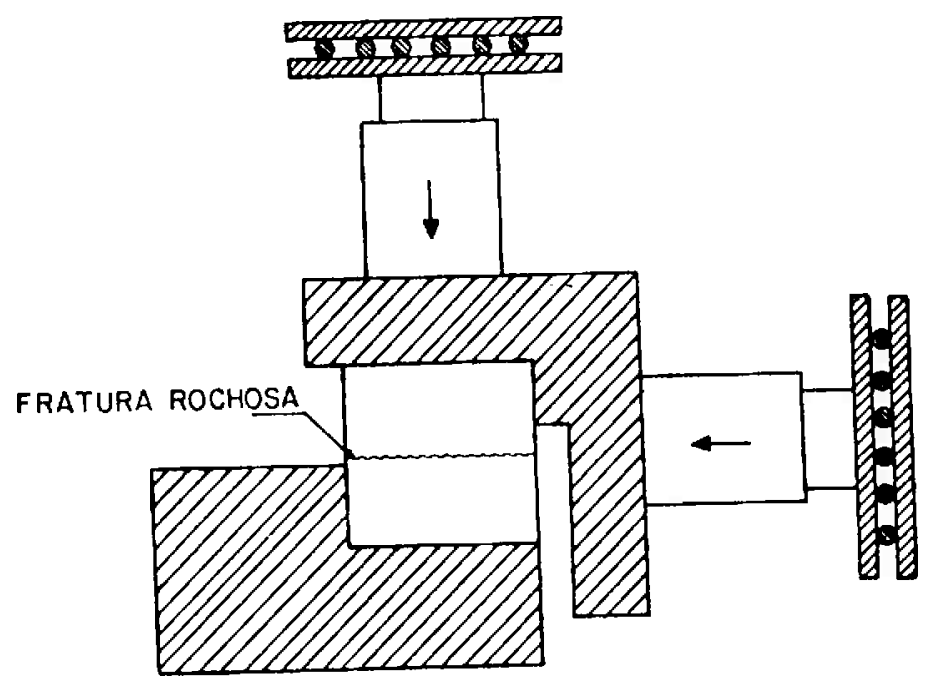

Figura 23 - Cisalhamento Simples em Amostras Cübicas (Apud PROTODYAKONOV, 1969)

d. Cisalhamento direto convencional-laboratório

E o método mais usual e difundido internacionalmente em que a principal característica reside na utilizaçäo de um sistema com duas caixas de cisalhamento. 
A amostra cilindrica, cúbica,prismática ou de forma irregular é fixada na caixa de cisalhamento com cimento ou re sina epóxica. A superfície descontínua do corpo de prova é mantida coincidente com o plano de cisalhamento e uma abertura de aproximadamente $1 \mathrm{~cm}$ (mais para rugosidade maior) é deixada entre as caixas. O carregamento normal e de cisalhamento e fornecido geralmente por macacos hidräu licos. A carga normal pode mover lateralmente acompanhan do a caixa superior mantendo-se centrado sobre ela.

A Figura 24 ilustra o esquema modificado de montagem utilizado desde 1968 pelo agrupamento de Mecânica de Rochas do IPT, em caixas de cisalhamento de $20 \times 20 \mathrm{~cm}$. Esta técnica foi inicialmente introduzida pelo Laboratório Nacional de Lisboa. Atualmente o IPT dispōe de equipamentos que permitem execução de ensaios de cisalhamento em laboratório em caixas de $10 \times 10 \mathrm{~cm}$ até $100 \times 100 \mathrm{~cm}$, munidos de registradores contínuos de cargas e deformações.

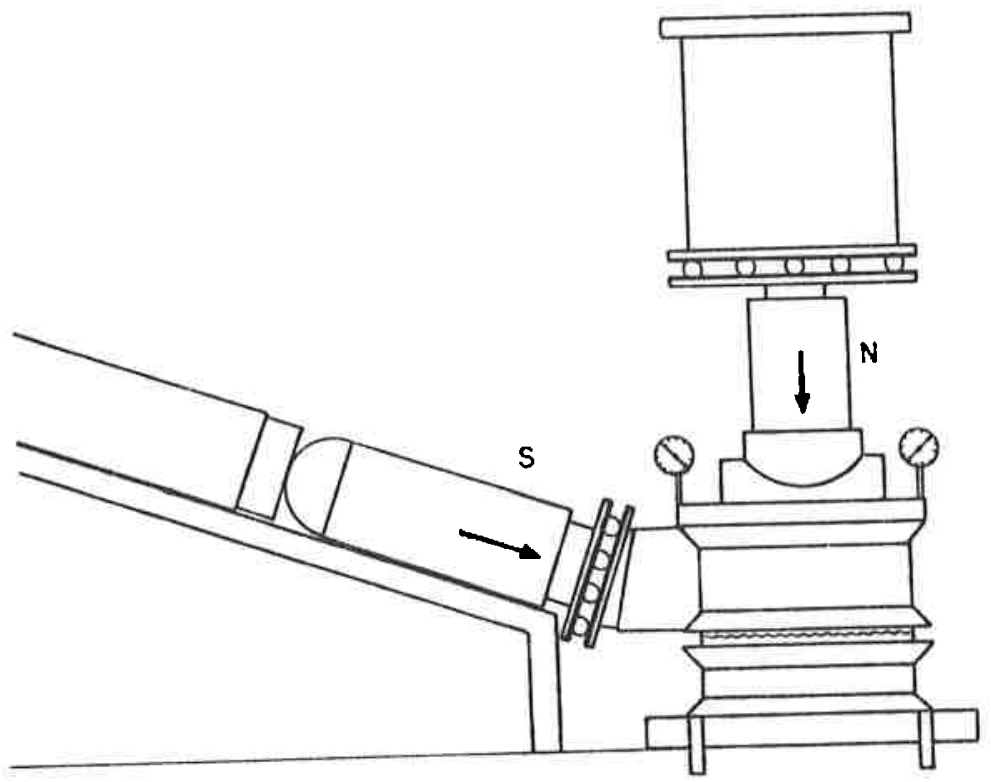

Figura 24 - Esquema de Montagem de Ensaios de Cisalhamento Utiliza do pelo IPT, Caixas de $20 \times 20 \mathrm{~cm}$. 
Com base no mesmo princípio, diferentes tipos de montagem tem $s$ ido apresentados por KRSMANOVIC e LANGOF (1964) LOCHER (1968), BERNAIX (1969), HOEK e PENTZ (1969), RENGER(1970), GOODMAN E OHNISHI (1973) e OUTROS.

Os primeiros ensaios laboratoriais em amostras de grandes dimensöes foram executados por EVDOKIMOV e SAPEGIN (1967) nas juntas e contatos litológicos das rochas de fundação da Barragem BRATSK no Rio Angara (URSS).

A Figura 25 apresenta o dispositivo de ensaio utilizado, especialmente desenvolvido por I.G. GONCHAROV, para amostras cilindricas de 80 a $100 \mathrm{~cm}$ de diâmetro.

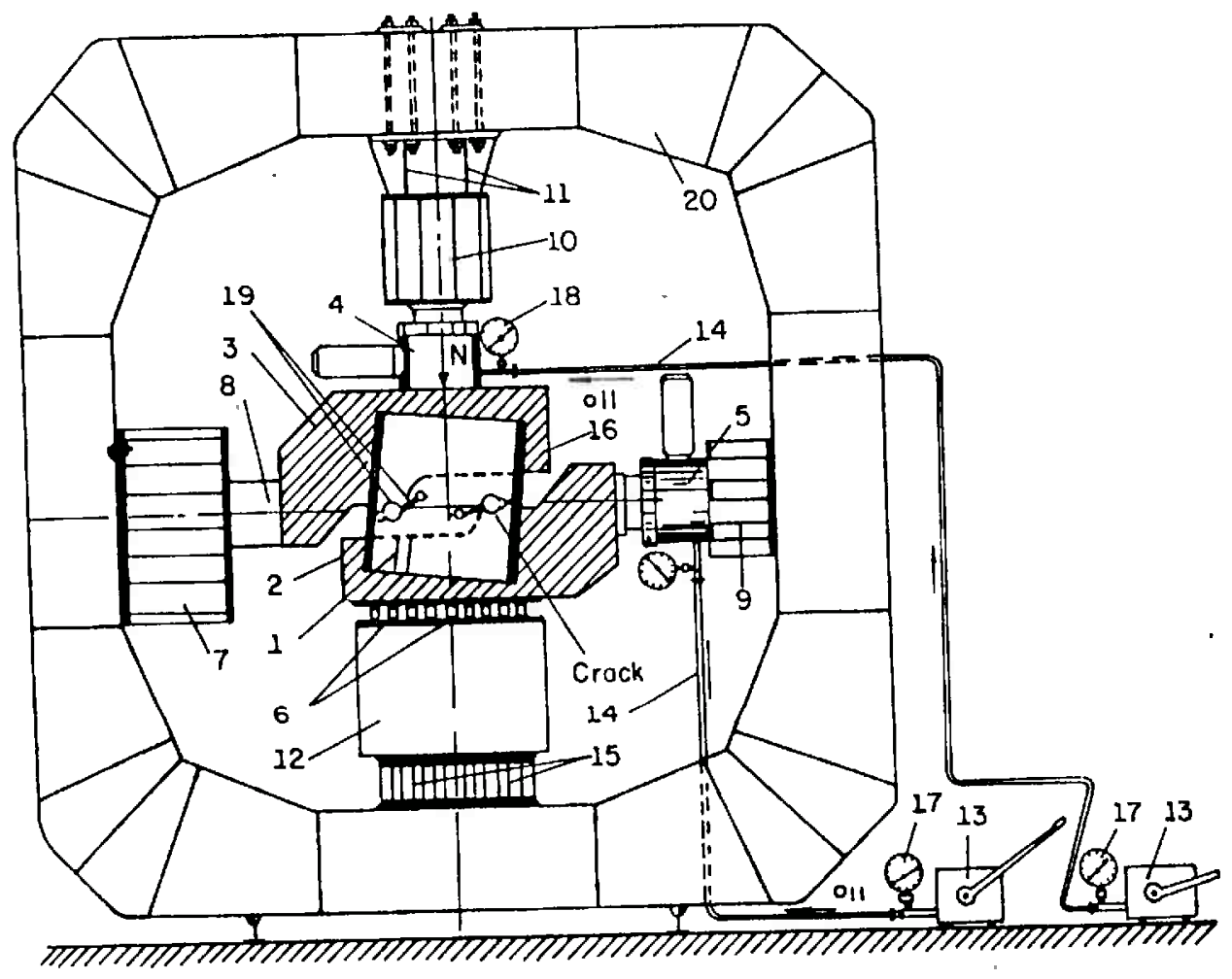

Figura 25 - Dispositivo para Ensaios de Cisalhamento em Laboraró rio Desenvolvido por I.G. GONCHAROV para Amositas de Grandes Dimensões (APud EVDOKIMOV e SAPEGIN, 1967). 
e. Cisalhamento direto convencional "in situ"

Como já mencionado a fratura se constitui na superfície pre ferencial de cisalhamento. As caracteristicas de resistència são determinadas forçando a ruptura exatamente nessas superficies, ao passo que na rocha intacta a ruptura é resultado de um estado de tensões estabelecido no seio da: subs táncia rochosa.

Em geral, a feição característica de fraturas rochosas é a presentar superfícies não planas, irregulares, denteadas com rugosidades se distribuindo caoticamente. Destarte, os espécimes de laboratório dificilmente contém ou representam todas as características relevantes do maciço rochoso.

Por esta razão, a execução de ensaios "in situll torna-se, às vezes, indispensävel quando se pretende determinar com maior rigor as características de cisalhamento de rochas fraturadas. MIDEIA et allii (1975) enfocaram o alcance e a limitação dos espécimes de laboratörio, salientando a necessidade de ensaios "in situ" em determinadas feições geo lögicas.

o ensaio "in situ" em princípio é muito simples. Uma monta gem utilizada pelo IPT é ilustrada na figura 26 e consiste em moldar blocos de $70 \times 70 \mathrm{~cm}$ a $200 \times 200 \mathrm{~cm}$ de base por 30 a $40 \mathrm{~cm}$ de altura com auxilio de uma máquina munida de serracircular diamantada.

- bloco é envolvido em carapaça de concreto ou em caixa me tálica. Os carregamentos normal e de cisalhamento são apli cados por macacos hidräulicos.

- quadro l abaixo apresenta os maiores ensaios de cisalhamen to "in situ" jà realizados. Atualmente, os ensaios"in situ" 
em blocos maiores do que $100 \times 100 \mathrm{~cm}$ de ärea tendem a desaparecer em vista do alto custo requerido.

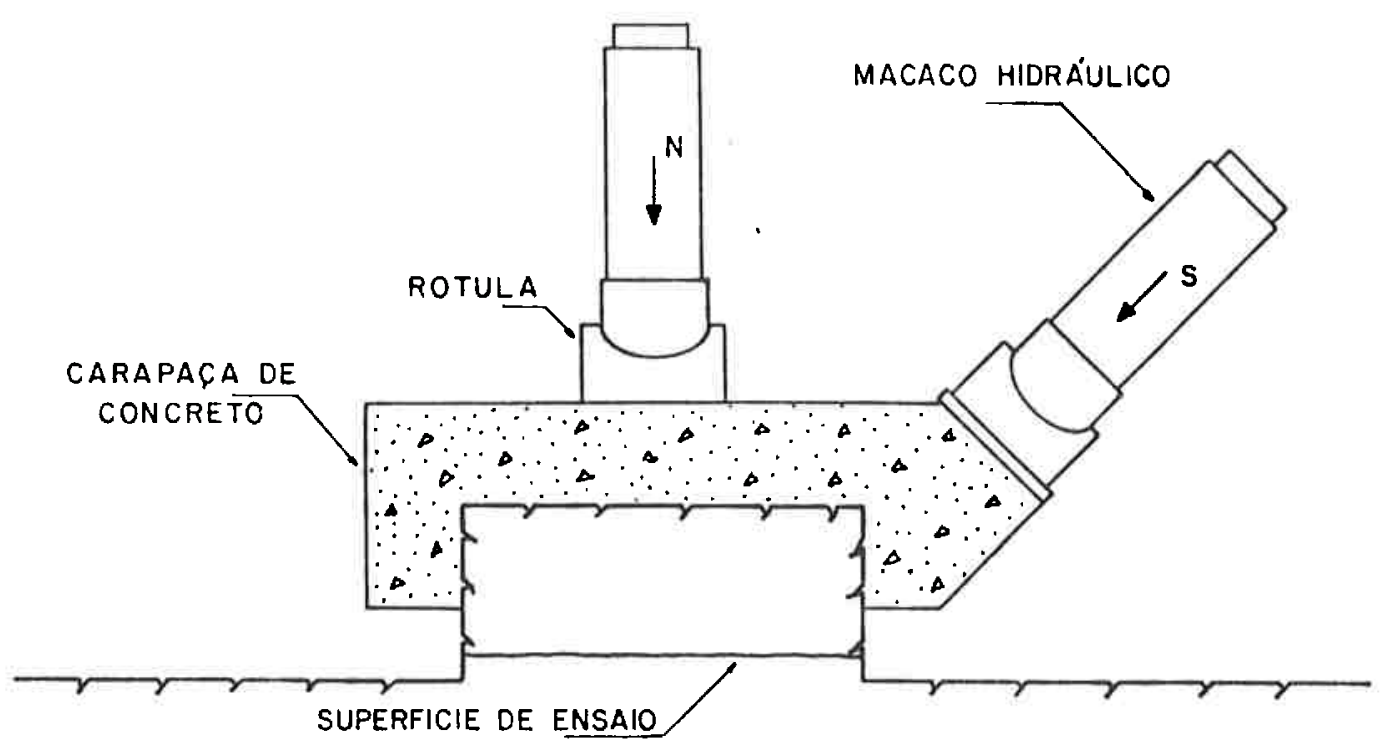

Figura 26 - Montagem Esquemática de Ensaios de Cisalhamento Direto "in situ" em Blocos de $70 \times 70 \mathrm{~cm}$

Quadro 1 - Ensaios de Cisalhamento "in situ" em Blocos de Grandes Dimensões

\begin{tabular}{|l|l|c|l|}
\hline \multicolumn{1}{|c|}{ BARRAGEM } & PAIS & $\begin{array}{c}\text { AREA DA BASE DO } \\
\text { BLOCO }\left(\mathrm{m}^{2}\right)\end{array}$ & REFERENCIAS \\
\hline KRASNOYARSK & RUSSIA & $8,0 \times 12,0$ & EVDOKIMOV e SAPEGIN(1970) \\
BRATSK & RUSSIA & $7,0 \times 7,0$ & EVDOKIMOV e SAPEGIN(1967) \\
ILHA SOLTEIRA & BRASIL & $6,6 \times 6,0$ & RUIZ et alii (1968) \\
JUPIA & BRASIL & $5,5 \times 5,5$ & RUIZ et alii (1966) \\
MEQUINENZA & ESPANHA & $4,0 \times 4,0$ & SALAS (1968) \\
\hline
\end{tabular}

4.3 Tëcnicas de Ensaios

As técnicas usuais de cisalhamento direto em laboratörio e cam po podem ser agrupadas em duas grandes categorias: 
a) Ensaios com ünica direção de carregamento

Nesses ensaios o carregamento é imposto numa única direção com a linha de ação passando pelo centro geométrico da base do bloco e inclinada de $\theta(200$ a 400$)$ em relação ao plano horizontal. Para ensaiar fraturas a direção de carre gamento deve ser escolhida, sempre que possivel, consideran do a inclinação mēdia da superfície a ser ensaiada, figura 27 .

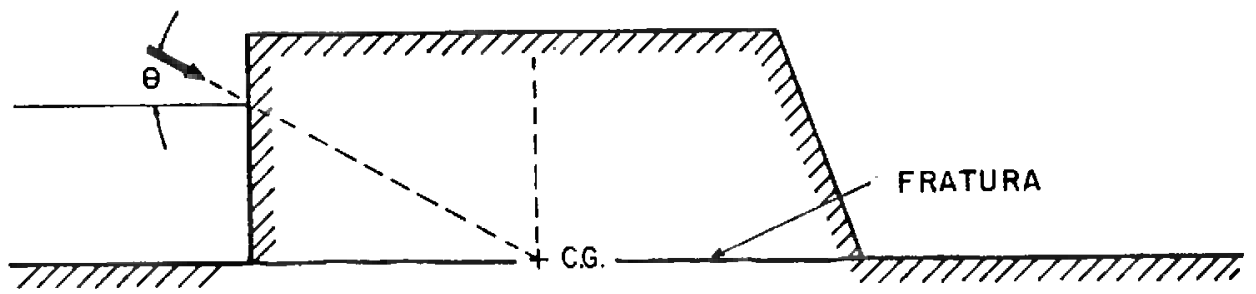

Figura 27 - Ensaio de Cisalhamento Direto com Onica Direção de Carregamento

Os primeiros ensaios "in situ" com esta concepção foram executados por TAKANO e FURUJo (1966), com $\theta$ variável $\left(21^{\circ}\right.$, $31^{\circ}$ e $\left.37^{\circ}\right)$. Posteriormente, a mesma técnica foi utilizada por SERAFIN e GUERREIRO (1966), nas juntas da rocha de fundação da Barragem Gran Suarna - Espanha

No Brasil, esta técnica foi adotada somente em 1978 em en saios de laboratörio pelo Instituto de Pesquisas Tecnológi cas, utilizando-se da prensa de cunhas chanfradas idealiza do por PROTODYAKONOV (1969), Figura 28.

A força vertical è automaticamente decomposta em componente normal e tangencial ao plano de cisalhamento.Para obter värias relaçōes entre os componentes, há um conjunto de cunhas que permite um ajustamento da inclinação do plano 
de ruptura. Para corpos de prova cilindricos, cunhas com chanfros cilíndricos são utilizadas de forma que o eixo do cilindro é colocado inclinado no mesmo àngulo do plano de cisalhamento.

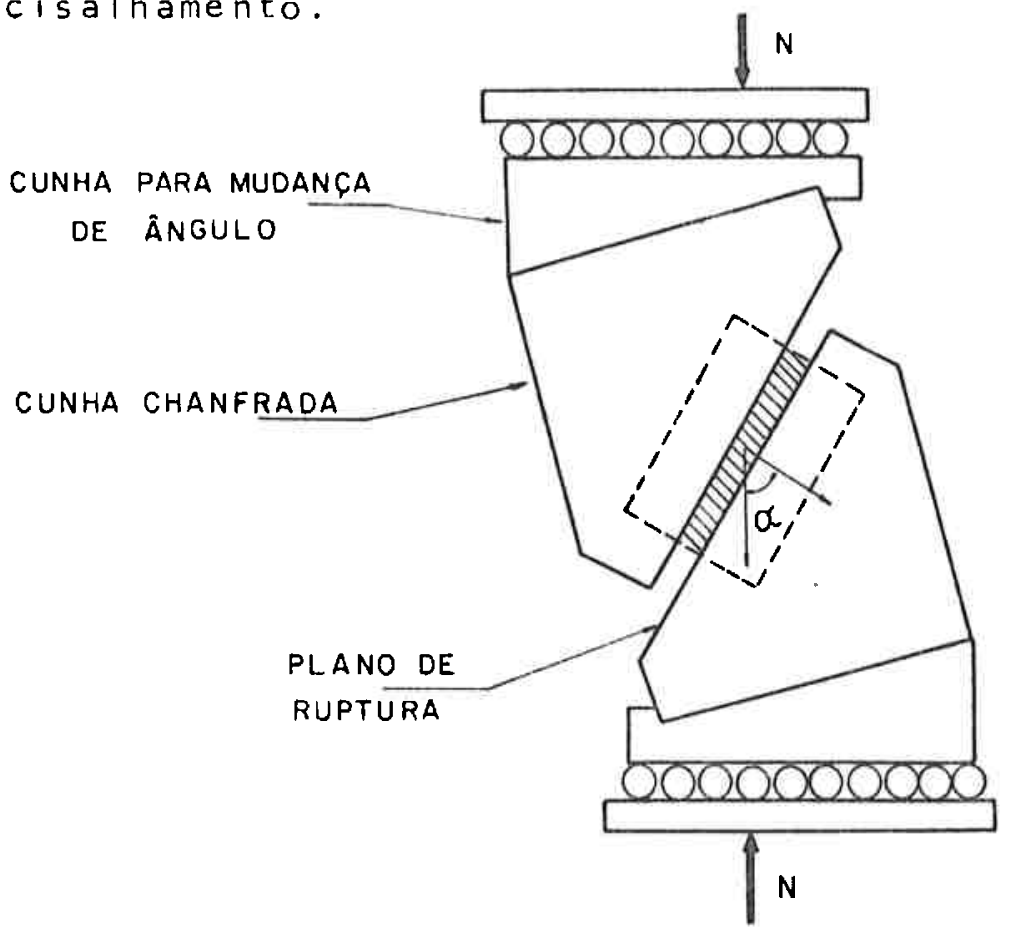

Figura 28 - Prensa com Onica Direção de Carregamento Idealizado por PROTODYAKONOV.

Este método é particularmente simples e tem sido utilizado com frequéncia pelos pesquisadores soviéticos.

b) Ensaios com duas direções de carregamento

São realizados com sistema de carregamentos distintos, um para aplicação da carga normal (N) a base do corpo de pro va, e o outro para carga de cisalhamento (S) podendo estar inclinado ou não em relação ao plano horizontal, Figuras 29 a e $29 b$.

A linha de ação dos dois carregamentos deve passar pelo cen tro geométrico (C.G.) do plano da base do corpo de prova. 
Nesse caso, a tensão normal ( $\sigma)$ e a tensão de cisalhamen to $(\tau)$ serão expressas por:

$\sigma=\frac{N}{A}+\frac{A}{S} \operatorname{sen} \theta \quad \tau=\frac{S}{A} \cos \theta$

Onde:

$S=$ Força de cisalhamento

$N=$ Força normal

$A=$ Area da superfície fraturada

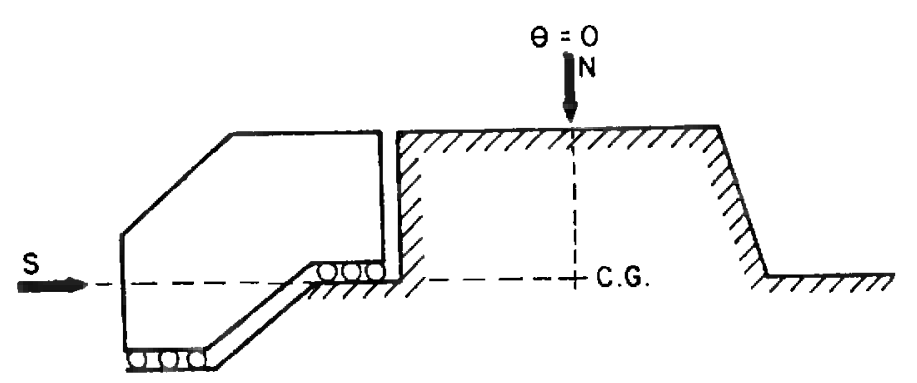

FIGURA a

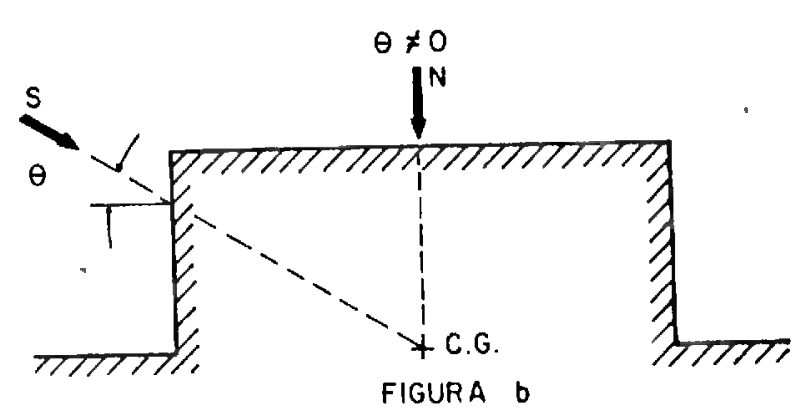

FIGURA O

Figura 29 - Ensaios de Cisalhamento Direto com duas Direções de Car regamento

Ensaio com $\theta=0$ foi introduzido por PFAFF e BOURIOT(1948) para estudar a aderéncia concreto-rocha, na Barragem de Grandval.

Ensaios "in situ" $\operatorname{com} \theta \neq 0$ foram primeiramente executados na lugos lävia em 1952 pelo Departamento de Aguas "Jaroslav Cerni", em blocos de $80 \times 80 \mathrm{~cm}$.Segundo relato de MILOVANo WIC (1967), esta técnica foi posteriormente adotada pelo Laboratörio Nacional de Engenharia Civil de Lisboa em blo$\cos$ de $70 \times 70 \mathrm{~cm}, \operatorname{com} \theta=15^{\circ}$. 
No Brasil, essa técnica de ensaio foi utilizada a partir de 1963, com ensaio "in situ" em Jupiá.

NIEBLE e GUIDICINI (1971) apresentaram no VII Seminärio Na cional de Grandes Barragens um relato completo sobre a ex periência acumulada em centenas de ensaios realizados.

EVDOKIMOV e CHIAREV (1966), realizaramensaios de aderência concreto-rocha com o carregamento normal excêntrico em relação ao centro geométrico da base do bloco, com excen tricidade idêntica à da barragem sob carga, Figura 30 .

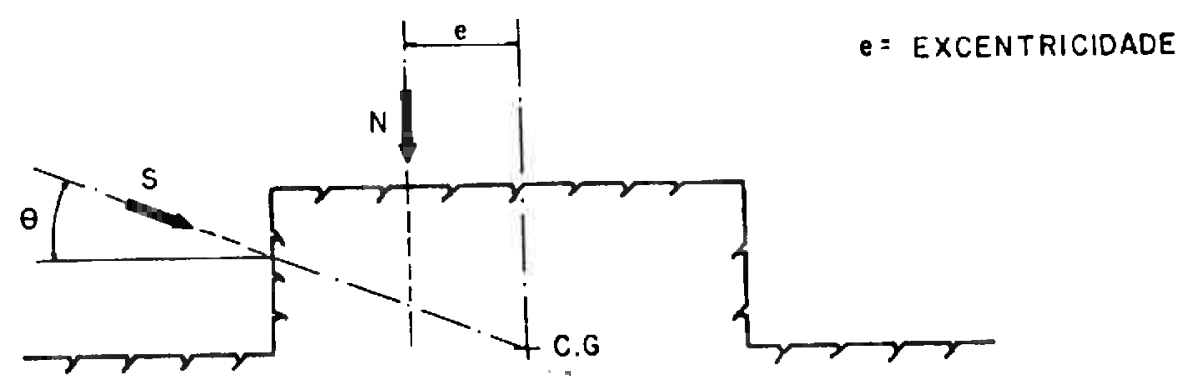

Figura 30 - Ensaios de Cisalhamento Direto com Carga Normal Excén trica

4.4 Fatores que Influem nas Caracteristicas de Cisalhamento

Vários são os fatores que afetam a resistência ao cisalha mento de rochas fraturadas. Genericamente eles podem ser agrupados como se segue:

- fatores geométricos

- fatores geotécnicos-geomecânicos

- fatores tensoriais 


\subsubsection{Fatores geométricos}

Relacionam-se com a geometria das irregularidades, magnitu de de deslocamento entre as superficies de fraturas, tamanho e forma dos corpos de prova etc. e se referemà :

- rugosidade e àrea de contatọ;

- deslocamento;

- ángulo de inclinação de rugosidades;

- efeito de escala.

Embora apresentados separadamente, a caracteristica final de resisténcia ao cisalhamento é determinada pela conjugação e disposição geométrica dos elementos acima, bem como da inter-relação dos fatores citados.

a) Rugosidade e àrea de contato

A rugosidade influi decisivamente nos valores de atrito entre duas superficies. TSCHEBOTARIOFF e WELCH (1948)rea lizaram testes de atrito entre pequenos blocos de quart zo. O coeficiente de atrito de 0,10 em superficie polida aumentou para 0,37 em superficie rugosa.

Inümeros pesquisadores como RIPLEY e LEE (1961), BYERLEE (1967a), JAEGER e ROSENGREN (1969), CHAPPEL (1975) e outros realizaram testes em diversos tipos de rocha e con firmaram a notável influência das rugosidades na resistência ao cisalhamento.

o exame detalhado da superficie de um sölido por micros cópio eletrónico e outros dispositivos mostra que é quase impossivel executar uma superficie verdadeiramente li sa. 
Medidas de condutividade elétrica em superficies metálicas justapostas revelam que a ärea real de contato è in variavelmente muito pequena e varia com o carregamento normal, podendo ser menor do que $1 / 10.000$ da área aparen te.

Portanto, a área real de contato quase independe do tama nho da àrea justaposta ou do grau de rugosidade da super fície. A área efetiva de contato muda com o carregamento e é de fato diretamente proporcional à tensão normal.

o comportamento perante às ações de cisalhamento reflete no início o efeito de superficies mantidas separadas pe las irregularidades. Isto significa que mesmo levemente carregadas, as pressōes nessas pequenas àreas de contato podem ser elevadas a ponto de causar fluéncia plástica mesmo em materiais mais duros.

b) Deslocamento

E comum observar no ensaio um räpido aumento da força de cisalhamento com pequeno deslocamento até atingir o valor máximo, quando ocorre queda brusca ou progressiva a companhada de grande deslocamento, até atingir a resistência ültima.

o valor de deslocamento para atingir o pico de resisténcia bem como a evolução subsequente da curva tensão-deformação estão fortemente relacionados com a natureza e com o tipo de "embricamento" entre as irregularidades.

BARTON (1971) conduziu uma sērie de testes em modelos fí sicos simulando superficies rugosas típicas de uma junta de tração, e relatou que a resistência atinge o pico após um deslocamento ou deformação tangencial de aproxi- 
madamente $1 \%$ do comprimento da junta ensaiada. A resistência última é atingida após deslocamento de aproximadamente $10 \%$ do comprimento da junta (por exemplo: junta de $20 \mathrm{~cm}$, pico em $2 \mathrm{~mm}$ e resistência ültima em $2 \mathrm{~cm}$ ).

Em amostras de grande dimensão $(40 \mathrm{~cm} \times 40 \mathrm{~cm})$ KRSMANOVIC e LANGOF (1964) concluiram que o pico é atingido em $0,05 \mathrm{~cm}$ a $0,20 \mathrm{~cm}$. Em alguns ensaios "in situ" chega a atingir deslocamentos de $1,5 \mathrm{~cm}$ a $5,0 \mathrm{~cm}$.

JAEGER e ROSENGREN (1969), agruparam as juntas segundo qua tro comportamentos fundamentais em funçāo do tipo de con tatos geométricos entre as irregularidades. As cinco cur vas caracteristicas correspondentes são ilustradas na Ta bela 111 .

- comportamento da curva 5 também pode ser considerado típico e foi obtido em inúmeros ensaios executados no la boratório do Instituto de Pesquisas Tecnológicas em jun tas de basalto.

Os estudos realizados por SCHNEIDER (1972) demonstraram claramente a influência das irregularidades em fraturas artificiais obtidas por tração em granito, arenito e cal căreo. A superfície de granito ficou mais rugosa enquan to a de calcáreo mais lisa e a de arenito situou-se entre as duas.

As figuras 31 a e 31 b, apresentam os resultados obtidos em dois niveis de tensōes normais $\sigma_{A}>\sigma_{B}$, para granito e calcäreo.

o granito apresenta pico de resistência seguido de queda no seu valor, enquanto que no calcáreo a resistência cres ce gradativamente e permanece praticamente constante com o deslocamento.

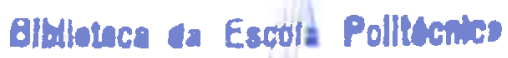 \\ Elo Paule \\ F.6249}




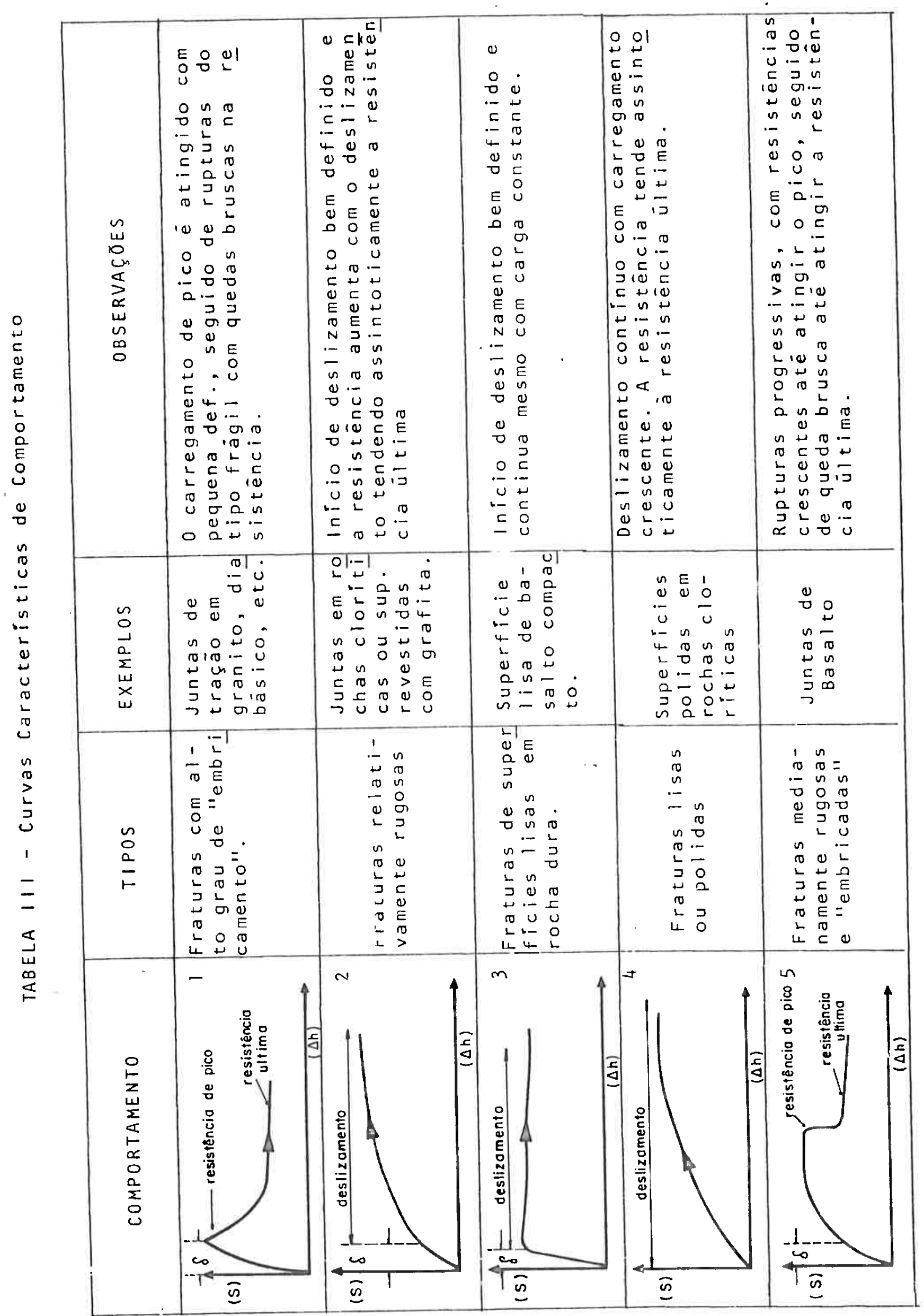




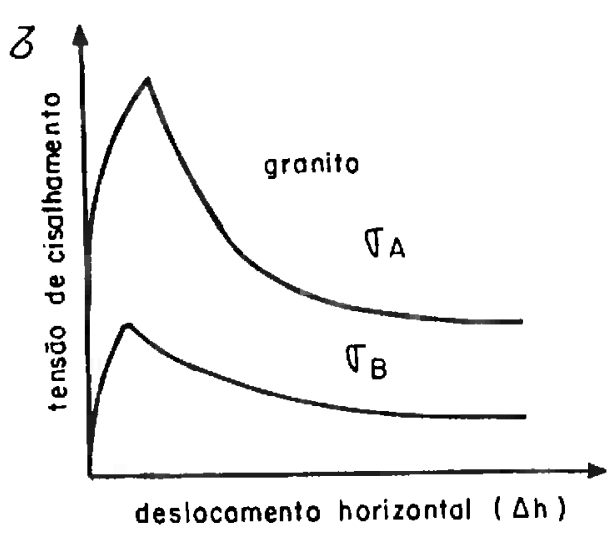

FIGURA o

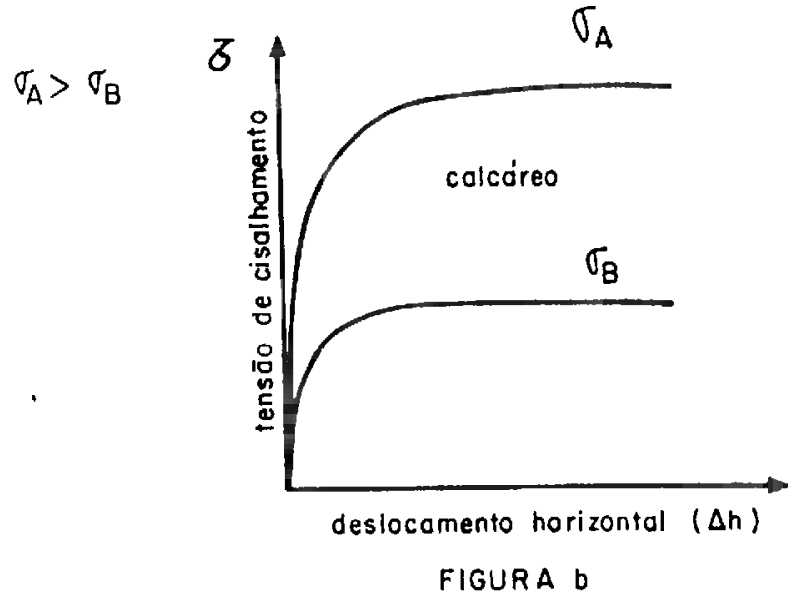

Figura 31 - Resultados de Ensaios em Fraturas Artificlais (APud SCHNEIDER - 1972)

0 arenito forneceu resultado situado entre os dois comportamentos.

c) Āngulo de inclinação de rugosidades

Entre os aspectos da medida de rugosidade, foi destacada a importāncia do ângulo de rugosidade, pois ele quan tifica geometricamente as irregularidades. Contudo, deve-se observar que o àngulo medido depende do método,do dispositivo de medidas e da escala em que ela foi medida e representada.

BARTON (1971) executou uma sērie de testes em modelos de juntas de tração. Segundo ele as rugosidades agudas de pequena amplitude controlariam a resistência de pico,mui to mais do que rugosidades de grande amplitude e de pequena inclinação. Estas passam a ter importãncia para tensões normais elevadas ou para grandes deslocamentos, muito maiores do que aqueles necessärios para mobilizar a resistência de pico. 
d) Dilatância

A dilatáncia tem sido representada de duas formas distintas. A mais comum é o diagrama de deslocamento vertical em função do deslocamento horizontal. O deslocamento vertical em qualquer momento depende da posição relativa entre as rugosidades, em decorréncịa do movimento de uma parte sobre a outra. A Figura 32 abaixo ilustra a evolução da dilatância em função dos deslocamentos.

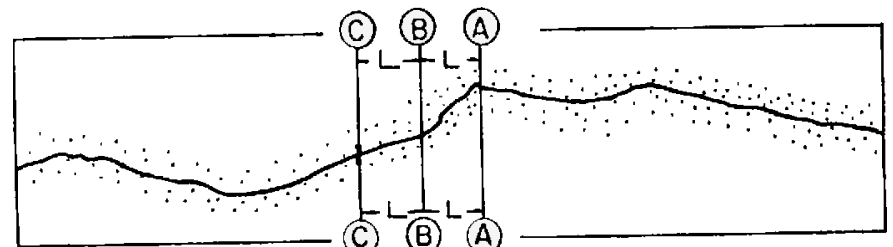

(C) (B) (A)
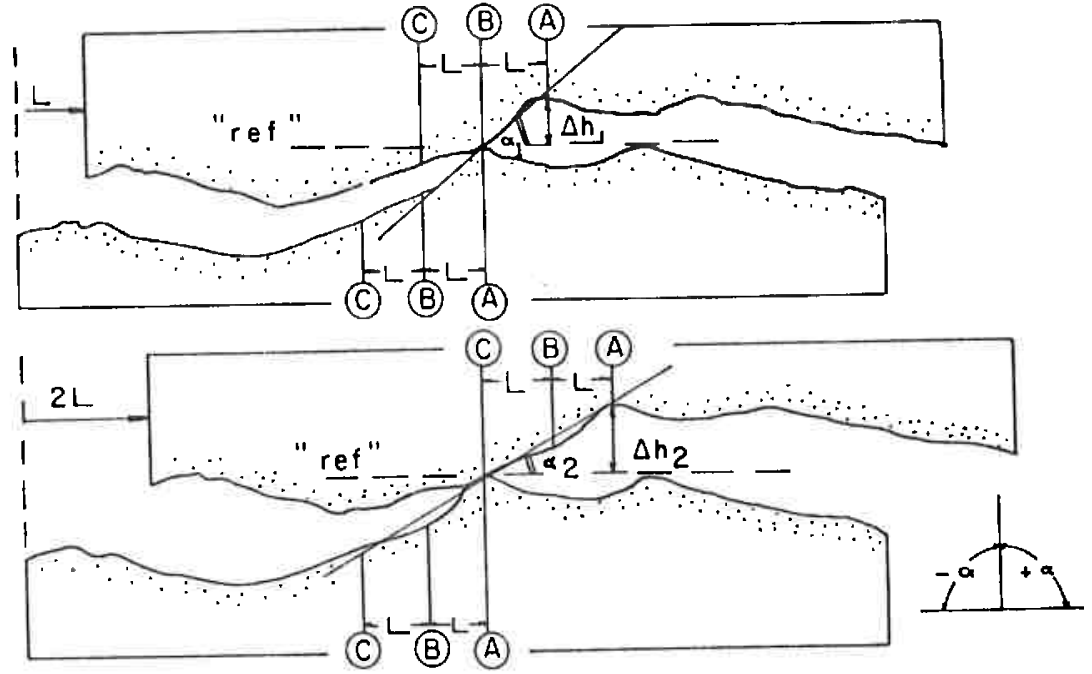

Figura 32 - Relação entre Superficies de Contato e Dilatância Durante Cisalhamento (Apud FECKER e RENGERS,1971).

Outra forma consiste representar a relação $d v / d h$ (dvodeslocamento vertical, $d h$ = deslocamento horizontal), em fun çäo de admensionais $\tau / \sigma$ ou $\sigma / C o$, onde: $\tau=$ tensão de cisaThamento, $\sigma=$ tensão normal, $C_{0}=$ resistência à compressão simples da rocha. 
BARTON (ig71) conduziu sēries de testes em modelo de juntas de tração e concluiu que existe uma relação linear en tre o valor de arc tg $t / \sigma$ e ángulo de dilatáncia i confor me sintetizado na Figura 33 .

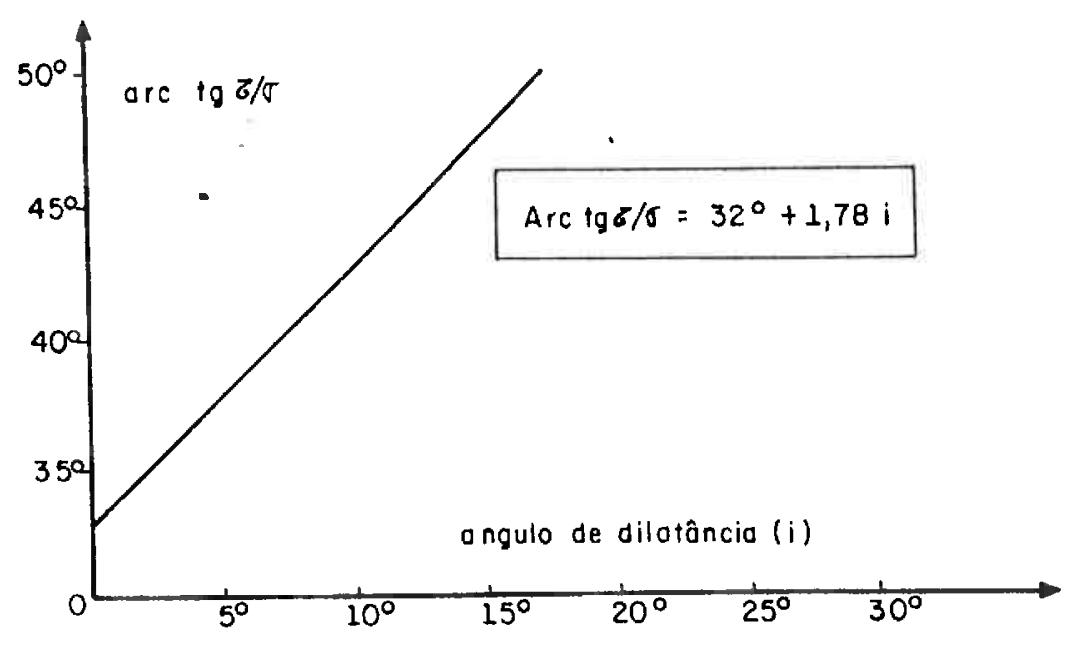

Figura 33 - Relação entre arc tg $T / \sigma$ e a Dilatáncia

Testou tambēm juntas de diferente resistência a compres são simples co, sob värias tensões normais, e mostrou que - ângulo de dilatáncia decresce com o aumento da relação $\sigma /$ Co, Figura 34 .

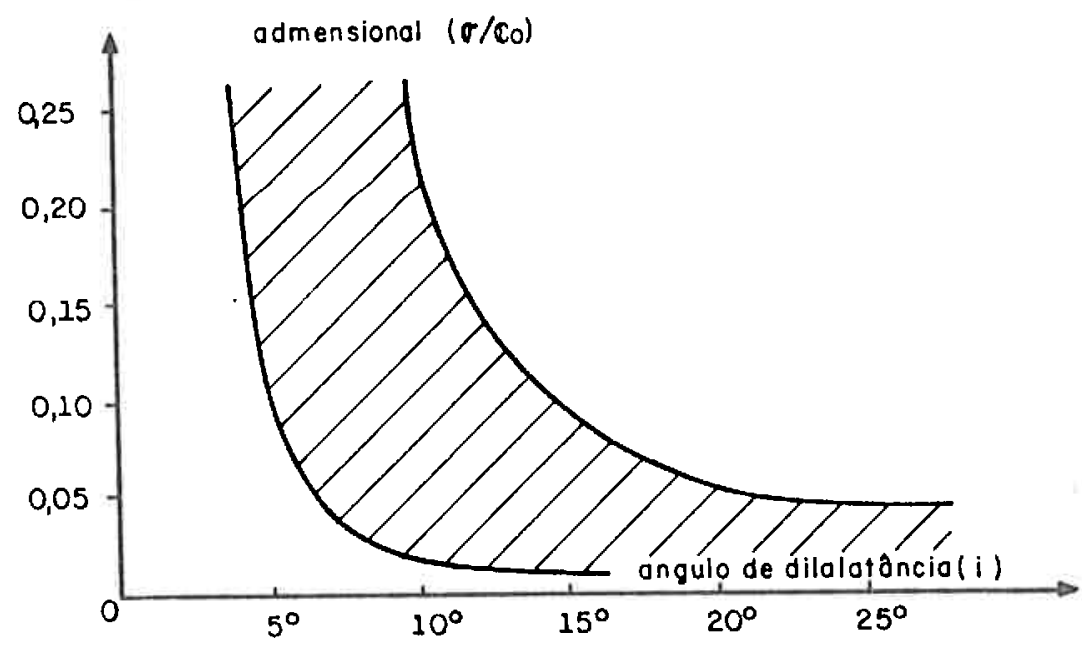

Figura 34 - Relaçāo entre o/Co e Ângulo de Dilatáncia (i) 
Resultados semelhantes foram obtidos por FUJIMURA e NIEBLE (1971) em arenito e basalto vesiculo-amigdaloidal fraturado das rochas de fundação da Eclusa da Usina de Promissão, Rio Tietê.

MATHEUS (1970) executou ensaios em superficies rochosas vi sando obter correlação entre a resistência ao cisalhamento e a dilatância. A figura 35 ilustra a posição das duas su perficies após deslizamento de $2.54 \mathrm{~cm}$.

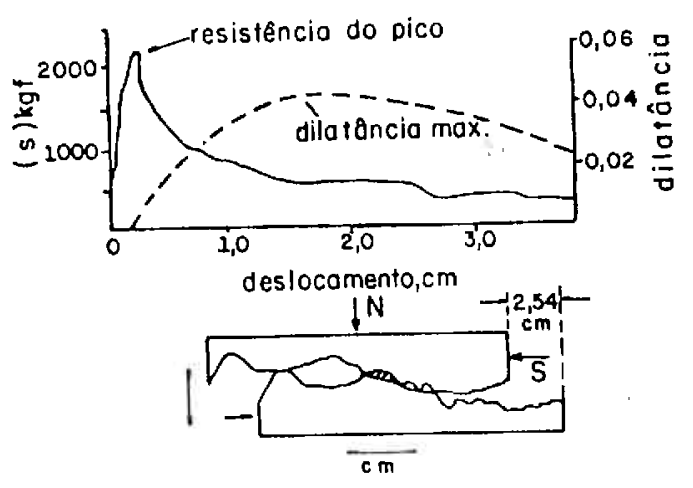

EZla- cisolhamento

Figura 35 - Resisténcia ao Cisalhamento e Dilatância

- pico de resistência,como se verifica,não está associado á di latáncia e foi mobilizado com deslocamento menor do que $0,25 \mathrm{~cm}$ enquanto a dilatáncia máxima ocorreu com deslocamento de $1,73 \mathrm{~cm}$.

e) Efeito de escala

A dimensäo do espécime rochoso pode alterar significativa mente os resultados obtidos, condicionando inclusive o me canismo de ruptura e deslizamento entre as superficies.

Assim, a representatividade de ensaios ficarä comprometida caso não haja escolha adequada do tamanho de corpo de prova em função de tipo e magnitude das irregularidades a serem ensaiadas. 
BARTON e CHOUBEY (1977) sugeriram o tamanho natural do bloco como a primeira aproximação do tamanho correto para estudos das características de rochas fraturadas (ensaios de cisalhamento ou anälises de superfícies irregu (ares).

De fato, os blocos e os vínculos de ligação compöem o ma ciço rochoso e como tal representam a unidade estrutural de uma compartimentação rochosa.

Normalmente, a mobilização da resistência de pico depende de deslizamento ou deformação relativa entre as super fícies até estabelecer o contato efetivo entre as rugos dades. Essa distäncia cresce com o comprimento das fratu ras.

Uma sērie de testes bastante instrutivos executados por BANDIS (1979) demonstrou claramente a influéncia da esca la nas características de cisalhamento. Quatroblocos mo delados cuidadosamente, com o mesmo tipo de "embricamentoll, porém com comprimentos de $360 \mathrm{~mm}, 180 \mathrm{~mm}, 120 \mathrm{~mm}$ e $60 \mathrm{~mm}$, foram testados sob uma mesma tensão normal, Figura 36 .

o deslocamento necessärio para mobilizar a resistência de pico aumentou significativamente com o aumento do tamanho do bloco, bem como o tipo de ruptura mudou de "frägil"pa ra "plàstico". A razão dessa mudança é explicada pela participaçäo cada vez maior de rugosidades de pequena in clinação e de grande amplitude, no mecanismo de deslizamento com o aumento do tamanho do bloco.

Obviamente, os ensaios de laboratörio são realizados em blocos rochosos individualizados ou em corpos de prova moldados. Desta forma, a reação do maciço rochoso circun- 
dante está ausente e aumenta a probabilidade de ruptura do tipo "fragil", condição raramente observada na natureza.

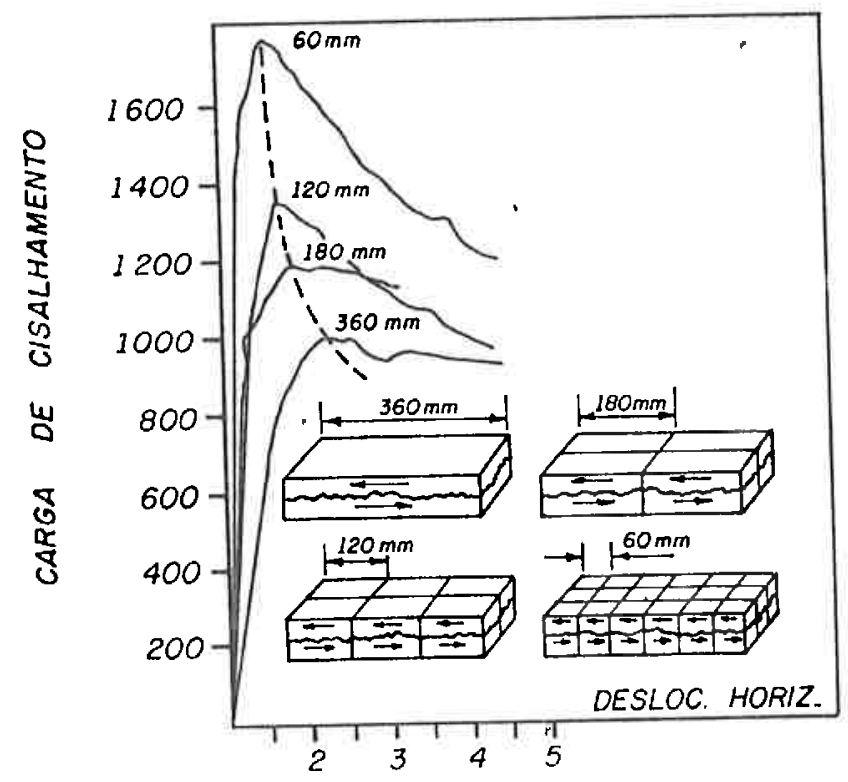

Figura $36^{\circ}$ - Mudanças no Comportamento em Função do Comprimento da Fratura (Apud BANDIS - 1979)

Assim, a determinação de resistência ao cisalhamento por meio de ensaios envolve uma seleção cuidadosa de locais e amostras, conhecimento da natureza de solicitações, deformação máxima permissivel das estruturas, relação modelo/protótipo e sobretudo do tamanho de corpo de prova ade quado às feições estruturais.

A utilização desses resultados em projeto deve ser criteriosa e condizente com o conhecimento das limitações e al cance desses ensaios.

4.4.2 Fatores geotëcnico-geomecánicos

São aspectos relacionados com a constituição rochosa e elementos usualmente presentes no maciço rochoso. 
Os principais são os seguintes:

- àgua

- material de preenchimento

- alteração da rocha

- grau de fraturamento

a) Agua

o atrito em rocha muda substancialmente com as condições de saturação. Mesmo a umidade natural do ambiente pode,em determinado tipo de rochas, afetar sensivelmente os valores. Os testes realizados por TSCHEBOTARIOFF e WELCH (1948) confirmam esta influência.

HORN e DEERE (1962) concluiram que na presença de água o valor de coeficiente de atrito estä ligado a estrutura crís talina do mineral. Resultados em quartzo mostram que o va lor permanece quase constante para umidade relativa baixa e aumenta com a saturação. Em muscovita, o atrito é parti cularmente sensível à variação da umidade relativa abaixo de $40 \%$. Acima deste ele decresce linearmente até o ponto de saturação quando cai bruscamente.

A àgua atua como fluido anti-lubrificante para minerais de estrutura cristalina maciça (tridimensional) tais como: quartzo, feldspato, calcita, etc, l enquanto ela serve de lubrificante para minerais de estrutura cristalina lamina da (bidimensional) tais como: biotita, muscovita, clorita, flogopita, ilita, caolinita, etc.

Nas anälises de estabilidade, esse fato deve ser sempre considerado e estudado a conveniencia ou não da drenagem 
do maciço rochoso.

b) Material de preenchimento

o tipo de material varia desde deposição hidrotermal de mi nerais resistentes, selando completamente a fenda, até ma teriais plásticos, poucos coesivos ou completamente soltos (argila, areia, fragmentos grosseiros de rochas, etc).

Do ponto de vista de comportamento mecánico, estes ültimos são os que mais afetam a resistencia mecānica do maci ço e, de acordo com o tipo de preenchimento, podem ser a grupados em:

1. Material solto de zonas cisalhadas ou falhadas

2. Produtos de decomposição e alteração da parede rochosa.

3. Materiais carreados da superfície

4. Deposição de produtos de lixiviação de rochas calcäreas GOODMAN et alli (1972) examinaram a influência da espessu ra do preenchimento argiloso em juntas de granito e arenito e concluiram que a resisténcia ao cisalhamento de pende da relação R/hi, onde:

$R$ = espessura do material de preenchimento

$h_{i}=$ altura média das rugosidades

Para preenchimento de pequena espessura a resistēncia é bastante afetada pela irregularidade da superfície fraturada. Com o aumento da espessura, a resistencia diminui e $\mathrm{R} / \mathrm{hi}=3$ é reduzido para o nível de material de preenchimento. 
Quando fragmentos de rocha imersos em argila preenchem a fratura, a resistência è determinada pela umidade do com ponente argiloso.

c) Alteraçäo da rocha

A alteração, segundo definição de YOSHIDA (1972), é o con junto de modificações sofridas pelas rochas na sua composição mineralógica, estrutura e propriedade, como resulta do da interação de complexos processos físico-quimicos.

o efeito da alteração não fica limitado a superfície mas estende profundamente na crosta em função do acesso de água e comunicação com a atmosfera.

Em consequéncia, a alteração reduz a competência da rocha, altera as propriedades físico-químicas e modifica as caracteristicas de cisalhamento tornando o seu comportamento semelhante a de material dútil ou fraturas com preen:chimento argiloso.

Em materiais granulares obtidos da britagem de basaldo de Capivara submetidos a processos artificiais de desagregaçóes acelerada, conduziram a resultados de até $20 \%$ de re dução no ángulo de atrito, conforme relatados por fuJIMURA et alli (1971b).

d) Grau de fraturamento

- fraturamento afeta tanto a resistência mecánica como tam bëm o comportamento geomecánico do maciço rochoso.

Ao lado da deformação em geral insignificante do componente intacto e elástico, as maiores deformaçōes decorrem do deslizamento e rotação entre os blocos e refletem a organ zaçāo estrutural de uma compartimentação rochosa, caracte- 
rística preponderante do grau de fraturamento do maciço rochoso.

Maciço rochoso constituido por blocos maiores possue me* nor liberdade de movimento do que maciços de pequenos blocos. Em consequência, estes se movimentam com maior fá cilidade, porém são sensiveís às rugosidades mais agudas e proeminentes, Fiqura 37 .

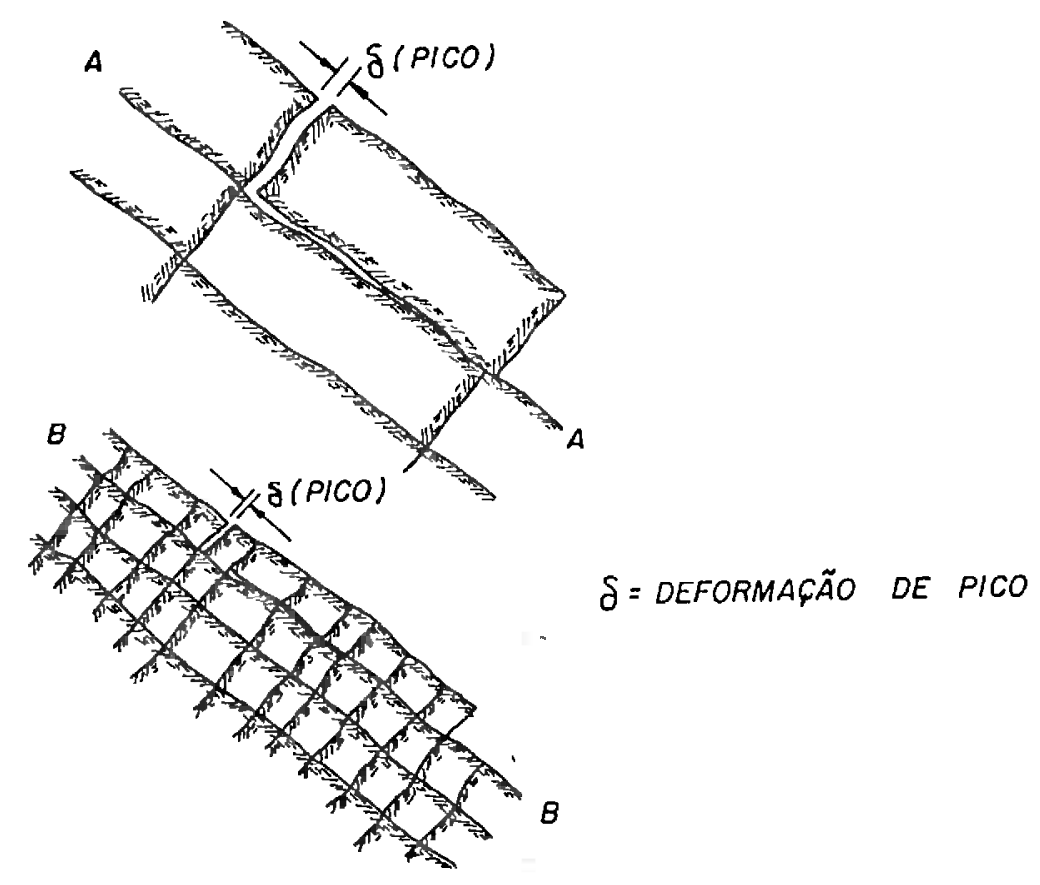

Figura 37 - Efeito Condicionado pelo Tamanho do Bloco (BARTON e. CHOUBEY - 1977)

Contudo deve-se observar que a liberdade de movimentos se altera com o confinamento ou com esforços aplicados per pendicularmente à direção do movimento.

Segundo BARTON e BANDIS(1980), os blocos de maciço muito fraturado quando observados individualmente, comportam de maneira mais "fragil" do que blocos maiores de maciço pou co fraturado. Coletivamente, quanto maior o número de blo cos o maciço tende a apresentar comportamento mais "plàstico". 
4.4.3 Fatores tensoriais

São fatores associados à tensões que direta ou indiretamen te afetam o valor da resistência. Genericamente, são os se guintes:

- tensão normal

- distribuição e concentração de tensões

- rigidez do equipamento e velocidade de deformação

a) Tensão normal

Para irregularidades com a mesma geometria, o pico de resis tência é diretamente proporcional ao valor da carga normal aplicado.

A Figura 38, ilustra esquematicamente a curva de resistência obtida por PATTON (1966) em 3 corpos de prova identicos modelados com único dente e testados sob carregamentos normais $\mathrm{N}_{3}>\mathrm{N}_{2}>\mathrm{N}_{1}$.

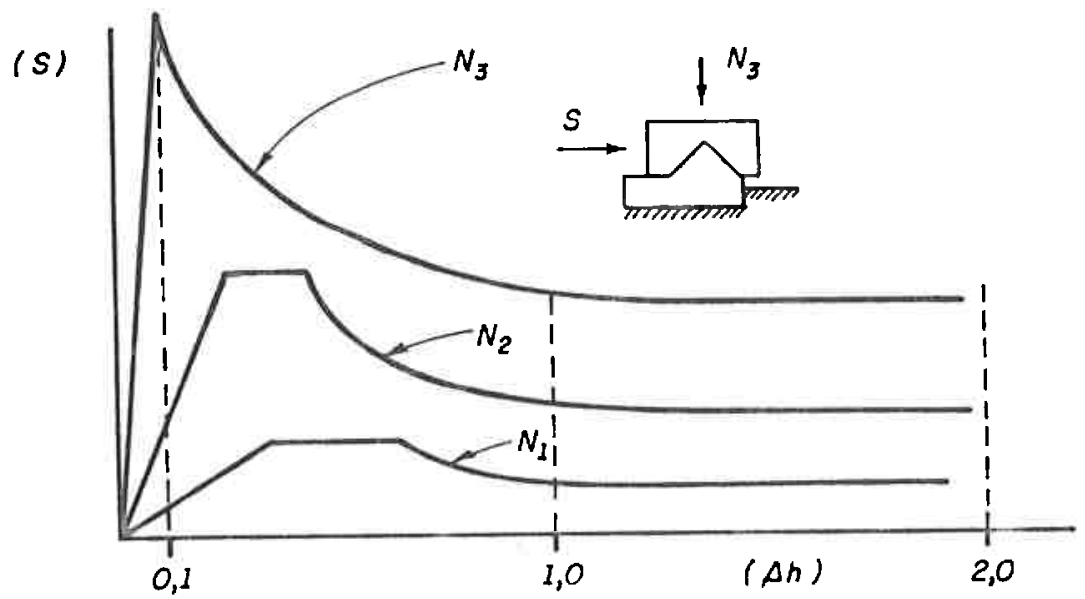

Figura 38. - Curva de Resistência ao Cisalhamento sob Tensões Nor mais Diferentes 
Sob carregamento normal elevado $\left(\mathrm{N}_{3}\right)$ a força máxima de ci salhamento é atingida com pequeno deslocamento $(0,1$ do comprimento da base), cisalhando a rugosidade praticamente pela base.

Sob carregamentos normais menores $\left(N_{1}\right.$ e $\left.N_{2}\right)$ o cisalhamento ocorre acima da base, e os valores máximos de cisalhamento são menores e proporcionais aos valores de $N_{1}$ e $N_{2}$. A resistência última para os três casos é atingida após deslocamento equivalente ao comprimento da base da rugosidade.

Geralmente em superficies rochosas, ocorrem rupturas pro gressivas e não a ruptura de todas as rugosidades "embricadas". de uma só vez.A tensão de corte se estabelece primeiramente nas rugosidades mais pröximas do lado de aplicaçäo da carga e estas são cisalhadas antes, rompendo sucessivamente as outras.

Assim a relação arc tg $\tau / \sigma$ não permanece constante com a variação da tensão normal, sugerindo mudança no valor do coeficiente de atrito $\mu$.

A resistência ūltima tambēm varia com. a tensão nórmal pois ela resulta de deslizamento entre duas superfícies, do esmagamento das irregularidades cisalhadas, do rolamento e compactação de partículas nas reentráncias.

- carregamento normal elevado aumenta o esmagamento das irregularidades e o trito residual passa a ser governado mais pelo rolamento das particulas diminuindo ain da mais o seu valor.

MAURER (1966) ensaiou diversos tipos de rocha e concluiu que o coeficiente de atrito residual decresce como au- 
mento da tensão normal e sugeriu a seguinte expressäo:

$$
\operatorname{tg} \phi \mu=a \sigma^{k}
$$

onde a e $k$ são constantes.

b) Distribuição e concentração dẹ tensões

Em todos os ensaios de cisalhamento diretos realizados em laboratório e campo, pressupōem-se uma distribuição uniforme de tensöes no plano de cisalhamento e representa o valor médio de carregamento normal e tangencial sobre o citado plano. Contudo,as anälises realizadas por vários in vestigadores demonstram uma distribuição não uniforme de tensões, devido a geometria dos corpos de prova e sistema de aplicação de cargas.

Um dos primeiros a se interessar pelo problema foi LORENTE DE NO (1968), que realizou investigação em modelo mate mático utilizando-se de elementos elasto-plásticos ideali zados por A.H.S. ANG e G.N.HARPER. Seus resultados, Figura 39, indicam uma distribuição nāo uniforme durante a fa se elástica de deformaçōes. Na ruptura a tensão de cisaIhamento é mais uniforme. Contudo, a concentração de tensöes normais a base, na extremidade oposta ao lado de car regamento, sugeriu momentos de flexão na base do bloco.

RUIZ et alli (1970) executaram ensaios em modelo bilinear isotrópico, homogéneo e elästico confeccionado em placa de borracha, aplicando lateralmente as cargas de cisalhamento sob värias inclinações, Figura 40. Seus resultados confirmaram a distribuição irregular de tensões na base do bloco, além da tensão de tração, junto a extremidade prin cipalmente para inclinação $\theta<200$. 


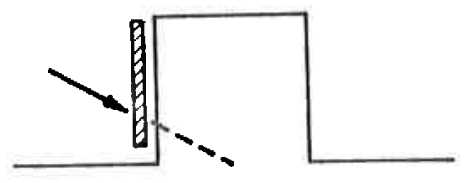

INICIO DE FLUËNCIA PLÁSTICA

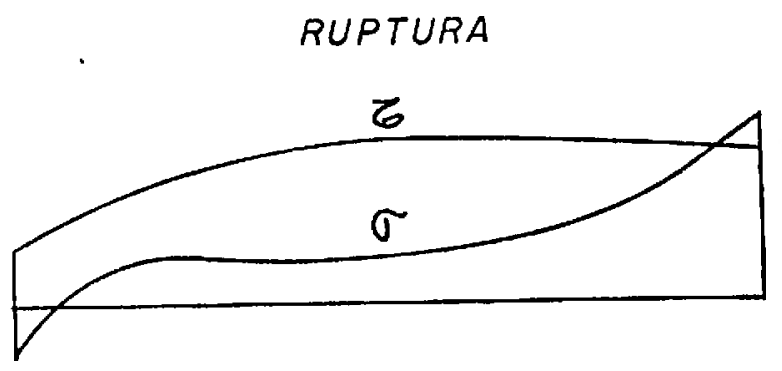

Figura 39 -Distribuição de Tensōes no Plano de Ruptura (Apud LORENT DE NO - 1968)
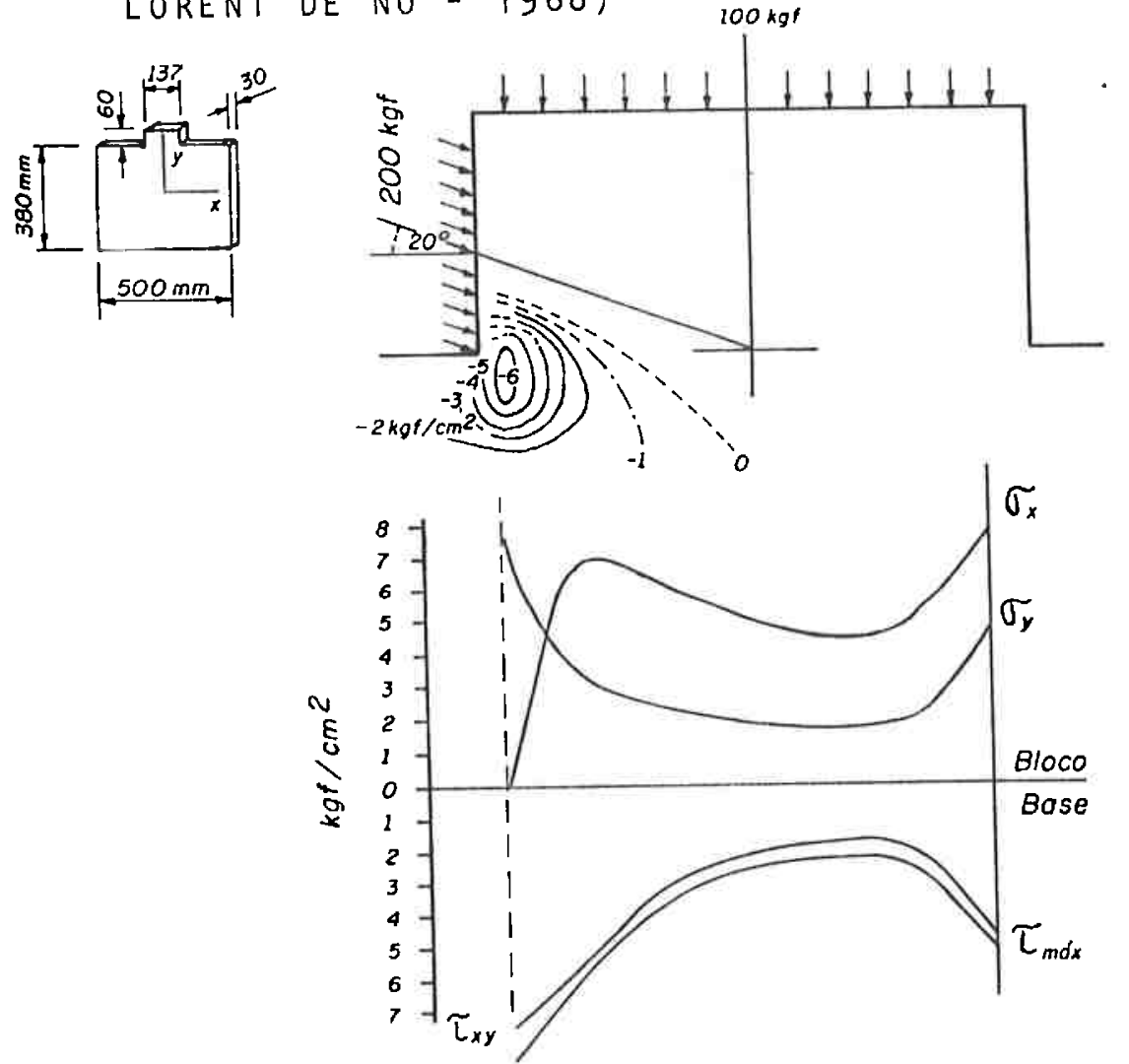

Figura 40 - Distribuição de Tensōes na Base do Bloco 
Segundo os autores a tensão máxima de cisalhamento ocorre fora do plano da base do bloco e contida numa superficie curva cuja forma e posição dependem da relação entre cargas aplicadas e a inclinação do carregamento lateral.

A análise de desenvolvimento de tensöes indicou o ângulo $\theta$ mais favorável nesses ensaios ao redor de $20^{\circ}$.

Mais tarde, o estudo comparativo da distribuição de tensões pelo Método de Elementos Finitos realizado no Instituto de Pesquizas Tecnológicas com aplicação de cargas c salhantes horizontais e inclinadas, permitiu visualizar a evolução e a trajetöria de tensões em cada um dos casos, Figura 41. Do ponto de vista de tensões, os resultados a-

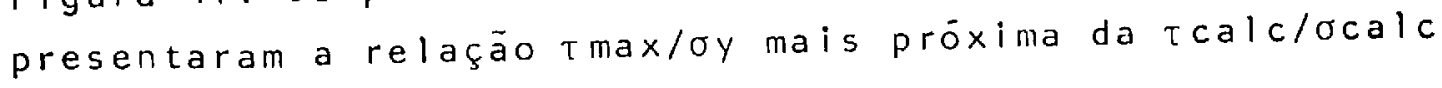
para os ensaios com cargas inclinadas, sugerindo uma melhor distribuição de tensöes do que as obtidas com cargas horizontais.

KUTTER (1971) analisou a influência de vazios e inclusão de materiais de baixa resistência mecánica no plano de ci salhamento pelo Método de Elementos Finitos. Os resultados indicaram uma distribuição de tensões relativamente $\underline{u}$ niforme em $70 \%$ da àrea na região central do plano de cisa Ihamento. Contudo, nas extremidades verificou-se aumento significativo na tensão normal e queda na tensão de cisalhamento.

Valores baixos de relação t/o nas extremidades levaram o autor admitir que as rupturas não iniciam nas extremida des, mas na região central onde as tensões de cisalhamen to obtidas estão mais próximas dos valores picos assumidos. Este ponto de vista foi compartilhado por LACKEY e BUDAVARI (1975). 

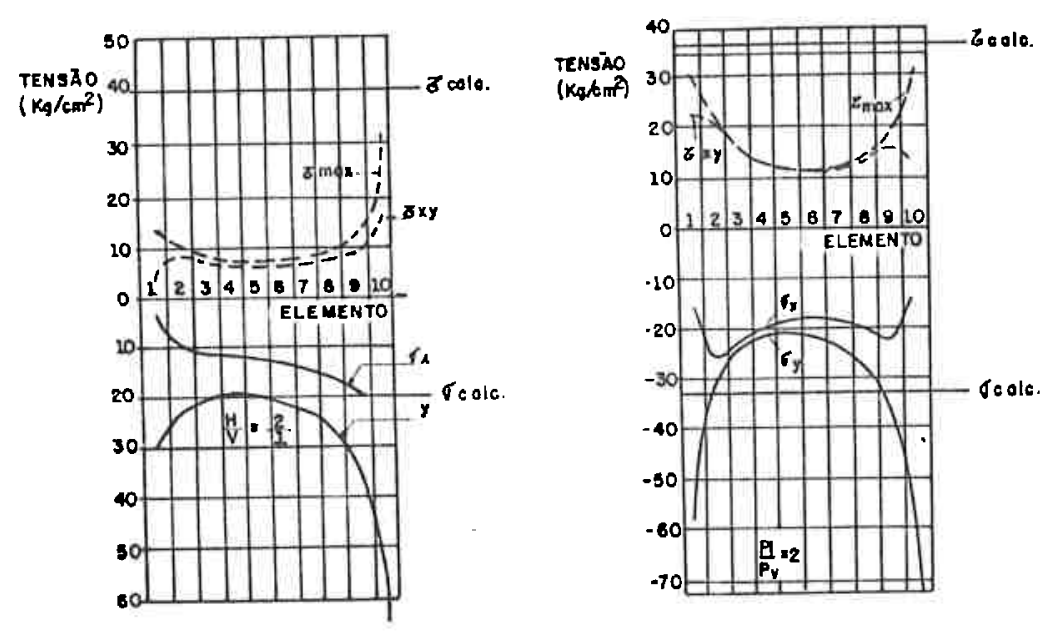

RELAÇÃO $\tau_{\max } / \sigma_{Y}$
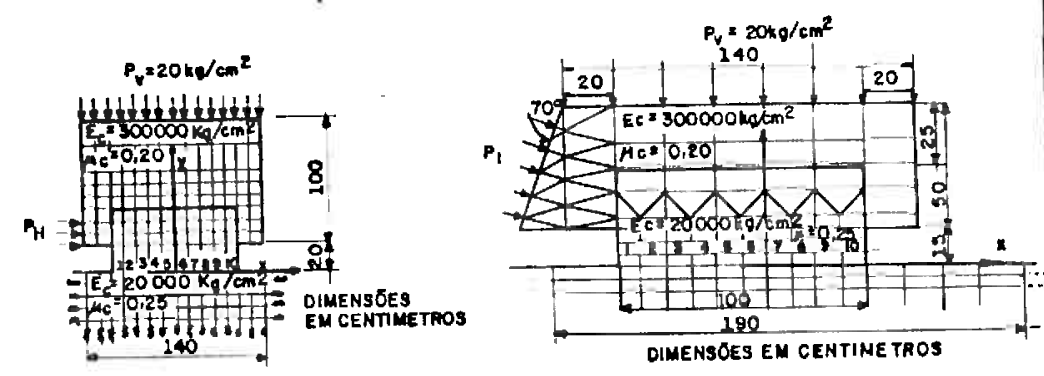

\begin{tabular}{|c|c|c|}
\hline ELEM & HORIZ. & INCL. \\
\hline 1 & 0,4 & 0,5 \\
\hline 2 & 0,5 & 0,8 \\
\hline 3 & 0,5 & 0,7 \\
\hline 4 & 0,3 & 0,6 \\
\hline 5 & 0,3 & 0,6 \\
\hline 6 & 0,4 & 0,6 \\
\hline 7 & 0,4 & 0,6 \\
\hline 8 & 0,4 & 0,5 \\
\hline 9 & 0,4 & 0,5 \\
\hline 10 & 0,4 & 0,5 \\
\hline
\end{tabular}

$\tau$ alc/ocalc $=2,0$

$\tau c a l c / \sigma c a l c=1,1$

Figura 41 - Estudo Comparativo da Distribuição e Concentração de Tensões na Base do Bloco

Entretanto, os resultados experimentais demonstram que es sa situação raramente ocorre devido a seguintes:

- mobilização de atrito e redução no "embricamento" jā ocorrem com pequenos deslocamentos antes mesmo de atingir a ruptura.

- distribuição não uniforme de tensões nos contatos entre as rugosidades, provoca ruptura em algumas delas antes do carregamento mäximo.

- as deformações devidas à carga tangencial de cisalhamen to são muito mais pronunciadas na regiäo próxima à apl 
cação de cargas favorecendo o início de rupturas nessa estre midades.

Todavia, os estudos em modelos, embora baseados em hipóteses simplificadoras e às vezes longe das condições reais, contri buem para melhor entendimento do mecanismo de ruptura rochosa.

c) Rigidez de equipamento e velocidade de deformação

Vários investigadores como BIENIAWSKI (1970), BROWN e HUDSON (1971), RUMMEL e FAIRHUST (1970) etc., analisaram a influência de rigidez na resistência e deformabilidade de amostras rochosas.

En contraste com os ensaios de compressão uniaxial, dis positivos de cisalhamento com pequena rigidez geralmente não provoca rupturas súbitas, porém pode ser a causa do efe ito "stick-slip".

Para tensão normal elevada a rigidez tende a limitar a dilatancia da junta e pode aumentar a resistência ao cisalhamento.Testes em granito e arenitos em equipamentos de duplo cisalhamento, sob diferente rigidez normal $(k=$ $=0,02 \mathrm{MN} / \mathrm{m}-200 \mathrm{MN} / \mathrm{m})$ revelaram que o pico de resistència para tensão normal baixo não é muito diferente, contudo para tensão normal elevada o resultado obtido com equipamento rigido pode ser até $20 \%$ maior, conforme OBERT et alli (1976).

Stick-slip: 0 deslizamento entre os blocos é acompanhado por oscila ções bruscas com quedas na tensão de cisalhamento. Este fenomeno ocorre quando o coeficiente de atrito dinâmico é menor do que o estático. 
As investigaçōes realizadas por SCHNEIDER (1976) revelam que o pico de resisténcia é maior para a velocidade de de formação elevada, e a resistēncia cai bruscamente após rup tura. Com velocidade lenta, o pico de resistência é menor e a queda de resistência após ruptura é menos pronunciada.

4.5 Paràmetros Geomecànicos

As técnicas de anälises estruturais experimentaram na ültima década um notăvel avanço, principalmente pelo grande desenvolvimento do Método de Elementos Finitos, possibili tando avaliar mais realisticamente o comportamento global do conjunto maciço-estrutura. Nessas anälises o maciço ro choso è tratado como parte integrando da estrutura total e desse modo as interações entre eles podem ser estabelecidas.

Os modelos matemáticos bi e tridimensionais tornaram exequiveis analisar o desenvolvimento de tensós e deformações no seio das estruturas, até mesmo em meios descontí nuos e visco-elasto-plásticos.

Contudo, por outro lado, as técnicas de obtenção e defini ção de dados característicos de rochas fraturadas não evo luiram com a mesma desenvoltura e, assim, os modelos geomecânicos elaborados ainda carecem de parâmetros geomecá nicos capazes de traduzir com maior fidelidade o comporta mento do maciço rochoso.

Portanto, apesar das amplas possibilidades abertas pelos modelos matemáticos, eles devem ser encarados dentro das restrições prōprias e inerentes aos métodos numéricos.

Considerando que as anälises de estabilidade em rochas fra 
turadas são realizadas comparando os esforços solicitantes e os resistentes (em geral fornecidos pelo maciço) e estes ültimos estão intimamente relacionados com as carac teristicas de resistência ao cisalhamento, será conveniente defini-los em:

- paràmetros de resistēncia.

- parámetros de comportamento

4.5.1 Parāmetros de resistência

São parâmetros relacionados apenas com as propriedades in trínsecas da rocha fraturada e representam a capacidade de sustentação de cargas, refletindo a constituição lito lögica, estado de alteraçāo, organização cristalina e características geométricas das irregularidades.

Esses parâmetros, coesão e atrito, são utilizados para definir as envoltörias intrinsecas de cisalhamento, nas condiçōes de resistēncia de pico e residual, utilizando- se das expressōes apresentadas no ítem 4.1.

Usualmente, as anālises de estabilidade são realizadas com base nessas envoltórias impondo o estado de equilíbrio li mite entre os esforços solicitantes e os resisfentes.

Contudo, frequentemente, essas anālises näo satisfazem as condições de segurança da obra, pois os esforços resisten tes são mobilizados a custa de deformações entre as par tes. Em consequéncia, mesmo sem ter atingido o regime de ruptura, os deslocamentos podem ser excessivos a ponto de comprometer irremediavelmente a estrutura.

Portanto, ao lado desses parámetros outros indicativos do comportamento de rochas fraturadas devem ser analisados. 
4.5.2 Parâmetros de Comportamento

São parámetros que repreentam o comportamento da substáncia rochosa em presença de determinados tipos de solicitação e reação. Em rochas fraturadas eles se relacionam com as deformações normais de fechamento e deformações tangênciaisde vido respectivamente aos componentes normais e tangénciais dos esforços solicitantes.

GOODMAN (1968), propós elementos especiais denominados de "unit joint stiffness", para representar os parámetros de comportamento em anälises por elementos finitos, dividos em:

- "Unit normal stiffness"(kn). Definida como relação entre o acréscimo de tensāo normal $(\Delta \sigma)$ e o correspondente des locamento normal na junta $(\Delta e)$, ou seja $k n=\frac{\Delta \sigma}{\Delta e}$ e repré senta a rigidez transversal à fratura.

- "Unit shear stiffness" (kt). Definida como relaçāo entre o acréscimo da tensão de cisalhamento $(\Delta \tau)$ e o deslocamen to tangencial correspondente $(\Delta h)$; na regiäo elástica de deformação $k t=\frac{\Delta \tau}{\Delta h}$ e representa a rigidez longitudinal à fratura.

Tais parämetros podem ser definidos para resisténcia de pico (ktp) ou residual ( $k t r)$ conforme apresentadas na figura 42.

o comportamento de um maciço rochoso fraturado depende não só do tipo de carregamento ou confinamento imposto, mas de propriedades de rigidez e resistencia e das características estruturais como um todo (sistema de fratura, orientação,con tinuidade, etc.). 


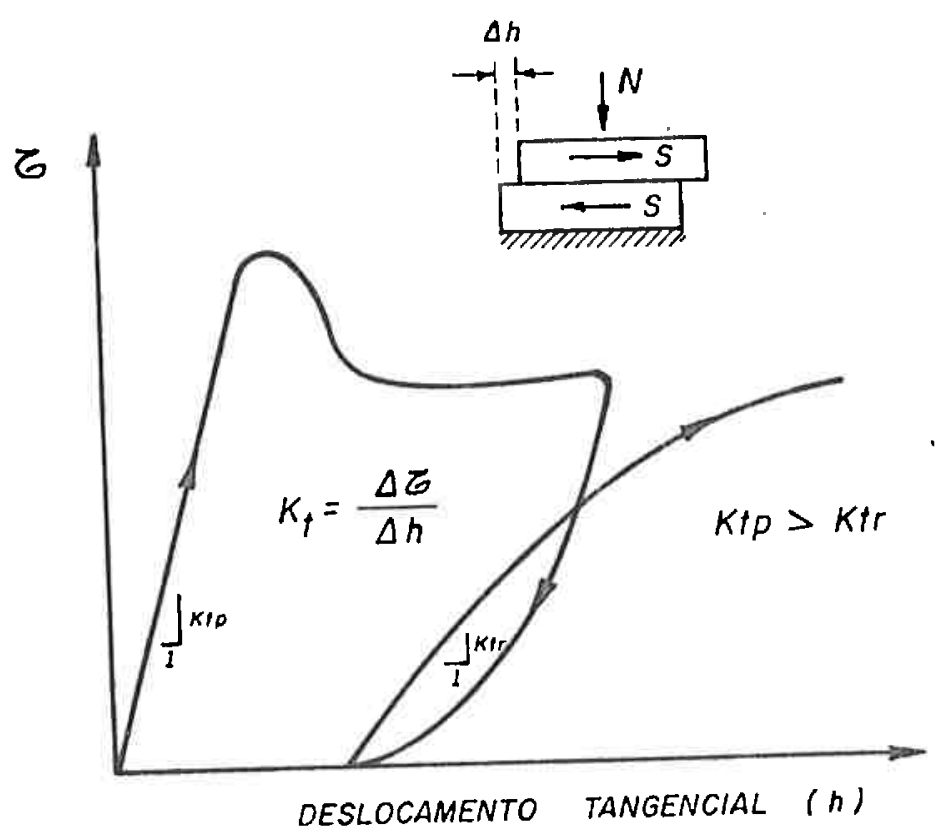

Figura $a$

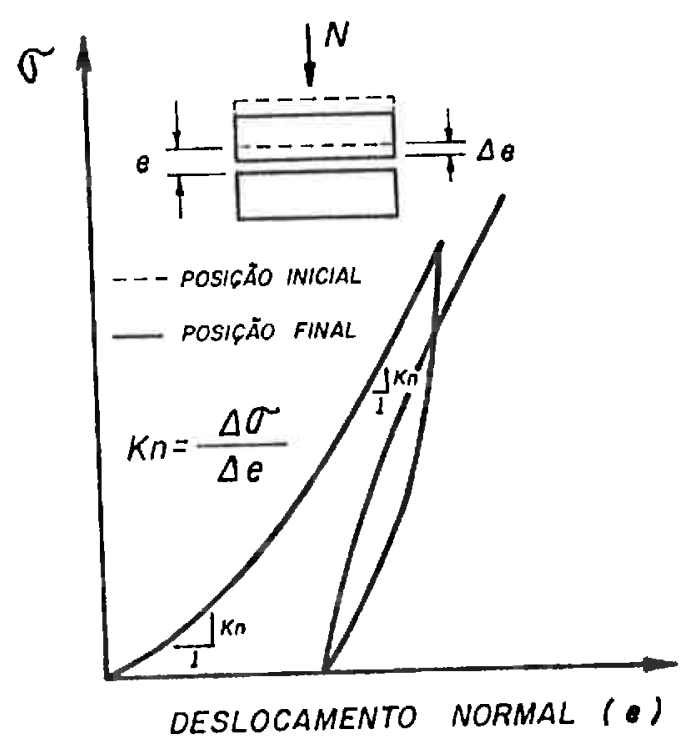

Figuro b

Figura 42 - Elementos de Junta kn e kt Definidos por GOODMAN

Sob esse ponto de vista torna-se bastante conveniente caracterizar a fratura por meio de $k n, k t$ e $s$ (coesão e atritol. Este conjunto de parámetros constitui uma descrição necessária para permitir a predição do comportamento potencial da rocha fraturada sob carregamento.

Uma ilustração instrutiva dos fatores que influem nos valores de $k n, k t$ e $S$ foi apresentada por GOODMAN et alli (1968), no diagrama de modelos de junta apresentado na F gura 43 .

Baseado nessa definição RUIz et alli (1976) analisaram os resultados de 63 ensaios de cisalhamento direto e 52 ensaios de deformabilidade, todos realizados no maciço basāltico "in situll das rochas de fundações dos principais Aproveitamentos Hidroelétricos Brasileiros e sugeriram uma relação exponencial entre $k t e \sigma$, estabelecendo inclusive um zoneamento no gräfico $k t=f(\sigma)$ segundo os tipos 
litológicos das descontinuidades.

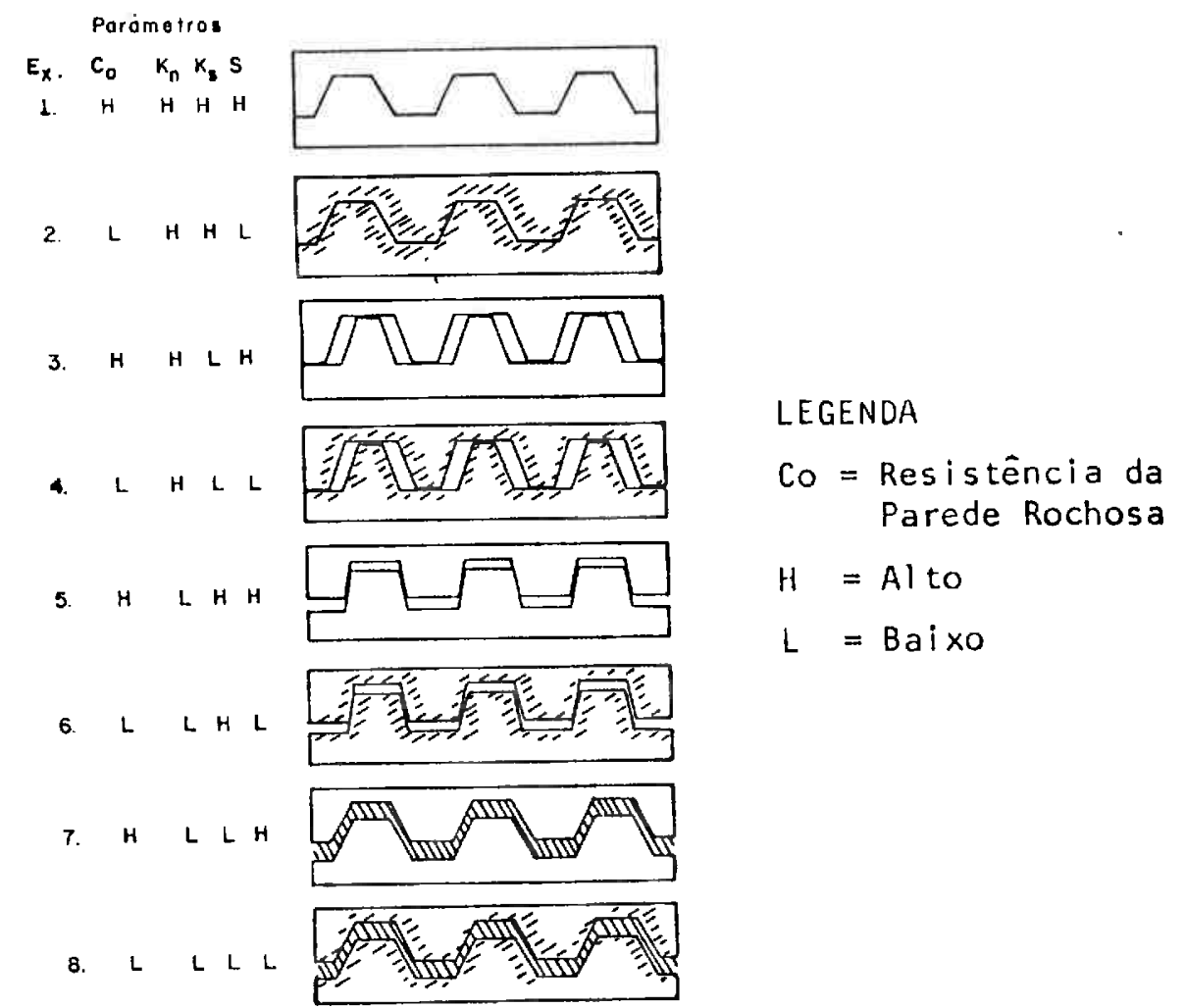

Figura 43 - Diagrama de llustração da Influência do Fechamento da Junta e Resistência da Parede Rochosa.

Valores de kt obtidos em ensaios de laboratörio e aspectos de correlação com os ensaios "in situ" foram relatados por FUJIMURA et alli (1976).

BARTON (1972), analisando ensaios de laboratorio e "in situ" identificou uma outra variävel, evidenciando influência do efeito escala sobre os parámetros de compor tamento.

A Figura 44, resume suas observações onde se nota a $5 \mathrm{ig}$ nificativa influência de tensão normal e da dimensão do corpo de prova no valor da "unit shear stiffness". 
Os valores médios de kt obtidos em ensaios de laboratório e campo, indicativos da resistência última das rochas de fundação de algumas Usinas Hidroelétricas Brasile ras, foram também incluidas na citada figura.
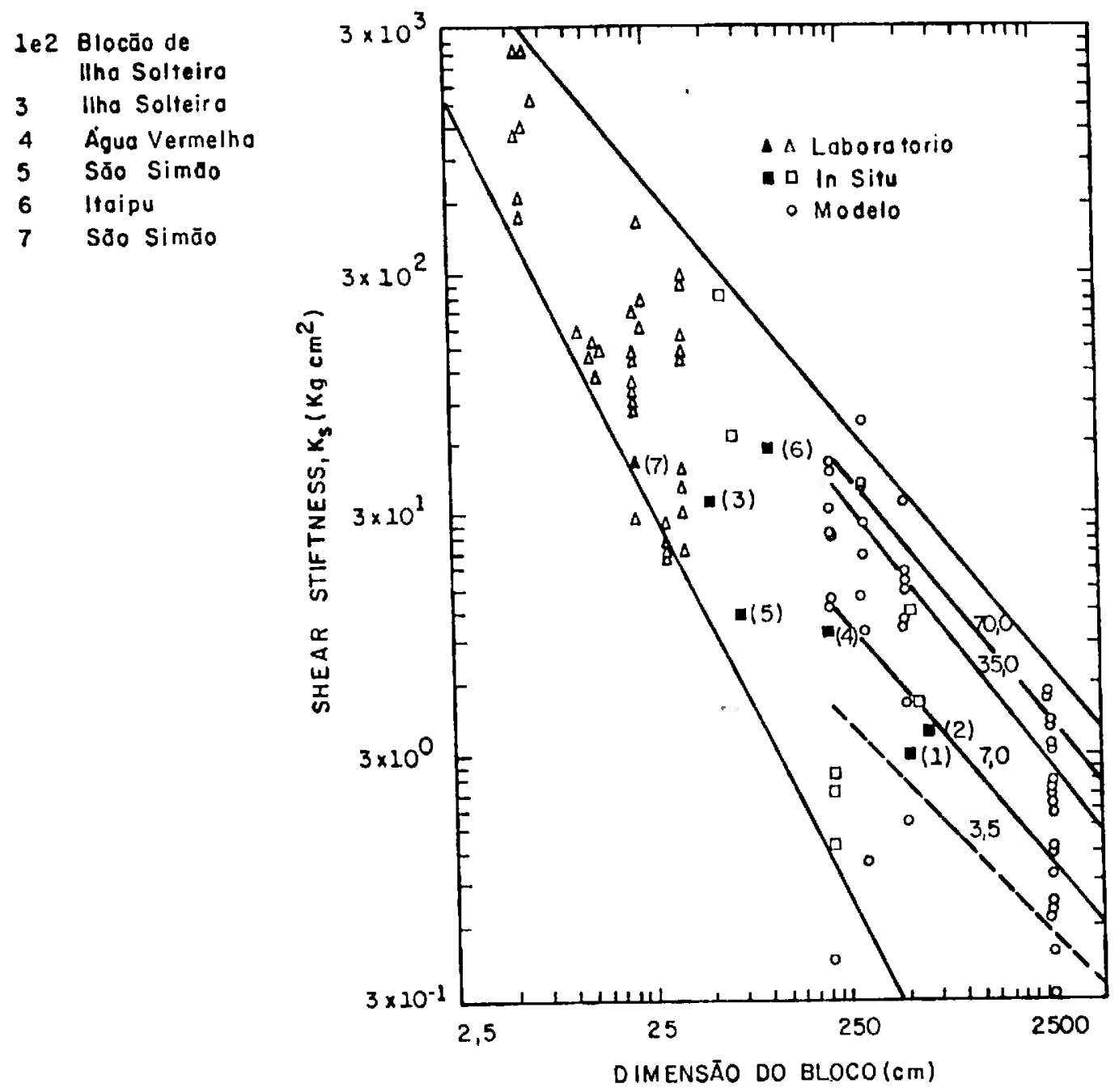

Figura 44 - "Unit Shear Stiffness" da Junta em Função da Dimensão do Bloco e da Tensão Normal de 3,5-7,0 - 35,0 $70,0 \mathrm{kgf} / \mathrm{cm}^{2}$ (Apud BARTON - 1972).

Entretanto, valores representativos de parämecros de comportamento na escala do maciço rochoso não são conhecidos e quando necessärios são assumidos nas análises.

A razão principal deve-se à dificuldade de ordem prätica 
na definição desses parámetros na escala abrangida pela obra. Usualmente, eles são determinados en amostras laboratoriais ou em pontos localizados no campo mediante ensaios "in situ". Os seus valores são extremamente sen siveis à técnica e equipamentos de ensaios, modo de fixa ção de corpo de prova e sobretudo de dispositivos de medida de deformação. 
5 CONCLUS $\dot{0}$ ES 
Projetos em engenharia requerem conhecimentos que permitam antever o desempenho da estrutura proposta. Portanto, quando ela interage com o maciço circundante, a resposta deformacional de am bos deve ser cuidadosamente analisada e compatibilizada.

Em relação às rochas fraturadas essa resposta depende da distribuição e transmissão de cargas, què por sua vez é função da orientação de fraturas, espaçamento, material de preenchimento, geometria das irregularidades e etc.

Diferente de outros materiais, o modo de ruptura na rocha é ex tremamente afetado pelas condiçóes de contorno, escala, carregamento, organização estrutural e vinculos de ligação entre os com ponentes rochosos.

A capacidade de sustentação de cargas é dada pelo atrito elou coe sāo, parâmetros característicos e indicativos da resistência ao cisalhamento da substancia rochosa, e a sua mobilização ocorre a custa de deformações ou deslocamentos.

A aparente presença de coesão em rochas fraturadas resulta do "embricamento" entre as rugosidades e o seu valor reflete o esforço necessärio para rompê-las, sob determinado carregamento nor mal.

A nivel de maciço rochoso, a coesão é dificil de ser definida. Contudo, a prática demonstra indiscutivelmente que a sua contribuição não pode ser negada nem menosprezada. Sempre que possível, - seu valor deve ser considerado nas anälises e obtido da experiência anterior ou através de avaliações realísticas das condi çōes geotécnicas.

Dada a peculiaridade de reaçöes muito diferente daquelas observa das em materiais homogêneos, contínuos e elästicos, as medidas de segurança em construções envolvendo estruturas rochosas devem 
estar muito mais voltadas ao seu próprio comportamento.

Em geral, as rochas passam por värios estägios de ruptura antes de atingir o regime de ruptura franca; desta forma épreferível u tilizar as deformaçōes como critério de estabilidade do que aque le empregado habitualmente pela engenharia.

Os parámetros geomecánicos representam o conjunto de propriedades necessárias para descrever as características de resistência e comportamento das rochas fraturadas, perante às cargas de cisalhamento.

Os fatores e as propriedades mais importantes que alteram essas caracteristicas são apresentados sucintamente a seguir:

a) Kn depende de:

- ärea de contato entre superfícies.

- amplitude e distribuição de descontinuidades (vazios) no sentido transversal.

- propriedades do material de preenchimento.

b) Kt depende de:

- rugosidade, distribuição, amplitude e inclinação das irregu laridades.

- amplitude e distribuição de vazios no sentido longitudinal.

- propriedades do material de preenchimento.

c) S depende de:

- atrito ao longo de fraturas.

- coesão devida ao "embricamento" entre irregularidades.

- resistencia do material de preenchimento, se presente. 
A fratura, o material de preenchimento e a umidade afetam os tres paràmetros e em geral reduzem seus valores. Em particular, argilas montmoriloniticas podem determinar condições extremamente favoráveis ao deslizamento.

A pressão d'ägua nas rochas fraturadas exerce uma força adicional, às vezes, bastante significativa. o princípio de tensões efetivas pode ser considerado, figurando poro-pressão no conjunto dos esforços solicitantes.

A caracterização de fraturas por meio de parâmetros permite intro duzi-los nos modelos geomecānicos e representar as descontinuidades presentes no maciço rochoso. As anälises de interação estrutura-maciço serão mais realístas e permitirão desenvolver projetos mais ajustados a condicionantes geológicos locais.

As dificuldades na obtenção ou na definição de parâmetros apropriados deverão ser progressivamente superadas através de experiências acumuladas, melhoria das técnicas de investigação,obser vação e controle direto de obras por instrumentação antes, duran te e após construção. os seus resultados fornecerão subsídios para - projeto, permitirão aferir os parâmetros, modelos de cálculoe, consequentemente, ir de encontro a uma solução mais segura e eco nômica. 
6. REFERENCIAS BIBLIOGRAFICAS 
BANDIS,S. - Experimental Studies on Shear Strenght-Size Relationships on Deformation Characteristics of Rocks Descontinuities. 1979. |PhD Thesis - Univ. of Leeds!.

BARTON,C.M. - A Analysis of Rock Structures and Fabric in the C.S. A. Mine - Cobar N.S.W., Div. Appl. Geom. Tech. Paper, Australia, 1975.

BARTON,D.C. - Notes on the Desintegration of Granite in Egypt. J. Geól. 24: $382-393,1916$.

BARTON,N.R. - A Relationship Between Joint Roughness and Joint Shear Strenght. Proc.Symp Rock Fracture, Nancy,197la,pp 1-8, London.

BARTON,N.R. - A Model of the Behavior of Steep Rock Slopes. London, $1971 \mathrm{~b} .520 \mathrm{p}$. |Thesis - Univ. London|.

BARTON,N,R. - A Model Study of Rock - Joint Deformation. Int. J.R. M. and Min. Sci., E Geomech. Abst.r. U.K., 9: 5, 1972.

BARTON,N. and BANDIS,S. - Some Effects of Scale on the Shear Strenght of Joints - Int. J.Rock Mech.Min.Sci.E Geome. Abstr., Great Britain, 17: 69-73, 1980 .

BARTON, N. and CHOUBEY, V. - The Shear Strenght of Rock Joint in Theory and Practice. Rock Mechanics, 10: 1-54, 1977.

BERNAIX,J. - New Laboratory Methods of Studing the Mechanical Properties of Rocks, I.J.R.M. e M.S., 6: $43,1969$.

BIENIAWSKI,Z.T. - Time-dependent Behavior of Fractured Rock - Rack Mech., 2: $123-137,1970$.

BOWDEN,F.P. - The Friction of Non-Metallic Solids. J. Ins. Petrol., 40: $89-103,1954$. 
BOWDEN,F.P., MOORE, A.J.W.and TABOR,D. - The Ploughing and Adhesion of Sliding Metals. J.Applied Physics, 14, 1943.

BOWDEN,F.P. and TABOR,D. - The Friction and Lubrification of Solids. Claredon Press, 0xford, $1,1950$.

BOWDEN,F.P. and TABOR,D. - The Friction and Lubrification of Solids, Claredon press, Oxford, $2,1964$.

BOWDEN,F.P. and TABOR,D. - Friction and Lubrification. Methuen, London, 1967.

BROWN,E.T. and HUDSON, J.A. - The Influence of Microstructure on Frac ture on Laboratory Scale. In: Symp Rock Fracture, I.S.R.M., Nancy, 1971 , Paper $11-20$.

BLACKWELDER,E. - The Insolation Hypotesis of Rock Weathering. Am. J.Sci., 26: $97-113,1933$.

BRAJNIKOV,B. - Les Pains du Sucre Bresil: Sont-ils Enracinés? Bull. Geöl.Soc.France, Paris, 6: 267-269, 1953.

BYERLEE,J.D. - Frictional Characteristics of Granite Under High Confining Pressure-J. Geophysical Res., 72: 3639, 1976a.

BYERLEE,J.D. - Theory of Friction Based on Britle fracture - J. Appl. Physics, 38: 2928-2934, 1976 b.

CHAPMAN,C.A. - The Control of Jointing by Topography. J.Geól. 66 : $552-558,1956$.

CHAPPEL,B.A. - Friction Characteristics of Graphite Coated Hedding Joint in Shale - Int. Journal Rock Mech. Min.Sci.E Geomech. Abstr. Great Britain, 12: 33-39, 1975. 
CHRISTENSEN, R.J., SWANSON,S.R. and BROWN,W.S. - Torcional Shearmeasurements of Frictional Properties of Westerly Granite" $3^{r d}$ Cong. Int.Soc. Rock Mech., Denver-Colorado, 2A: 221-225, 1974.

COULOMB,C.A. - Théorie des Machines Simples - Memóries de Mathematique et de Physique de L'Academie Royale des Sciences - 1875 , in Enciclopaedia Britannica, 9: 9.34-935, 1978.

COULSON,J.H. - Shear Strenght of Flat Surface in Rock - Proc.13th Symposium on Rock Mechanics (ASCE), 1972, 77 p.

DE SITTER,L.U. - Structural Geology, Mac Graw Hill - New York, $1956,551 \mathrm{P}$.

EINSTEIN,H.H., BRUHN,R.W. and HIRSCHFELD,R.C. - Mechanics of Join ted Rock - Experimental and Theoretical Studies M.1.T-Cambridge Dept.. Civil Eng? Rep., 1970, 115 p.

EVDOKIMOV,P.D. et CHIAREV,R.A. - Quelques Lois de la Resistance an Cisallement des Ouvrages de Retenue en Béton Sur Fondation Rocheuses, tst Cong. of Int.Soc. of Rock Mech., Lisboa, 1:661-666, 1966.

EVDOKIMOV,P.D. and SAPEGIN,D.D. - Stability, shear and Sliding Resistance and Deformation of Rock Foundation - Israel Program for Scientific Translation, Jerusalem, 1967

EVDOKIMOV,P.D. and SAPEGIN,D.D. - A Large Scale Field Shear Test on Rock, Proc. 2nd Congr. I.S.R.M., Beograd, 2:3-17, 1970.

FECKER, E. and RENGERS, N. - Measurement of Large Scale Roughnesses of Rock Planes by Means of Profilograph and Geological Compass Proc.Int. Symp. on Rock Fract., Nancy, 1971, pp 1-18.

FRIEDMAN,M. - Petrofabric Techniques for the Determination of Principal Stress Direction in Rock, in state of Stress in the 
Earth's Crust, Proc. Int.Conf., California, 1964, pp.451-550.

FUJIMURA, F., MIDEIA,N.F. e NIEBLE,C.M. - A Influéncia do Fenōmeno de Desagregação na Resistência ao Cisalhamento e Compressibili dade de Materiais Basalticos Granulares Utilizados em Barragens de Enrocamento, VIl Seminärio Nacional de Grandes Barragens, Rio de Janeiro, 2 (1): 7, 1971b.

FUJIMURA, F. e NIEBLE,C.M. - Ensaios de Mecãnica de Rochas nas Fundações da Eclusa da Usina de Promissão, Rio Tieté SP. VII Seminärio Nacional de Grandes Barragens, Rio de Janeiro, 1 (1): 11 , 1971 a.

FUJIMURA,F., RIGONATTI,A. e CAMPOS FERNANDES,A.C. - Ensaios de Ci Ihamento Direto em Rochas - Estruturas Tipo Junta. Aspectos de Correlação entre Ensaios "In Situ" e Laboratōrio - $x \mid$ Semiñärio Nacional de Grandes Barragens, Fortaleza-Cearä, $\underline{3}(4): 35 p, 1976$.

GILBERT,G.K. - Domes and Dome Structures of High Sierra,Bull.Geol. Soc.Amer-1904, in: TWIDALE,C.R. - On the Orign of sheet Jointing, Journal of the Int.Soc. of R.Mech., 5: 163-187, 1973 .

GOODMAN,R.E. - The Resolution of Stress in Rock Using Stereogra phic Proj. - J.of Rock Mech. and Sci.,U.K., 1: 93-103, 1963.

GOODMAN,R.E. - A Model for the Mechanics of Jointed Rock - $\underline{\text { J. of }}$ the Am. Soc. Civil Engineers SM3, -1968 .

GOODMAN,R.E. - The Deformability of Joint - Proc. Symp.Det.of the "In Situ" Mod.of Def.of Rock, Denver-Colorado,A.S.T.M. Spec. Tech. Pub. 477, 1970, p.p 174-196.

GOODMAN,R.E. - The Mechanical Properties of Joints, $3^{\text {rd }}$ Congr. I.R.S.M., Denver, IA: 127-135, 1974. GOODMAN,R.E. - HEUZE, F.E. and OHNISHI, Y. Research on Strenght, Deformability - Water Pressure Relationship for Faults in Direct 
Shear - Rep. ARPA Contract, Univ. California-Berkely, 1972.

GOODMAN, R.E. and OHNISHI, Y. - Undrained Shear Testing of Jointed Rock, Rock Mechanics, New York, 5: 129-149, 1973.

GRIGGS,D.T. - The Factor of Fatique in Rock Exfoliation - J.Geol. 44: $783 \div 796,1936$.

HANDIN,J. and STEARNS, D.W. - Sliding Friction of Rock - Trans. Am. Geophysical Union, 45: 103, 1964.

HODGSON,R.A. - Regional Study of Jointing in Comb Ridge - Navajo Mountain Area, Am. Assoc. Pet. Geol., Arizona, 45: 1-38, 1961.

HOEK,E. and BRAY,J. - Rock Slope Engineering - London Institution of Mining and Metalurgy,London, 1974, $309 \mathrm{p}$.

HOEK, E. and FRANKLIN,J.A. - Simple Triaxial Cell for Field or Laboratory Testing of Rock - Trans. Inst. Min. Metall., London, $1968,22 \mathrm{p}$.

HOEK,E. and PENTZ,D.L. - Reviw of the Role of Rock Mechanics Re search in the Design of Opencast Mines - Proc. $9^{\text {th }}$ Comm. Min. Metall_Congr., London, 1969, pp 389 - 404.

HORN,H.M. and DEERE, D.U. - Frictional Characteristics of Minerals Geotechnique the Int. Journal of Soil Mech, 12 (4): $319-335$, 1962.

HUDSON,J.A. and PRIEST,S.D. - Discontinuities and Rock Mass Geome try - Int. J. Rock Mech. Min. Sci. E Geomech. Abstr., Great Britain, 16:339-362, 1979. 
JAEGER,J.C. - The Frictional Properties of Joint of Rock, Geofísica Pura e Applicata, 43: $148-158,1959$.

JAEGER, J.C. and ROSENGREN,K.J. - Friction and Sliding of Joints Proc. Aust. Inst. of Min. and Metall, 229: 93 - 104, 1969.

KLAUS,W.J. - An Approch to Rock Mechanics, J. Soil Mech.Found.Div. A.S.C.E., $88(4): 1-30,1962$.

KRAGELSKII,I.V. - Friction and Wear - Translated from Russiam London, Butterworths, 1965, $346 \mathrm{p}$.

KRANCK,E.H. - On Folding Movements in the Zone on the Basements, Geol. Rund, 46: $261-282,1957$.

KRSMANOVIC,C.D. and LANGOF, Z. - Large Scale Laboratory Tests of the Shear Strenght of Material, Rock Mech. and Geol. Supp. II 1: $20-30,1964$.

KUTTER,H.K. - Stress Distribuition in Direct Shear Test Samples, Proc. Int. Symp. Rock Fracture, Nancy, 1971 , pp 2-6.

KUTTER,H.K. - Rotatory Shear of Rock Joint, 3 rd Congr. Int. Soc. Rock Mech., Denver - Colorado, 2A: 254-262, 1974.

LADANYI,B . and ARCHAMBAULT,G. - Simulation of the Shear Behavior of a Jointed Rock Mass - Proc. 11 th Symp Rock Mech., BerkeleyCalifornia, 1969, pp $105-125$.

LAKEY,S.F. and BUDAVARI,S. - A Finite Element study of the Stresses Induced on Joint Surfaces in Direct Shear Tests - New Zeland Conference of Geomechanics. Austrälia, 1975, pp $264-268$.

LAMA,R.D. - Mechanical Behavior of Jointed Rock Mass, Inst. Soil Mechanics $\&$ Rock Mechanics, Karlsruhe, Rep. K.126-1972, in: 
LAMA,R.D. and VUTUKURI, V.S., Mechanical Properties of Rocks, Irans. Tech. Public., Clausthal, Germany, 1978,V.111,515 P.

LAMA,R.D. and VUTUKURI,V.S. - Handbook on Mechanical Properties of Rocks - Testing Techniques and Results, Clausthal - Germany, 4 : $256,1978$.

LANE,K.S. - Stability of Reservoir Slopes - Eight Symposium on Rock Mechanics, Minesota, 13: 321-336, 1966.

LEET,L.D. and JUDSON,S. - Physical Geology, 4 th Edition, Prentice$-\mathrm{HaIl}, 1971$.

LOCHER,H.G. - Some Results of Direct Tests on Rock Discontinuities Proc. Int. Symp. on Rock Mechanics, Madrid, 2: $171-173,1968$.

LORENTE DE NO,C. - Elasto-PIástic Stress-strain Distribuition During "in situ" Shear Tests - Proc. Int. Symp. on Rock Mech., Madrid, 2 (8): $183-187,1968$.

MAc. CURBY,E. - The Notebooks of Leonardo da Vinci,1938, in: HORN, H.M. and DEERE,D.V. - Frictional Characteristics of Mineral, Geot. the Journal of Soil Mech. 12(4): $319-335,1962$.

MATHEUS, K.E. - Escavation Design in Hard and Fractured Rock at the Mount Isa Mine-Austrälia, Queensland, Brishane, 1970, I M. Sc. Thesis - Univ. Queensland|.

MAURER,W.C. - Shear Failure of Rock Under and Hydrostatic Pressure Proc.1st Int.Cong. Int.Soc. Rock Mech., Lisbon, 3 (18): 337-341,1966

MIDEIA,N.F., FUJIMURA,F. e PAULA,L.C. - Observaçöes sobre a Neces sidade de Ensaios "in situ" em Derrames Basalticos - VIII Seminärio Nacional de Grandes Barragens, Paraná-Curitiba, 1 (1): 19, 1975. 
MILOVANOVIC, M. - De Certaines Caratéristiques Méchaniques et de Quelques Propertiés de la Rocheuse Soumise à la Grande Contrainte de Cisallement dans le Foundations de la Construction In Panel Discussion of the Geotechnical Conference, 0 slo, 2(4): 223-

- 228, 1967.

MOHR,0. - Welch Umstände Bedingen die Elastizitäsgrenze und den Bruch Eines Materials - 1900, in: JAEGER,J.C. and COOK,N.G.Fun damentals of Rock Mechanics. Science Paperbacks, London, 1969,515p.

MÜLleR,L. - Discussion on Approach to Rock Mechanics - Proc. Am. Soc. Civ. Eng:, 2: 137-139, 1963a...

MÜLLER,L. "Der Felsbau"; Stuttgart, Ferdinand Enke - Verlag 1963 b in GOODMAN,R.E. - Methods of Geological Engineering, West Publishing Company, $1976,472 \mathrm{p}$.

NEWLAND,P.L. and ALLELY,B.H. - Volume Changes in Drained Triaxial Tests on Granular Materials - Geotechnique, I (1): 17-34,1957.

NIEBLE,C.M e GUIDICINI,G. - Vinte Anos de Ensaios de Mecánica de Rochas Aplicada às Fundaçōes de Barragens, no Instituto de Pes quisas Tecnológicas de São Paulo - Vil Seminärio Nacional de Grandes Barragens, - Rio de Janeiro, 1971, 21 .

OBERT,L., BRADY, B.T. and SCHMECHEL,F.N. - The Effects of Normal Stiffness on the Shear Resistance of Rock, Rock Mec., B (2): $57-72,1976$.

PATTON,F.D. - Multiples Modes of Shear Failure in Rock Proc. Ist Int. Cong. Int. Soc. Rock Mech., Lisboa, I(3): 509-513, 1966.

PATTON,F.D. and DEERE,D.U. - Significant Geologic Factor in Rock Slope Stability - In Symposium on the Theoretical - Background to the Planning of Open Pit Mines Special References to Slope Stability - Proc.Johannesburg, 1970, pp $143-151$. 
PITEAU,D.R. - Geological Factor Significant to the Stability of Slopes Cut in Rock, ln: Symposium on the Theoretical Background to the Planning of Open Pit Mines with Special References to slope Stability - Proc. Joanesburgo, 3: $33-34,1970$.

PFAFT,M. et BOURRIOT - Essais D'Adherence Béton-Rocher - 111 Congress Int. de Grandes Barragens, Stockoim, 1948, R. 39 .

PRICE,N.J. - Mechanics of Jointing in Rock - Geol. Mag. 96: 149 - 167, 1959.

PRICE,N.J. - Fault and Joint Development in Britle and Semi-britle Rock, Oxford, Pergamon Press, 1966.

PROTODYAKANOV, M. Methods of Determining of Shearing Strenght of Roads - Israel Program for Scientific Translation - Jerusalém 1969, pp $15-33$.

RAMSAY,J.G. - Folding and Fracturing of Rock - New York - Mac Graw $\underline{\mathrm{Hi} I \mathrm{I}}-1967$.

RENGER,N. - The Influence of Surface Roughness on the Friction Properties of Rock Planes - Proc. 2nd Cong. Int. Soc. Rock Mech., Bel.grade, 1: 1 - 31, 1970.

RIPLEY, C.I. and LEE,K.L - Sliding Friction on Sedimentary Rocks Specimes - Trans. $7^{\text {th }}$ Congr. Large Dams, Rome, $4: 657-671$, 1961.

RODRIGUES,F.D. - Determination of Shear Throught the Rock and Slide Along Joint,Proc. Int. Symp. on Rock Mech.,Madrid, $\underline{2}$ (7): $175-132 ., 1968$.

ROSENGREN, K.J. - Rock Mechanics of the Black Star Open Cut, Mount Isa, Austrália, 1968.|PhD - Thesis, Univ. Camberral. 
ROWE, P.W., BARDEN, I. and LEE, I.K. - Energy Components During the Triaxial Cell and Direct Shear Tests - Geotch.,14 (3): 247 $-261,1964$.

RUIZ,M.D. and CAMARGO,F.P. - A Large-Scale Field Shear Tests on Rock - Proc. 1st Int. Congr. I.S.R.M., Lisboa, I (3): 275-261, 1966.

RUIZ,M.D., CAMARGO,F.P., MIDEA,N.F. and NIEBLE,C.M. - Some Consideration Regarding the Shear Strenght of Rock Masses - Proc. Int. Symposium on Rock Mech., Madrid, 2 (5): 159-169, 1968.

RUIZ,M.D., NIEBLE,C.M. and TARRAM,F.C. - Distribuição de Tensões em Ensaios Usualmente Realizados em Mecânica das Rochas. Meios Elästicos, Isotrópicos e Contínuos - 2a Sem. Paulista Geol. Aplicada, São Paulo, 2 : 507-550, 1970 .

RUIZ,M.D., RE,G., CELESTINO,T.B. e BUOSI, M - Síntese das Características Geomecañicas de Maciços Basalticos como Fundação de Barragens 1 Congr. Brasil. de Geol. de Engenharia, Rio de Janeiro, $1976,26 \mathrm{p}$.

RUMMEL, F, and FAIRHUST, C. - Determination of Post-Failure Behavior of Britle Rock Using a Servo Controlled Testing Machine - Rock Mech., 2: $189-204,1970$.

SALAS, J.A.J. - Mechanical Resistences. Introductory Lecture -Proc. of the Int. Symp. on Rock Mech., Madrid 2(6): $11-129,1968$.

SCHNEIDER,H.J. - Investigation into de Question of the Residual. Friction on Rock Joint - Inst. Soil Mech. E Rock Mech. Univ. Karlsruhe - Karlsruhe, 1972.

SCHNEIDER,H.J. - Rock Friction - A Laboratory Investigation-Proc. 3rd Congr. I.S.R.M., Denver, V.2A, 1974, 311p. 
SCHNEIDER,H.J. - Influence of Machine Stiffness and Shear Rate on the Friction Behavior of Rock Joints, Bull. Int. Ass. of Eng? Geol., Krefeld, 13: 109-112, 1976 .

SERAFIN,L. and GUERREIRO,M. - "In Situ" Testes for the Study of Rock Foundation of Concrete Dam - Proc. Ist Cong. of the Int. Society of Rock Mech., Lisboa, 2. (8): 549-556, 1966.

TAKANO,M. and FURUJ0,1. - Deformation and Resistance "In Situ" Shear Test on a $B$ lack Schist and Characteristic Loading Pattern Proc. $1^{\text {st }}$ int. Cong. Int. Soc. of Rock Mech., Lisboa, 1(3): 765-768, 1966.

TAYLOR,D.W. - Fundamentals of Soil Mechanics - John Wiley and Sons New York, 1948.

TERZAGHI, K. - Erdbaumechanik - Deuticke, Wien 1925; In: HORN,A.M. and DEERE - Frictional Characteristics of Mineral, Geotechnique the Int.Journal of Soil Mech., 12(4): 319-335, 1962.

TERZAGHI, K. - Stability of Steep Slopes on Hard Unwethered Rock Geotechnique, 12: $251-270,1962$.

TSCHEBOTARIOFF,G.P. and WELCH,J.D. - Lateral Earth Pressures and Friction Between Soil Minerals - Proc. 2nd Int. Cong. Soil Mech., I : $135-138,1948$.

TWIDALE,C.R. - A Contribuition to the General Theory of Domed Iselbergs - Trans. Int Brit. Geogr., 34: $91-113,1964$.

TWIDALE,C.R. - Structural Landsforms, Camberra, Austr. Univ. Press, 1971 .

TWIDALE,C.R. - On Origin of Sheet Jointing - Journal fo the Int. Soc. of Rock Mech., New York, $\underline{5}$ : 163-187, 1973. 
VON KARMAN,T.H. - Strenght Tests with Triaxial Compression - Z.Ver Dt. Ing. 55: 1749-1757, 1911. In: VUTUKURI,V.S., R.D.and SALUJA, Handbook on Mechanical Properties of Rocks - Trans Tech. Publications, Clausthal Germany, V.I, 1974, $280 \mathrm{p}$.

WHITNEY,J.D. - Geology of California, California Sate Dept. Mines, San Francisco, 1865, In: TWIDALE,C.R. - On the Orign of sheet Jointing, Rock Mechanics, N.Y., 5: 163-187, 1973.

WILLIS,B. and WILLIS,R. - Geologic Structure - Mac Graw Hil1, 1934, $544 \mathrm{p}$.

WITHERS, J.H. - Sliding Resistance Along Discontinuities in Rock Masses, 111 inois, 1964 | PhD Thesis - Univ. Mllinois!.

YOSHIDA,R. - Contribuição ao Conhecimento de Características Tecnológicas de Materiais Rochosos, São Paulo, 1972 /Tese de Doutoramento - I.G. USP |

ZARUBA, $Q$. and MENCL,V. - Landslides and their control, Amsterdam, Elsevier, $1969,205 \mathrm{p}$. 